\title{
Selective Capture of Carbon Dioxide from Hydrocarbons Using a Metal-Organic Framework: Relevance to the Purification of Natural Gas and Acetylene
}

\author{
Omid T. Qazvini ${ }^{1,2}$ and Shane G. Telfer ${ }^{*, 1}$ \\ ${ }^{1}$ MacDiarmid Institute for Advanced Materials and Nanotechnology, School of Fundamental Sciences, Massey University, Palmerston North, New Zealand \\ ${ }^{2}$ Department of Chemical Engineering and Analytical Science, The University of Manchester, Oxford Road, Manchester M13 9PL, UK.
}

\begin{abstract}
Efficient and sustainable methods for carbon dioxide $\left(\mathrm{CO}_{2}\right)$ capture are highly sought after. Mature technologies involve chemical reactions that absorb $\mathrm{CO}_{2}$, but they have many drawbacks. Energy-efficient alternatives may be realized by porous physisorbents with void spaces that are complementary in size and electrostatic potential to molecular $\mathrm{CO}_{2}$. Here, we present a robust, recyclable and inexpensive adsorbent termed MUF-16 (MUF = Massey University Framework). This metal-organic framework captures $\mathrm{CO}_{2}$ with a high affinity in its one-dimensional channels. The position of the $\mathrm{CO}_{2}$ molecules sequestered in the framework pores, as determined by X-ray crystallography, illustrate how complementary noncovalent interactions envelop the $\mathrm{CO}_{2}$ while repelling other guest molecules. The low affinity of the MUF-16 pores for these competing gases underpins new benchmarks for the adsorption of $\mathrm{CO}_{2}$ over methane, acetylene, ethylene, ethane, propylene and propane. IAST calculations show that for 50/50 mixtures at $293 \mathrm{~K}$ and 1 bar, the $\mathrm{CO}_{2} / \mathrm{CH}_{4}$ selectivity is 6690 and the $\mathrm{CO}_{2} / \mathrm{C}_{2} \mathrm{H}_{2}$ selectivity is 510 , for example. Breakthrough gas separations under dynamic conditions benefit from short time lags in the elution of the weakly-adsorbed component to deliver high-purity hydrocarbon products. Ultimately, MUF-16 may be applicable to the removal of $\mathrm{CO}_{2}$ from sources such as natural gas and chemical feedstocks.
\end{abstract}

\section{Introduction}

Chemical separation processes consume vast quantities of energy. ${ }^{1}$ Economical and practical pathways to alleviating this burden are required. This is especially relevant to the capture of $\mathrm{CO}_{2}$, which is a common impurity in crude gas streams. $\mathrm{CO}_{2}$ removal is integral to upgrading natural gas and biogas, for example, and to the purification of valuable hydrocarbons prior to polymerization or chemical derivatization. ${ }^{2}$ These processes are separations that rely on discrimination between $\mathrm{CO}_{2}$ and other gases. One established technology is to trap the $\mathrm{CO}_{2}$ by a chemical reaction with an absorbent. This typically involves chemisorption to an amine in aqueous solution. ${ }^{3,4}$ Chemisorption incurs multiple drawbacks, however, including a high energy penalty during regeneration, amine losses due to degradation and evaporation, and the corrosion of hardware and pipelines. ${ }^{5}$ Other conventional separation methods involve solvent extraction or cryogenic distillation, which are burdened with a high energy penalty and large amount of solvent waste.

The physisorption of $\mathrm{CO}_{2}$ in nanoporous materials is an attractive alternative. ${ }^{6,} 7$ Physisorption is governed by weak, noncovalent bonding interactions in pores that are structured on the molecular scale. ${ }^{8}$ Ideally, they lower the energy requirements for regeneration since driving off the trapped $\mathrm{CO}_{2}$ simply involves breaking interactions that are inherently weak. Effective physisorbents combine rapid guest diffusion, recyclability and long-term stability with selectivity for $\mathrm{CO}_{2}$ over competing gases at relevant concentrations. ${ }^{9}$ Thus, they may offer a sustainable solution to $\mathrm{CO}_{2}$ capture. In this context, metal-organic frameworks (MOFs) have risen to prominence. ${ }^{10-14}$ MOF materials are built up from metal ions and organic ligands, and their pore shape, size and chemical environment can be systematically designed. In turn, this allows interactions between framework hosts and molecular guests to be tailored. In the search of effective MOF physisorbents, it is clear that simply searching for materials with ever-higher levels of $\mathrm{CO}_{2}$ uptake per se is unlikely to produce an adsorbent that is adept at gas separations. Instead, significant advances will emerge by suppressing the uptake of competing gases, ${ }^{15},{ }^{16}$ developing scalable synthetic protocols, mitigating the impact of common impurities such as water vapour and oxygen, and developing low energy pathways to adsorbent recycling.

The removal of $\mathrm{CO}_{2}$ from hydrocarbons is an important process. ${ }^{2}$ While natural gas and biogas are primarily composed of methane (at high pressure and low pressure, respectively), contamination by $\mathrm{CO}_{2}$ can prevent optimal heat release from gas combustion, and cause pipeline corrosion and dry ice formation. ${ }^{17} \mathrm{MOFs}$, however, offer a means of reducing the $\mathrm{CO}_{2}$ concentration in the presence of dominant quantities of methane. ${ }^{10},{ }^{18}, 19$ Acetylene $\left(\mathrm{C}_{2} \mathrm{H}_{2}\right)$ is an essential feedstock for the industrial production of commodity materials. ${ }^{20}, 21$ When acetylene is generated, however, it typically $\mathrm{coexists}$ with $\mathrm{CO}_{2}$ impurities. ${ }^{22}$ The separation of $\mathrm{C}_{2} \mathrm{H}_{2}$ and $\mathrm{CO}_{2}$ is challenging due to their similar physical properties (Table S4). MOF physisorbents offer a potential solution but most show an affinity toward $\mathrm{C}_{2} \mathrm{H}_{2}$ rather than $\mathrm{CO}_{2}{ }^{11}$ The selective adsorption of the $\mathrm{CO}_{2}$ component has seldom been reported despite its operational simplicity in process design and the promise of energy efficiency. Conversely, gas purification using hydrocarbon-selective MOFs requires additional stages if the eluent is contaminated by adsorbed $\mathrm{CO}_{2}$ during the desorption step. ${ }^{23}$ Despite recent advances in MOF chemistry, challenges remain in producing framework adsorbents that combine good separation capabilities with wider performance characteristics such as 
scalability, recyclability and easy low-energy regeneration. MOF adsorbents that may be applied to methane purification and that preferentially adsorb $\mathrm{CO}_{2}$ from $\mathrm{C}_{2} \mathrm{H}_{2}$ are in particular demand.

a)

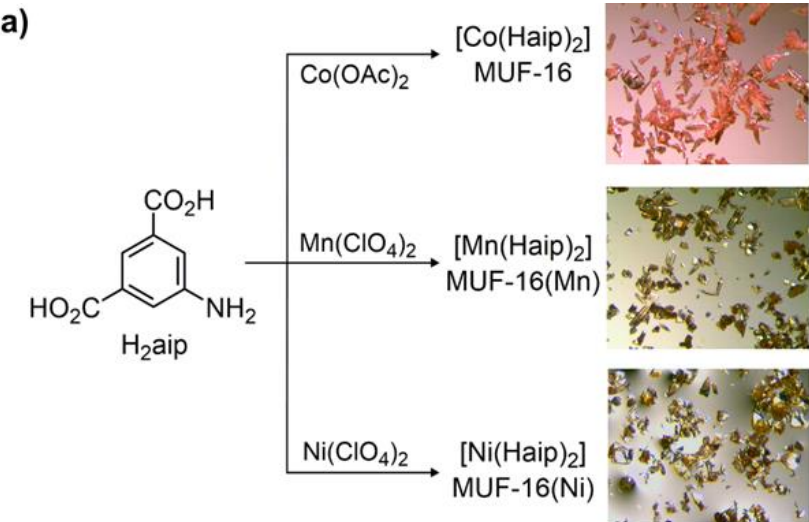

b)

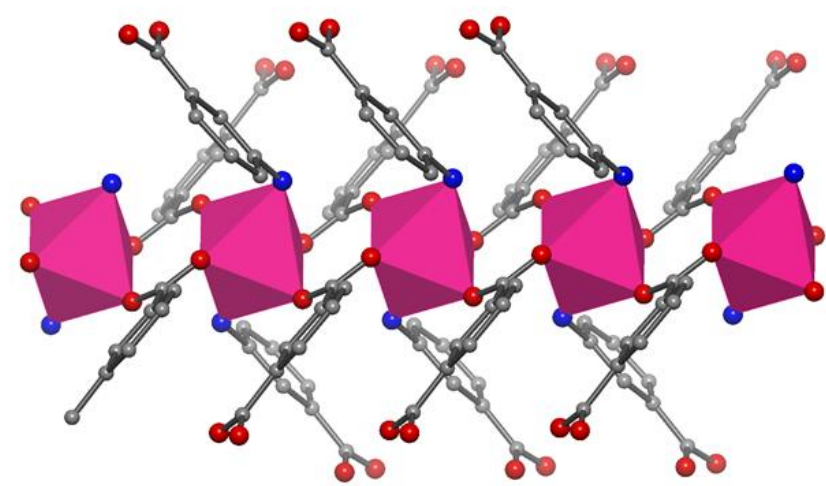

c)

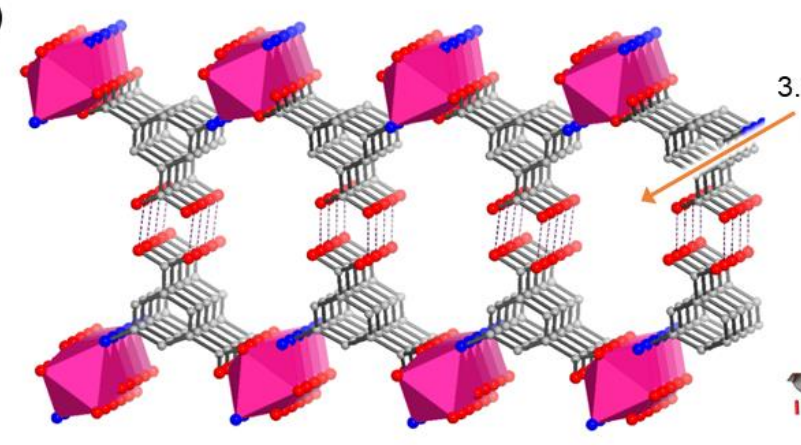

d)

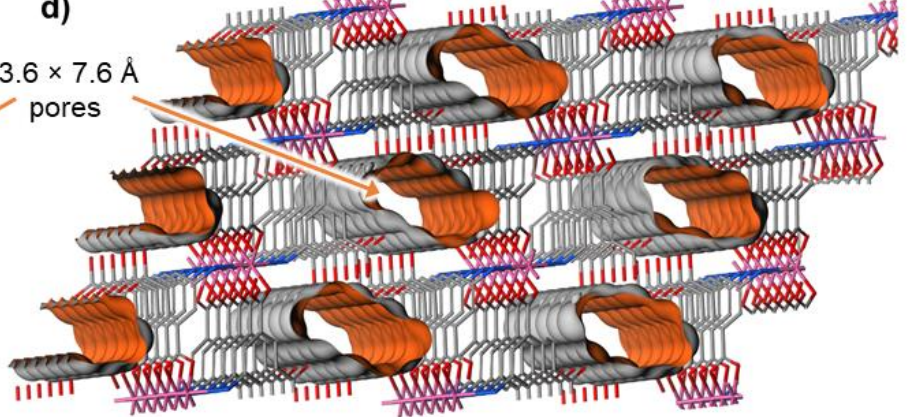

Figure 1. (a) Synthetic routes to the MUF-16 family and optical micrographs of the reaction products. (b) Infinite secondary building units (iSBUs) in MUF-16 comprise one-dimensional cobalt(II) chains connected by $\mu_{2}$-bridging carboxylate groups of the Haip ligands $\left(\mathrm{H}_{2}\right.$ aip $=5$ aminoisophthalic acid). The cobalt(II) ions are depicted as filled octahedra. (c) The iSBUs are linked into planar two-dimensional sheets by the Haip ligands and further connected into a three-dimensional framework by hydrogen bonding (depicted as dashed lines) between adjacent sheets. (d) MUF-16 features one-dimensional channels with approximate dimensions of $3.6 \times 7.6 \AA$ that propagate through the framework. The Connolly surface of the framework is shown in orange and defined with a probe of diameter $1.0 \AA$. Colour code: $\mathrm{Co}=$ magenta; $\mathrm{O}=$ red; $\mathrm{C}=$ grey, $\mathrm{N}=$ blue.

\section{Results and Discussion}

Inspired by the superb properties of MOFs derived from straightforward and readily-available linkers, ${ }^{24,}{ }^{25}$ our interest was captured by the MUF-16 (MUF = Massey University Framework) series of materials. These frameworks are prepared by combining 5-aminoisophthalic acid ( $\mathrm{H}_{2}$ aip), an inexpensive, commercially-available linker, with cobalt(II), nickel(II), or manganese(II) salts in methanol (Figure 1a). This delivers a family of compounds with the general formula $\left[\mathrm{M}(\mathrm{Haip})_{2}\right],{ }^{26,27}$ referred to as MUF-16 (M =Co), MUF-16(Ni) and MUF-16(Mn), respectively. These easily-handled crystalline materials are high yielding on gram scales and tolerant to oxygen and water vapour. Their crystal structures were determined by single crystal $\mathrm{X}$ ray diffraction (Table S1). The three frameworks are isostructural, belonging to the I2/a space group. Individually, the metal ions adopt an octahedral geometry with four carboxylate and two amino donors arranged trans to one another. These ions are aligned into one-dimensional chains along a crystallographic axis supported on each side by $\mu_{2}$-bridging carboxylate groups (Figure 1b). Adjacent chains are connected into two-dimensional sheets by Haip ligands that extend across the plane by coordinating to adjacent one-dimensional chains with both their amino and carboxylate donors (Figure 1b). Only one of the two carboxyl groups of each Haip ligand coordinates to the metal. The other remains protonated and engages in hydrogen-bonding with a partner from an adjacent layer (Figure 1c). These interactions link the layers into three-dimensional frameworks. The frameworks support one-dimensional channels of approximately $3.6 \times 7.6 \AA$ (accounting for the van der Waals surfaces of the atoms, Figure $1 \mathrm{~d}$ ). In their as-synthesized form the pores contain occluded water, which can be easily removed by heating at $130^{\circ} \mathrm{C}$ in vacuo.

Thermogravimetric analysis demonstrated the thermal stability of the MUF-16 materials beyond $330{ }^{\circ} \mathrm{C}$ (Figure S2). Their purity was established by both elemental analysis and powder X-ray diffraction (Figure S5). The frameworks are chemically 
robust, being unaffected by soaking in water or exposure to humid air for prolonged periods, as confirmed by powder X-ray diffraction and gas adsorption analysis (vide infra and Figures S6-S8 and S13).

As suggested by SCXRD, the MUF-16 frameworks are accessible to a range of incoming gases. Activation to give permanently porous materials is straightforward. Nitrogen adsorption isotherms measured at $77 \mathrm{~K}$ gave BET surface areas of 214,205 and $204 \mathrm{~m}^{2} / \mathrm{g}$ for MUF-16, MUF-16(Mn), and MUF-16(Ni), respectively (Figures S19-S21). Total pore volumes of $0.11 \mathrm{~cm}^{3} / \mathrm{g} \mathrm{were}$ established for all three frameworks (Table S3). These values are comparable with the geometric surface areas and pore volumes calculated from the crystallographic coordinates. The pore size distribution of MUF-16 also was calculated, which is consistent with the pore dimensions observed by SCXRD (Figure S12).

$\mathrm{CO}_{2}$ isotherms were collected at $293 \mathrm{~K}$ and up to 1 bar (Figure $2 \mathrm{a}$ and see Figure $\mathrm{S} 11$ for other temperatures). Both MUF-16 and MUF-16(Ni) take up $2.13 \mathrm{mmol} / \mathrm{g}\left(48 \mathrm{~cm}^{3} / \mathrm{g}\right)$ at $1 \mathrm{bar}$, and MUF-16(Mn) adsorbs $2.25 \mathrm{mmol} / \mathrm{g}(50.5 \mathrm{~cm} / \mathrm{g})$. This equates to approximately 0.9 molecules of $\mathrm{CO}_{2}$ per metal site (Table S5). $\mathrm{CO}_{2}$ saturation is only marginally higher at $273 \mathrm{~K}$ (Figure S11). The isosteric heat of adsorption $\left(Q_{s t}\right)$ at zero-coverage was calculated to be $32 \mathrm{~kJ} / \mathrm{mol}$ for MUF-16 and $37 \mathrm{~kJ} / \mathrm{mol}$ for its Ni and $\mathrm{Mn}$ analogues (Figure $2 \mathrm{~b}$ ). The $Q_{s t}$ increases at higher loadings, which can be attributed to intermolecular interactions between the adsorbates when the $\mathrm{CO}_{2}$ loading levels are high. These interactions were experimentally verified by SCXRD (vide infra). The moderate $Q_{s t}$ values, even at high $\mathrm{CO}_{2}$ loading, are well below values observed for MOFs with open metal sites ${ }^{28}$. It follows that the energy required to regenerate the frameworks by $\mathrm{CO}_{2}$ desorption is likely to be low.
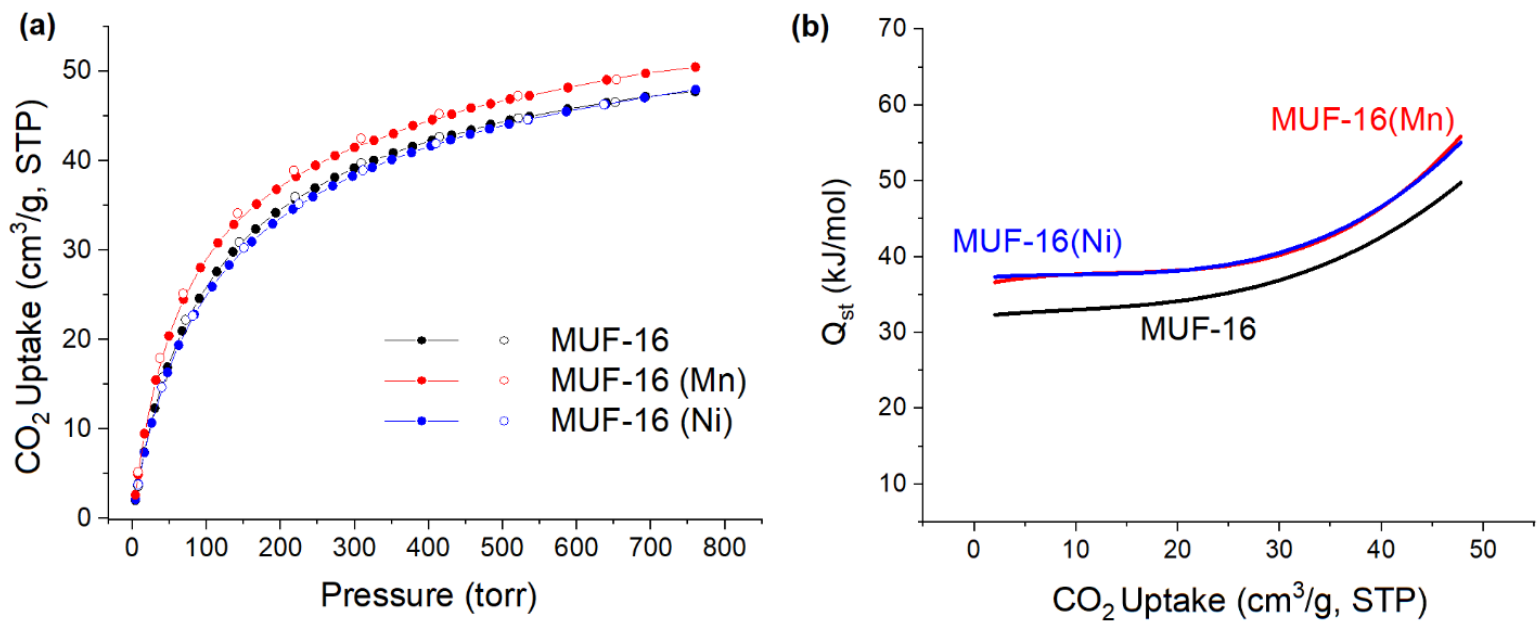

Figure 2. (a) Volumetric adsorption (filled circles) and desorption (open circles) isotherms of $\mathrm{CO}_{2}$ at $293 \mathrm{~K}$ and for MUF-16 (black), MUF-16(Mn) (red), and MUF-16(Ni) (blue). (b) Heats of adsorption $\left(Q_{s t}\right)$ calculated for $\mathrm{CO}_{2}$ binding to MUF-16 (black), MUF-16(Mn) (red), and MUF-16(Ni) (blue) as a function of $\mathrm{CO}_{2}$ uptake. A high affinity for $\mathrm{CO}_{2}$ coupled to a moderate heat of adsorption promise an adsorbent that takes up significant quantities of gas yet is easily recycled.

Single-crystal X-ray diffraction was used to identify the $\mathrm{CO}_{2}$ binding sites in these frameworks. MUF-16(Mn) was selected for this study since its darker colour streamlined crystal handling (the pale colour of the $\mathrm{Co}(\mathrm{II})$ and $\mathrm{Ni}(\mathrm{II})$ analogues make them difficult to see when loaded in a glass capillary). The results obtained for MUF-16(Mn) are directly applicable to MUF-16 and MUF-16(Ni) due to their identical structure and $\mathrm{CO}_{2}$ adsorption behavior (Figures $2 \mathrm{a}$ and S5). After transferring a MUF-16(Mn) single crystal into a capillary, it was activated in vacuo and the capillary flame-sealed. This allowed the guest-free structure of MUF-16(Mn) to be determined crystallographically (Table S2). We then filled $\mathrm{CO}_{2}$ into the capillary to a pressure of 1.1 bar to determine the structure of the $\mathrm{CO}_{2}$-loaded framework. We noted only minor changes to the framework itself upon evacuation and filling with $\mathrm{CO}_{2}$. A clear picture of the affinity of MUF-16 for $\mathrm{CO}_{2}$ arises from the $\mathrm{CO}_{2}$-loaded SCXRD structure. First, the dimensions of the framework pores are well matched to the size of the $\mathrm{CO}_{2}$ molecules. This allows the guests to be enveloped by multiple non-covalent contacts (Figure 3a). Second, these contacts are favourable since the electric quadrupole of the $\mathrm{CO}_{2}$ is complementary to the polarization of the MUF-16 pore surface. For example, one of the electronegative oxygen atoms of each $\mathrm{CO}_{2}$ molecule engages in $\mathrm{N}-\mathrm{H} \cdots \mathrm{O}$ and $\mathrm{C}-\mathrm{H} \cdots \mathrm{O}$ interactions with hydrogen atoms of amino and phenyl groups at distances of $2.55,2.81$, and $2.87 \AA$. The electropositive carbon atom of each $\mathrm{CO}_{2}$ molecule engages in similar close-range contacts with the oxygen atoms of two non-coordinated carboxyl groups (2.87 and $3.04 \AA$ ). Two sites, which are related by crystallographic symmetry and share a common location for one of the oxygen atoms, are available to the $\mathrm{CO}_{2}$ guests. They are occupied with a 50/50 ratio to give one $\mathrm{CO}_{2}$ molecule per $\mathrm{Mn}$ centre overall, in accord with the adsorption isotherm. The $\mathrm{CO}_{2}$ guest molecules are aligned along the channels and tilted with respect to the pore axis (Figure $3 \mathrm{~b}$ ). Attractive C...O intermolecular interactions 
between adjacent molecules are evident at a distance of $3.78 \AA$. This array of $\mathrm{CO}_{2}$ guests probably underlies the observed increase in $Q_{s t}$ as a function of gas loading observed in the adsorption isotherms.

The adsorption of nitrous oxide, $\mathrm{N}_{2} \mathrm{O}$, by MUF-16 corroborates this model of $\mathrm{CO}_{2}$ affinity. The molecular size and electrostatic distribution of $\mathrm{N}_{2} \mathrm{O}$ closely matches that of $\mathrm{CO}_{2}$ (Figure S9). In parallel with $\mathrm{CO}_{2}, \mathrm{~N}_{2} \mathrm{O}$ possesses atoms with partial negative charges at its termini that can bind to positively-charged regions of the pore surface, and vice-versa for its central nitrogen atom. MUF-16 adsorbs $1.91 \mathrm{mmol} / \mathrm{g}\left(43 \mathrm{~cm}^{3} / \mathrm{g}\right)$ of $\mathrm{N}_{2} \mathrm{O}$ at 1 bar and $293 \mathrm{~K}$. This is only slightly less than the uptake of $\mathrm{CO}_{2}$.

The high uptake of $\mathrm{CO}_{2}$ by MUF-16 contrasts with its low affinity for hydrocarbons. Adsorption isotherms of $\mathrm{CH}_{4}, \mathrm{C}_{2} \mathrm{H}_{2}, \mathrm{C}_{2} \mathrm{H}_{4}$, $\mathrm{C}_{2} \mathrm{H}_{6}, \mathrm{C}_{3} \mathrm{H}_{6}$ and $\mathrm{C}_{3} \mathrm{H}_{8}$ were measured on MUF-16 at $293 \mathrm{~K}$ (Figure $4 \mathrm{a}$ and Table 1). MUF-16 takes up just $1.20 \mathrm{~cm}^{3} / \mathrm{g}$ of $\mathrm{CH}_{4}$ at 1 bar and $293 \mathrm{~K}$ and $3.99 \mathrm{~cm}^{3} / \mathrm{g}$ of $\mathrm{C}_{2} \mathrm{H}_{2}$. The highest adsorption amount was $5.35 \mathrm{~cm}^{3} / \mathrm{g}$ observed for $\mathrm{C}_{3} \mathrm{H}_{6}$. The $Q_{s t}$ values for these gases are much lower than for $\mathrm{CO}_{2}$ (Table S6). Since only modest quantities of these gases are adsorbed, care was taken to ensure the accuracy of these measurements by using large sample quantities.
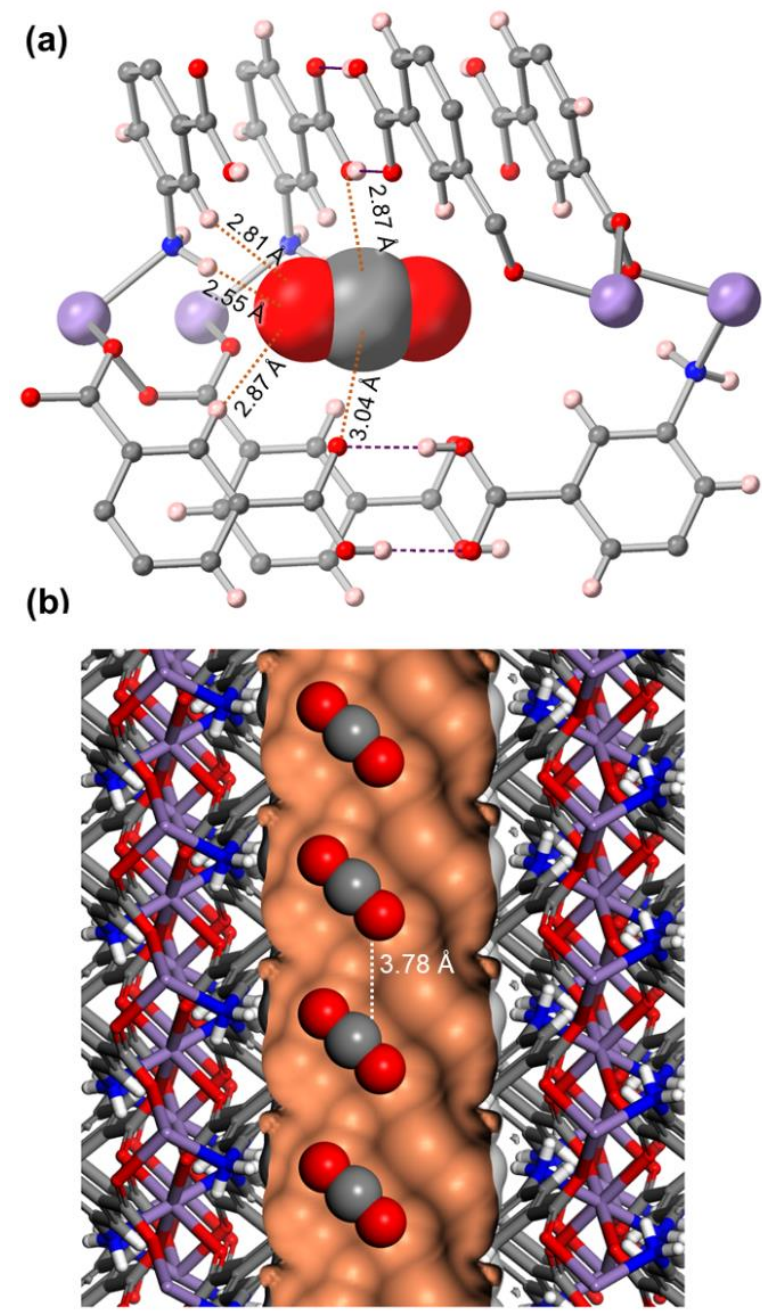

Figure 3. (a) The adsorption sites of $\mathrm{CO}_{2}$ molecules in the pores of MUF-16(Mn), as determined by single-crystal X-ray diffraction. The $\mathrm{CO}_{2}$ is depicted in space-filling mode. Key intermolecular distances between MUF-16(Mn) and the adsorbed $\mathrm{CO}_{2}$ are shown with dashed orange lines. A second, symmetry-equivalent $\mathrm{CO}_{2}$ adsorption site exists. (b) Adsorbed $\mathrm{CO}_{2}$ molecules in $\mathrm{MUF}-16(\mathrm{Mn})$ highlighting the arrangement of adsorbed $\mathrm{CO}_{2}$ in the framework channels and potential attractive noncovalent interactions between adjacent guests. The $\mathrm{CO}_{2}$ molecules are shown in representative orientations in one of two symmetry-related crystallographic orientations. Colour code: manganese = lilac; nitrogen = blue; oxygen = red; carbon = grey; hydrogen = pale pink or white; pore Connolly surface $=$ orange.

Uptake ratios provide a useful indication of the preference of an adsorbent for certain gases over others. For MUF-16, the $\mathrm{CO}_{2} / \mathrm{CH}_{4}$ uptake ratio is 39.8 (293 K and 1 bar). This is comparable to $\left[\mathrm{Cd}_{2} \mathrm{~L}\left(\mathrm{H}_{2} \mathrm{O}\right)\right](42.9)^{29}$ and exceeded by only one other reported material (SIFSIX-14-Cu-i, 85) (Table S10). ${ }^{30}$ Typical physisorbents show a preference for unsaturated hydrocarbons over $\mathrm{CO}_{2}$, especially when bonding between the guest's $\pi$ electrons and open metal sites can occur. ${ }^{23,31-45}$ However, MUF-16 exhibits a uniform preference for $\mathrm{CO}_{2}$ over all $\mathrm{C} 2$ and $\mathrm{C} 3$ hydrocarbons at $293 \mathrm{~K}$ and 1 bar (Table 1). Here, the uptake ratios fall between 12 (acetylene), 15.6 (ethane) and 8.9 (propene). While the limited uptake of $\mathrm{CH}_{4}$ is a well-established function of 
its small size and low polarizability, the low affinity of MUF-16 for larger and more polar/polarizable hydrocarbon guests is notable. Inverted selectivity of this kind, that is, a preference for $\mathrm{CO}_{2}$ over small hydrocarbons, is a sought after yet seldom reported phenomenon. ${ }^{23,} 46-52$ With an uptake ratio of 12 , MUF-16 surpasses all reported materials that preferentially adsorb $\mathrm{CO}_{2}$ over $\mathrm{C}_{2} \mathrm{H}_{2}$, including SIFSIX-3-Ni (1.2 at $298 \mathrm{~K}$ and 0.1 bar) ${ }^{23}$, CD-MOF-2 $(1.3 \text { at } 298 \mathrm{~K} \text { and } 1 \text { bar })^{46}, \mathrm{~K}_{2}\left[\mathrm{Cr}_{3} \mathrm{O}(\mathrm{OOCH})_{6}(4-\right.$ ethylpyridine $\left.)_{3}\right]_{2}\left[\alpha-\mathrm{SiW}_{12} \mathrm{O}_{40}\right](4.5 \text { at } 278 \mathrm{~K} \text { and } 1 \mathrm{bar})^{50}$ and $[\mathrm{Mn}(\mathrm{bdc})(\mathrm{dpe})]\left(6.4\right.$ at $273 \mathrm{~K}$ and 1 bar) ${ }^{47}$ (Table S11). The diminished affinity of MUF-16 for $\mathrm{C}_{2} \mathrm{H}_{2}$ may result from the reversed quadrupole moment of this guest vis-à-vis $\mathrm{CO}_{2}$. Specifically, electropositive regions around the $\mathrm{C}_{2} \mathrm{H}_{2}$ termini may induce repulsive interactions with the framework pore surface, as illustrated by a hypothetical loading model (Figure S10).

Table 1. Summary of gas adsorption data and IAST-calculated selectivities for the MUF-16 family at 1 bar and $293 \mathrm{~K}$.

\begin{tabular}{lccc}
\hline & MUF-16 & MUF-16(Mn) & MUF-16(Ni) \\
\hline $\mathrm{Q}_{\text {st }}$ & & & \\
\hline $\mathrm{CO}_{2}{ }^{a}$ & 32.3 & 36.6 & 37.3 \\
Uptake ${ }^{b}$ & & & \\
\hline $\mathrm{CO}_{2}$ & 47.78 & 50.5 & 47.97 \\
$\mathrm{CH}_{4}$ & 1.20 & 3.10 & 2.77 \\
$\mathrm{C}_{2} \mathrm{H}_{2}$ & 3.99 & 9.69 & 7.53 \\
$\mathrm{C}_{2} \mathrm{H}_{4}$ & 3.17 & 8.31 & 5.42 \\
$\mathrm{C}_{2} \mathrm{H}_{6}$ & 3.06 & 8.81 & 5.67 \\
$\mathrm{C}_{3} \mathrm{H}_{6}$ & 5.35 & - & - \\
$\mathrm{C}_{3} \mathrm{H}_{8}$ & 4.82 & - & - \\
$\mathrm{IAST} \mathrm{selectivity}$ & & & \\
\hline $\mathrm{CO}_{2} / \mathrm{CH}_{4}{ }^{c}$ & 6690 & 470 & 1220 \\
$\mathrm{CO}_{2} / \mathrm{C}_{2} \mathrm{H}_{2}{ }^{c}$ & 510 & 31 & 46 \\
$\mathrm{CO}_{2} / \mathrm{C}_{2} \mathrm{H}_{4}{ }^{c}$ & 600 & 150 & 130 \\
$\mathrm{CO}_{2} / \mathrm{C}_{2} \mathrm{H}_{6}{ }^{c}$ & 600 & 55 & - \\
$\mathrm{CO}_{2} / \mathrm{C}_{3} \mathrm{H}_{6}{ }^{c}$ & 260 & - & - \\
$\mathrm{CO}_{2} / \mathrm{C}_{3} \mathrm{H}_{8}{ }^{c}$ & 84 & -10 & \\
\hline
\end{tabular}

${ }^{a}$ In $\mathrm{kJ} / \mathrm{mol}$ at zero loading. ${ }^{b} \mathrm{In} \mathrm{cm}^{3} / \mathrm{g} .{ }^{c} 50 / 50$ ratio at 1 bar and $293 \mathrm{~K}$ as calculated by IAST.

Building on the preferential affinity indicated by the uptake ratios, we quantified the selectivity of MUF-16 by Ideal Adsorbed Solution Theory (IAST) calculations. ${ }^{53}$ At $293 \mathrm{~K}$ and 1 bar, the IAST selectivity of MUF-16 for $\mathrm{CO}_{2}$ over $\mathrm{CH}_{4}(50 / 50$ mixture) is 6690 (Figure 4b). MUF-16 is thus the best physisorbents known for this separation (Figure 5 and Table S10). For equimolar mixtures of $\mathrm{CO}_{2}$ and $\mathrm{C}_{2} \mathrm{H}_{2}, \mathrm{C}_{2} \mathrm{H}_{4}, \mathrm{C}_{2} \mathrm{H}_{6}, \mathrm{C}_{3} \mathrm{H}_{6}$ and $\mathrm{C}_{3} \mathrm{H}_{8}$ the selectivity of MUF-16 is also high (Table 1). Here, MUF-16 sets a new benchmark for the separation of $\mathrm{CO}_{2} / \mathrm{C}_{2} \mathrm{H}_{2}(50 / 50)$ with a selectivity of 510 . As recognised in the literature for related systems, ${ }^{15}, 16,54$ high selectivities emerge by suppressing the uptake of the hydrocarbon gases while maintaining proficient $\mathrm{CO}_{2}$ capture.

While the pore characteristics of MUF-16 clearly favour the uptake of $\mathrm{CO}_{2}$ over other gases, its affinity could potentially rely on molecular sieving if the larger adsorbates are excluded from the framework on the basis of their size. This was ruled out by measuring hydrocarbon adsorption isotherms at $195 \mathrm{~K}$, which showed that MUF-16 is able to take up significant amounts of $\mathrm{CH}_{4}, \mathrm{C}_{2} \mathrm{H}_{2}$ and $\mathrm{C}_{2} \mathrm{H}_{6}$ (Figure S15). Guest molecules of this size can freely enter the pore network of MUF-16. However, since 
their uptake is low at ambient temperatures their interactions with the framework must be weak. Further, the kinetics of adsorption of several guest molecules were measured (Figure S16). All gases display a similar kinetic profile and reach their equilibrium uptake in well under one minute. Therefore, thermodynamic - rather than kinetic - effects have the most decisive impact on the differential affinity of these gases for MUF-16.
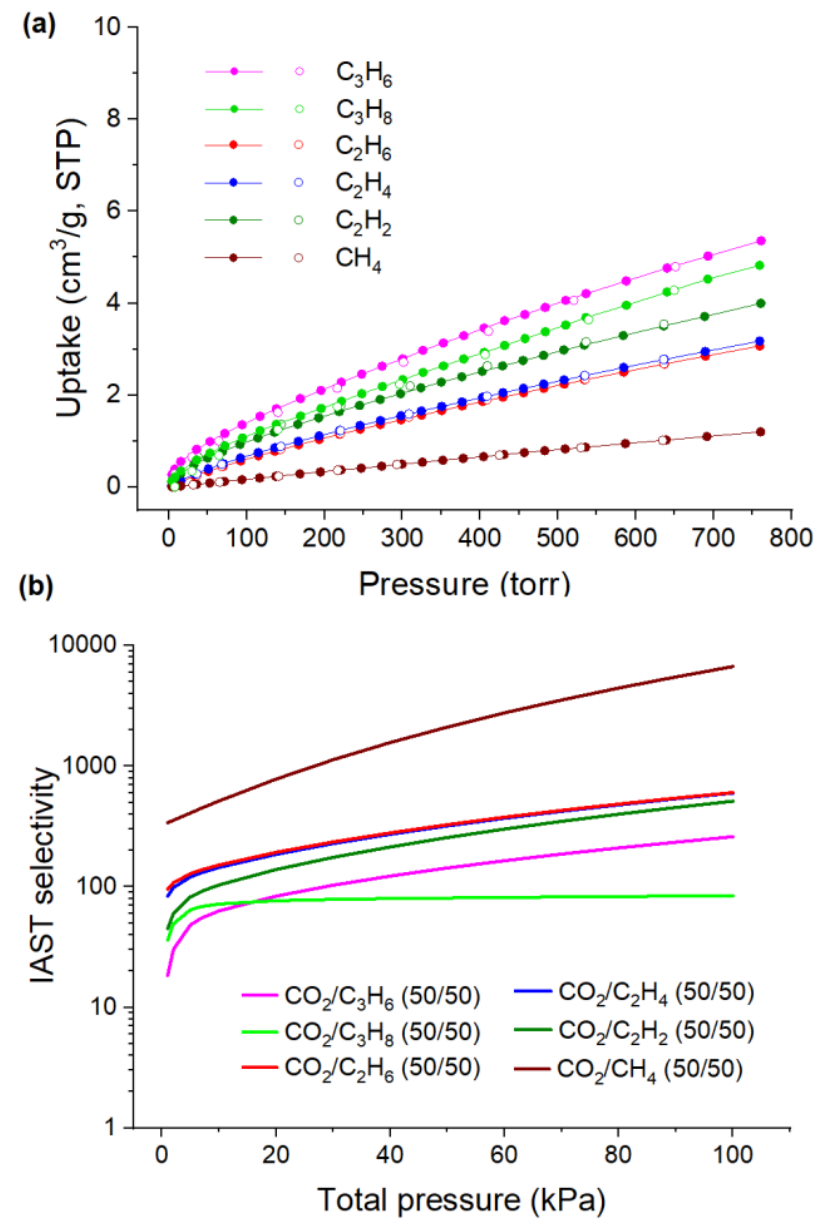

Figure 4. (a) Experimental $\mathrm{CH}_{4}, \mathrm{C}_{2} \mathrm{H}_{2}, \mathrm{C}_{2} \mathrm{H}_{4}, \mathrm{C}_{2} \mathrm{H}_{6}, \mathrm{C}_{3} \mathrm{H}_{6}$ and $\mathrm{C}_{3} \mathrm{H}_{8}$ adsorption (solid spheres) and desorption (open spheres) isotherms of MUF16 measured at 293 K. (b) Predicted IAST selectivities, displayed with a log scale, of MUF-16 for various gas mixtures at $293 \mathrm{~K}$.

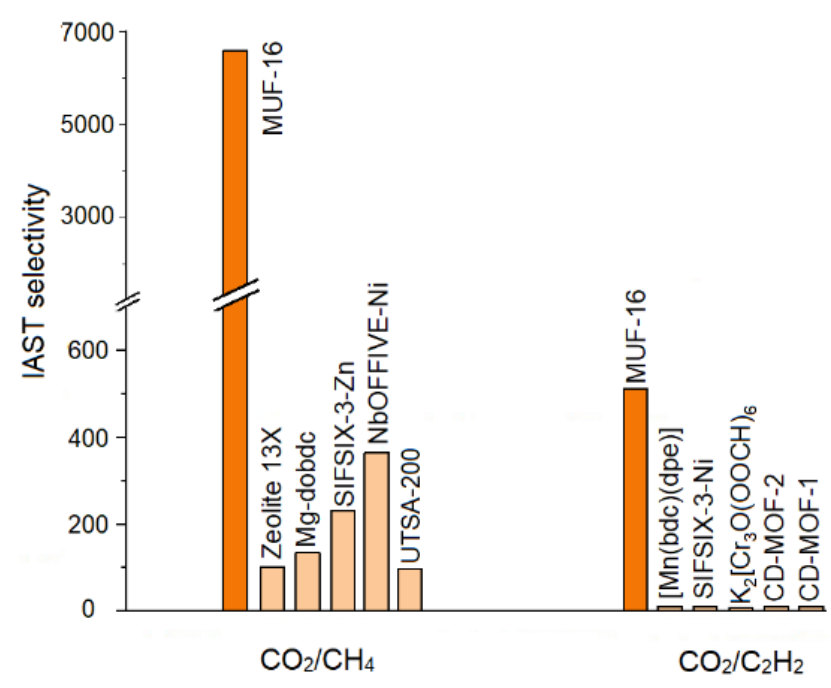

Figure 5. IAST selectivity of MUF-16 in comparison to a selection of top-performing physisorbents for $\mathrm{CO}_{2} / \mathrm{CH}_{4}(50 / 50)$ and $\mathrm{CO}_{2} / \mathrm{C}_{2} \mathrm{H}_{2}(50 / 50)$ mixtures at ambient temperature and 1 bar. For clarity, the y axis is broken in two parts with different scales. 
Invigorated by these results, we then investigated the feasibility of $\mathrm{CO}_{2}$ /hydrocarbon separations under dynamic conditions. Experimental breakthrough curves were measured for various gas mixtures at $293 \mathrm{~K}$ and 1.1 bar: $\mathrm{CO}_{2} / \mathrm{C}_{2} \mathrm{H}_{6}(50 / 50), \mathrm{CO}_{2} / \mathrm{C}_{2} \mathrm{H}_{4}$ $(50 / 50)$ and $\mathrm{CO}_{2} / \mathrm{C}_{2} \mathrm{H}_{2}\left(50 / 50\right.$ and 5/95) (Figures 6a,b S44 and S51). Figure 6a,b shows the dimensionless concentration of $\mathrm{CO}_{2}$ and the hydrocarbons (measured independently) exiting an adsorbent bed packed with MUF-16 (0.9 gram) as a function of time.

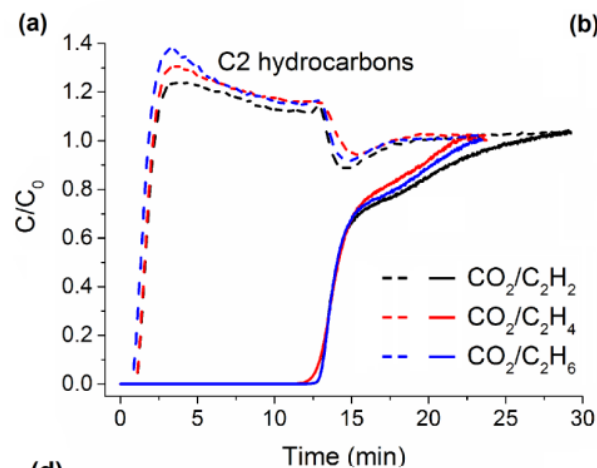

(d)

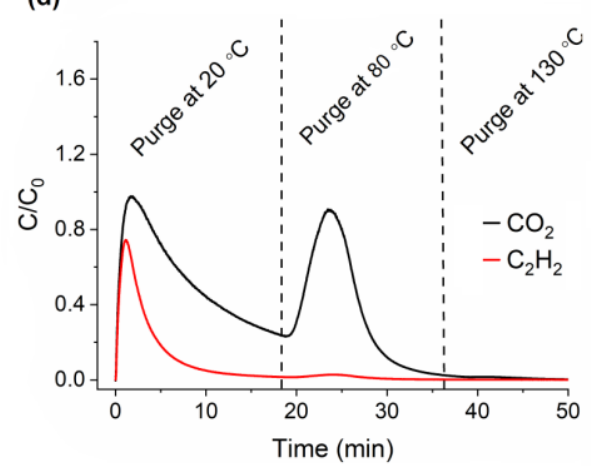

(b)

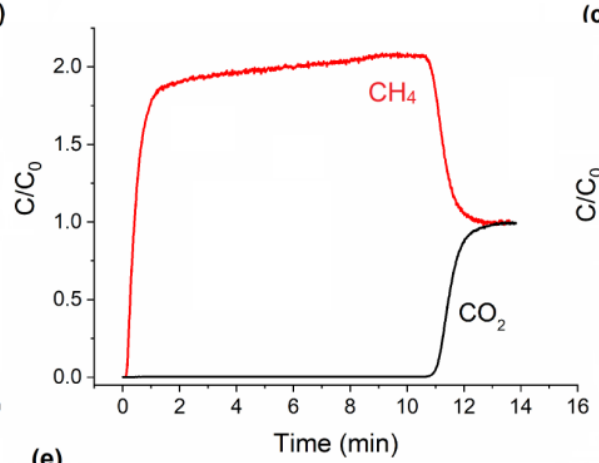

(e)

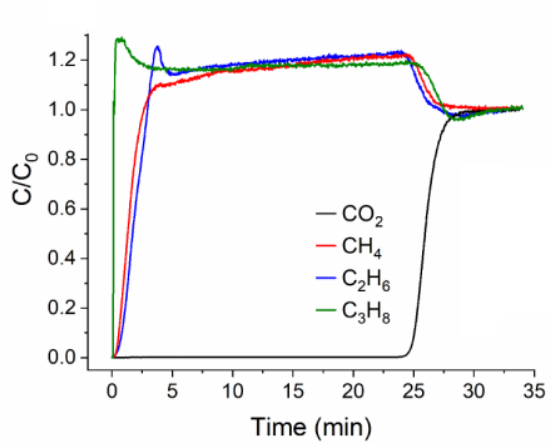

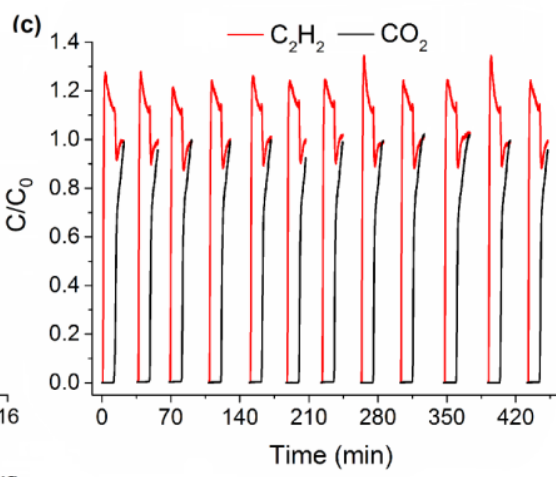

(f)

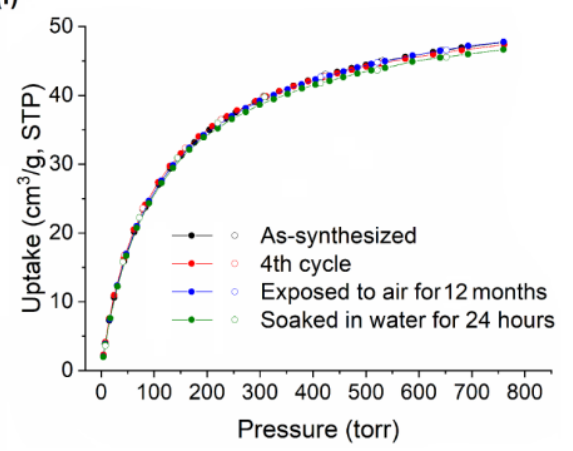

Figure 6. (a) Experimental breakthrough curves for 50/50 mixtures of $\mathrm{CO}_{2}$ and the three $\mathrm{C} 2$ hydrocarbons (measured independently) at $293 \mathrm{~K}$ and 1.1 bar in an adsorption column packed with MUF-16. (b) Experimental breakthrough curves for $50 / 50$ mixtures of $\mathrm{CO}_{2}$ and $\mathrm{CH}_{4}$ at $293 \mathrm{~K}$ and 1.1 bar in an adsorption column packed with MUF-16. (c) Twelve separation cycles for a $\mathrm{CO}_{2} / \mathrm{C}_{2} \mathrm{H}_{2}$ mixture (50/50 mixture). Each separation process was carried out at $293 \mathrm{~K}$ and 1.1 bar. MUF-16 was regenerated between cycles by placing it under vacuum at ambient temperature for 20-25 min. (d) Experimental desorption profile of MUF-16 following the separation of $\mathrm{CO}_{2}$ and $\mathrm{C}_{2} \mathrm{H}_{2}$ upon heating under a helium flow of 5 $\mathrm{ml}_{\mathrm{N}} / \mathrm{min}$ at 1.1 bar. No adsorbates were removed upon further heating at $130{ }^{\circ} \mathrm{C}$ indicating that they had been fully expelled at lower temperatures. (e) Experimental breakthrough curves for a $15 / 80 / 4 / 1 \mathrm{CO}_{2} / \mathrm{CH}_{4} / \mathrm{C}_{2} \mathrm{H}_{6} / \mathrm{C}_{3} \mathrm{H}_{8}$ mixture at 1.1 bar and $293 \mathrm{~K}$ in an adsorption column packed with MUF-16. (f) $\mathrm{CO}_{2}$ adsorption isotherms $(293 \mathrm{~K})$ of as-synthesized MUF-16 after four consecutive adsorption-desorption cycles, after exposing it to air with $\sim 80 \%$ humidity for 12 months, and after immersion in water for 48 hours.

Complete separation was realized by MUF-16, whereby the hydrocarbons broke through from the column at an early stage because of their low affinity for the framework. Conversely, the signal of $\mathrm{CO}_{2}$ was not detected for at least 10 minutes due to its adsorption by MUF-16. The dynamic adsorption capacity for $\mathrm{CO}_{2}$ fell in the range $1.2-1.5 \mathrm{mmol} / \mathrm{g}$ which is nearly identical to the equilibrium capacity at the relevant partial pressures of $\mathrm{CO}_{2}$ (Table S7). Significant volumes of pure hydrocarbons can be obtained in this way. Productivity calculations showed $1 \mathrm{~kg}$ of MUF-16 produces $27 \mathrm{~L}$ of the hydrocarbons from an equimolar mixture with $\mathrm{CO}_{2}$ at $293 \mathrm{~K}$ and 1 bar. The ability of MUF-16 to selectively adsorb $\mathrm{CO}_{2}$ is an important advantage of this MOF as pure hydrocarbons can be produced directly in a single adsorption. In literature reports to date, the capture of $\mathrm{CO}_{2}$ over $\mathrm{C}_{2}$ hydrocarbons has so far largely been restricted to cryogenic temperatures and/or static conditions. ${ }^{47-50,52,55}$ With respect to $\mathrm{CO}_{2} / \mathrm{C}_{2} \mathrm{H}_{2}$ mixtures at ambient temperatures, we are aware of only three reported materials, CD-MOF- $1^{46}$, CD-MOF-2 ${ }^{46}$ and SIFSIX-3-Ni, ${ }^{23}$ for which $\mathrm{CO}_{2}$ trapping has been verified by experimental breakthrough measurements. Since these MOFs adsorb $\mathrm{C}_{2} \mathrm{H}_{2}$ (in addition to $\mathrm{CO}_{2}$ ) strongly at moderate pressures, their uptake ratios are modest. They are limited to very low partial pressures of $\mathrm{CO}_{2}$ and suffer from low productivity.

Subsequent multiple breakthrough tests revealed that MUF-16 maintains its $\mathrm{CO}_{2}$ uptake and the complete removal of $\mathrm{CO}_{2}$ over at least 12 separation cycles (Figure 6c). MUF-16 was regenerated between cycles by placing it under vacuum or by purging with an inert gas (Figure $6 \mathrm{~d}$ ). Virtually all of the adsorbed acetylene and around half of the $\mathrm{CO}_{2}$ can be removed from the bed by purging at room temperature. The remainder can be fully desorbed at $80^{\circ} \mathrm{C}$.

To investigate separations involving trace $\mathrm{CO}_{2}$, we simulated breakthrough curves of feed gases with low $\mathrm{CO}_{2}$ partial pressures. First, a mass transfer coefficient was empirically determined based on measured breakthrough results. This 
produces an excellent match between simulated and experimental breakthrough curves. ${ }^{24,56}$ With this realistic mass transfer coefficient in hand, we predicted breakthrough curves using feeds containing $0.1 \% \mathrm{CO}_{2}$ in $\mathrm{C}_{2} \mathrm{H}_{2}$ (Figure S57). These calculations revealed that MUF-16 is capable of eliminating trace quantities of $\mathrm{CO}_{2}$, as often required in industrial processes.

We then turned our attention to the separation of more complex gas mixtures. Using $\mathrm{CO}_{2} / \mathrm{CH}_{4} / \mathrm{C}_{2} \mathrm{H}_{6} / \mathrm{C}_{3} \mathrm{H}_{8}(15 / 80 / 4 / 1)$ as a feed mixture, we observed complete $\mathrm{CO}_{2}$ capture by MUF-16. $\mathrm{CH}_{4}, \mathrm{C}_{2} \mathrm{H}_{6}$ and $\mathrm{C}_{3} \mathrm{H}_{8}$ broke through quickly with steep elution profiles (Figure 6e). Crucially, the relatively large adsorbates $\mathrm{C}_{2} \mathrm{H}_{6}$ and $\mathrm{C}_{3} \mathrm{H}_{8}$, do not diminish the $\mathrm{CO}_{2}$ capture capabilities of MUF-16. This is an important observation for the removal of $\mathrm{CO}_{2}$ from both biogas and natural gas, which often contain these hydrocarbons. ${ }^{17}$ To further probe its applicability to natural gas sweeting, we conducted breakthrough measurements at higher pressure ( 9 bar). $\mathrm{CO}_{2}$ was cleanly removed from the gas stream (Figures $\mathrm{S} 45$ and $\mathrm{S} 46$ ). Breakthrough simulations at pressures relevant to natural gas processing (50 bar) led to the prediction that MUF-16 can competently capture $\mathrm{CO}_{2}$ from natural gas (Figure S50). Water vapour is a component of crude natural gas streams and it can affect gas adsorption by physisorbents. ${ }^{57}$, ${ }^{58}$ To test the moisture resistance of MUF-16, we measured its $\mathrm{CO}_{2}$ adsorption properties after exposure to air and immersion in water (Figure 6f). The framework retains its $\mathrm{CO}_{2}$ adsorption capacity following these mistreatments. More detailed analysis, including the resistance of MUF-16 to other common natural gas impurities such as $\mathrm{H}_{2} \mathrm{~S}$, is an important next step.

\section{Conclusion}

The pores in MUF-16 are complementary to $\mathrm{CO}_{2}$ in size and electrostatic potential. This underlies its high affinity for molecular $\mathrm{CO}_{2}$ guests. Fortuitously, its pores have a low affinity for methane and $\mathrm{C} 2$ and $\mathrm{C} 3$ hydrocarbons. The intersection of these characteristics imbues the material with a high selectivity for $\mathrm{CO}_{2}$ over hydrocarbon guests. Benchmark selectivities were determined for $\mathrm{CO}_{2} / \mathrm{CH}_{4}$ and $\mathrm{CO}_{2} / \mathrm{C}_{2} \mathrm{H}_{2}$ separations. MUF-16 operates efficiently across a range of $\mathrm{CO}_{2} /$ hydrocarbon mixtures and pressures. These data highlight the performance improvements that are embodied in MUF-16. These findings are relevant to the practical challenges of purifying both natural gas and industrial feedstocks. MUF-16 has the potential to be produced economically on large scales and its chemical stability meets the demands of a long-lived physisorbent. Given these characteristics, MUF-16 has promise for applications involving the capture of $\mathrm{CO}_{2}$ from hydrocarbon streams.

\section{Supporting Information}

Crystallographic data and files of MUF-16 as synthesized, under vacuum and loaded with $\mathrm{CO}_{2}$ (CCDC 1948901, 1948905 and 1948904), additional structural plot, TG curves, PXRD, multiple cycle sorption isotherm, dual site Langmuir isotherm model fitting, isosteric heat of adsorption calculation, BET surface area calculations, IAST calculations of adsorption selectivities, breakthrough curves simulations and models used and column breakthrough test setup with procedures and measurements (PDF). This material is available free of charge via the Internet at...

\section{Author Contributions}

The manuscript was written through contributions of all authors. All authors have given approval to the final version of the manuscript.

\section{Notes}

A patent on MUF-16 has been lodged (WO 2020/130856 A1).

\section{ACKNOWLEDGMENTS}

We would like to thank Seok June (Subo) Lee and Adil Alkas for useful discussions and assistance with X-ray crystallography and Steve Denby for expert engineering assistance. We gratefully acknowledge the MacDiarmid Institute and RSNZ Marsden Fund (contract 14-MAU-024) for financial support.

\section{References}

1. Sholl, D. S.; Lively, R. P., Seven chemical separations: to change the world: purifying mixtures without using heat would lower global energy use, emissions and pollution--and open up new routes to resources. Nature 2016, 532 (7600), 435-438.

2. Ravanchi, M. T.; Sahebdelfar, S., Carbon dioxide capture and utilization in petrochemical industry: potentials and challenges. Appl. Petrochem. Res. 2014, 4 (1), 63-77.

3. Rochelle, G. T., Amine scrubbing for CO2 capture. Science 2009, 325 (5948), 1652-1654.

4. Yu, C.-H.; Huang, C.-H.; Tan, C.-S., A review of $\mathrm{CO}_{2}$ capture by absorption and adsorption. Aerosol Air Qual. Res. 2012, 12 (5), 745-769.

5. Kohl, A.; Nielsen, R., Gas Purification. 5th ed.; Gulf Publishing Company: Houston, 1997.

6. Oschatz, M.; Antonietti, M., A search for selectivity to enable $\mathrm{CO}_{2}$ capture with porous adsorbents. Energ. Environ. Sci. 2018, 11 (1), 5770.

7. Sreenivasulu, B.; Sreedhar, I.; Suresh, P.; Raghavan, K. V., Development trends in porous adsorbents for carbon capture. Environ. Sci. Technol. 2015, 49 (21), 12641-12661.

8. Yang, R. T., Gas separation by adsorption processes. Butterworth-Heinemann: 2013.

9. Lu, A.-H.; Dai, S., Porous materials for carbon dioxide capture. Springer: 2014.

10. Lin, R.-B.; Xiang, S.; Xing, H.; Zhou, W.; Chen, B., Exploration of porous metal-organic frameworks for gas separation and purification. Coord. Chem. Rev. 2019, 378, 87-103.

11. Li, H.; Li, L.; Lin, R.-B.; Zhou, W.; Zhang, Z.; Xiang, S.; Chen, B., Porous metal-organic frameworks for gas storage and separation: Status and challenges. EnergyChem 2019, 1 (1), 100006. 
12. Ding, M.; Flaig, R. W.; Jiang, H.-L.; Yaghi, O. M., Carbon capture and conversion using metal-organic frameworks and MOF-based materials. Chem. Soc. Rev. 2019, 48 (10), 2783-2828.

13. Mukherjee, S.; Kumar, A.; Zaworotko, M. J., 2 - Metal-organic framework based carbon capture and purification technologies for clean environment. In Metal-Organic Frameworks (MOFs) for Environmental Applications, Ghosh, S. K., Ed. Elsevier: 2019; pp 5-61.

14. Qazvini, O. T.; Telfer, S. G., A robust metal-organic framework for post-combustion carbon dioxide capture. J. Mater. Chem. A 2020, 8 (24), 12028-12034.

15. Balashankar, V. S.; Rajagopalan, A. K.; Pauw, R. d.; Avila, A. M.; Rajendran, A., Analysis of a Batch Adsorber Analogue for Rapid Screening of Adsorbents for Postcombustion $\mathrm{CO}_{2}$ Capture. Ind. Eng. Chem. Res. 2019, 58, 3314-3328.

16. Rajagopalan, A. K.; Avila, A. M.; Rajendran, A., Do adsorbent screening metrics predict process performance? A process optimisation based study for post-combustion capture of CO2. Int. J. Greenh. Gas. Con. 2016, 46, 76-85.

17. Rufford, T. E.; Smart, S.; Watson, G. C.; Graham, B.; Boxall, J.; Da Costa, J. D.; May, E., The removal of $\mathrm{CO}_{2}$ and $\mathrm{N}_{2}$ from natural gas: A review of conventional and emerging process technologies. J. Petrol. Sci. Eng. 2012, 94, 123-154.

18. Madden, D. G.; O’Nolan, D.; Chen, K.-J.; Hua, C.; Kumar, A.; Pham, T.; Forrest, K. A.; Space, B.; Perry, J. J.; Khraisheh, M., Highly selective $\mathrm{CO}_{2}$ removal for one-step liquefied natural gas processing by physisorbents. Chem. Commun. 2019, 55 (22), $3219-3222$.

19. Belmabkhout, Y.; Bhatt, P. M.; Adil, K.; Pillai, R. S.; Cadiau, A.; Shkurenko, A.; Maurin, G.; Liu, G.; Koros, W. J.; Eddaoudi, M., Natural gas upgrading using a fluorinated MOF with tuned H 2 S and CO 2 adsorption selectivity. Nature Energy 2018, 3 (12), $1059-1066$.

20. Matar, S.; Hatch, L. F., Chemistry of Petrochemical Processes. Gulf Professional Publishing: 2001.

21. Hort, E. V.; Taylor, P., Acetylene - Derived Chemicals. Kirk - Othmer Encyclopedia of Chemical Technology 2000.

22. Pässler, P.; Hefner, W.; Buckl, K.; Meinass, H.; Meiswinkel, A.; Wernicke, H. J.; Ebersberg, G.; Müller, R.; Bässler, J.; Behringer, H., Acetylene. Ullmann's Encyclopedia of Industrial Chemistry 2008, 1, 177-227.

23. Chen, K.-J.; Scott, H. S.; Madden, D. G.; Pham, T.; Kumar, A.; Bajpai, A.; Lusi, M.; Forrest, K. A.; Space, B.; Perry, J. J.; Zaworotko, M. J., Benchmark $\mathrm{C}_{2} \mathrm{H}_{2} / \mathrm{CO}_{2}$ and $\mathrm{CO}_{2} / \mathrm{C}_{2} \mathrm{H}_{2}$ Separation by Two Closely Related Hybrid Ultramicroporous Materials. Chem 2016, 1 (5), 753-765

24. Qazvini, O. T.; Babarao, R.; Shi, Z.-L.; Zhang, Y.-B.; Telfer, S. G., A Robust Ethane-Trapping Metal-Organic Framework with a High Capacity for Ethylene Purification. J. Am. Chem. Soc. 2019.

25. Qazvini, O. T.; Babarao, R.; Telfer, S. G., Multipurpose Metal-Organic Framework for the Adsorption of Acetylene: Ethylene Purification and Carbon Dioxide Removal. Chem. Mater. 2019, 31 (13), 4919-4926.

26. Tang, E.; Dai, Y.-M.; Zhang, J.; Li, Z.-J.; Yao, Y.-G.; Zhang, J.; Huang, X.-D., Two Cobalt(II) 5-Aminoisophthalate Complexes and Their Stable Supramolecular Microporous Frameworks. Inorg. Chem. 2006, 45 (16), 6276-6281.

27. Tian, C.-B.; He, C.; Han, Y.-H.; Wei, Q.; Li, Q.-P.; Lin, P.; Du, S.-W., Four New Mnll Inorganic-Organic Hybrid Frameworks with Diverse Inorganic Magnetic Chain's Sequences: Syntheses, Structures, Magnetic, NLO, and Dielectric Properties. Inorg. Chem. 2015, 54 (6), 2560-2571.

28. Sumida, K.; Rogow, D. L.; Mason, J. A.; McDonald, T. M.; Bloch, E. D.; Herm, Z. R.; Bae, T.-H.; Long, J. R., Carbon Dioxide Capture in Metal-Organic Frameworks. Chem. Rev. 2012, $112(2)$, 724-781.

29. Hou, L.; Shi, W.-J.; Wang, Y.-Y.; Guo, Y.; Jin, C.; Shi, Q.-Z., A rod packing microporous metal-organic framework: unprecedented ukv topology, high sorption selectivity and affinity for $\mathrm{CO}_{2}$. Chem. Commun. 2011, 47 (19), 5464-5466.

30. Jiang, M.; Li, B.; Cui, X.; Yang, Q.; Bao, Z.; Yang, Y.; Wu, H.; Zhou, W.; Chen, B.; Xing, H., Controlling Pore Shape and Size of Interpenetrated Anion-Pillared Ultramicroporous Materials Enables Molecular Sieving of $\mathrm{CO}_{2}$ Combined with Ultrahigh Uptake Capacity. ACS Appl. Mater. Interfaces 2018, 10 (19), 16628-16635.

31. Moreau, F.; da Silva, I.; Al Smail, N. H.; Easun, T. L.; Savage, M.; Godfrey, H. G. W.; Parker, S. F.; Manuel, P.; Yang, S.; Schröder, M., Unravelling exceptional acetylene and carbon dioxide adsorption within a tetra-amide functionalized metal-organic framework. Nat. Commun. 2017, 8, 14085.

32. Xiang, S.; Zhou, W.; Gallegos, J. M.; Liu, Y.; Chen, B., Exceptionally High Acetylene Uptake in a Microporous Metal-Organic Framework with Open Metal Sites. J. Am. Chem. Soc. 2009, 131 (34), 12415-12419.

33. Li, P.; He, Y.; Zhao, Y.; Weng, L.; Wang, H.; Krishna, R.; Wu, H.; Zhou, W.; O'Keeffe, M.; Han, Y.; Chen, B., A Rod-Packing Microporous Hydrogen-Bonded Organic Framework for Highly Selective Separation of $\mathrm{C}_{2} \mathrm{H}_{2} / \mathrm{CO}_{2}$ at Room Temperature. Angew. Chem., Int. Ed. 2015, 54 (2), 574-577.

34. Lee, J.; Chuah, C. Y.; Kim, J.; Kim, Y.; Ko, N.; Seo, Y.; Kim, K.; Bae, T. H.; Lee, E., Separation of Acetylene from Carbon Dioxide and Ethylene by a Water-Stable Microporous Metal-Organic Framework with Aligned Imidazolium Groups inside the Channels. Angewandte Chemie International Editions 2018, 57 (26), 7869-7873.

35. Luo, F.; Yan, C.; Dang, L.; Krishna, R.; Zhou, W.; Wu, H.; Dong, X.; Han, Y.; Hu, T.-L.; O’Keeffe, M.; Wang, L.; Luo, M.; Lin, R.-B.; Chen, B., UTSA-74: A MOF-74 Isomer with Two Accessible Binding Sites per Metal Center for Highly Selective Gas Separation. J. Am. Chem. Soc. 2016, 138 (17), 5678-5684.

36. Zhang, J.-P.; Chen, X.-M., Optimized Acetylene/Carbon Dioxide Sorption in a Dynamic Porous Crystal. J. Am. Chem. Soc. 2009, 131 (15), 5516-5521.

37. Zhang, L.; Jiang, K.; Li, L.; Xia, Y.-P.; Hu, T.-L.; Yang, Y.; Cui, Y.; Li, B.; Chen, B.; Qian, G., Efficient separation of $\mathrm{C}_{2} \mathrm{H}_{2}$ from $\mathrm{C}_{2} \mathrm{H}_{2} / \mathrm{CO}_{2}$ mixtures in an acid-base resistant metal-organic framework. Chem. Commun. 2018, 54 (38), 4846-4849.

38. Peng, Y.-L.; Pham, T.; Li, P.; Wang, T.; Chen, Y.; Chen, K.-J.; Forrest, K. A.; Space, B.; Cheng, P.; Zaworotko, M. J.; Zhang, Z., Robust Ultramicroporous Metal-Organic Frameworks with Benchmark Affinity for Acetylene. Angew. Chem., Int. Ed. 2018, 57 (34), 10971-10975.

39. Scott, H. S.; Shivanna, M.; Bajpai, A.; Madden, D. G.; Chen, K.-J.; Pham, T.; Forrest, K. A.; Hogan, A.; Space, B.; Perry Iv, J. J.; Zaworotko, M. J., Highly Selective Separation of $\mathrm{C}_{2} \mathrm{H}_{2}$ from $\mathrm{CO}_{2}$ by a New Dichromate-Based Hybrid Ultramicroporous Material. ACS Appl. Mater. Interfaces 2017, 9 (39), 33395-33400.

40. Matsuda, R.; Kitaura, R.; Kitagawa, S.; Kubota, Y.; Belosludov, R. V.; Kobayashi, T. C.; Sakamoto, H.; Chiba, T.; Takata, M.; Kawazoe, Y.; Mita, Y., Highly controlled acetylene accommodation in a metal-organic microporous material. Nature 2005, 436, 238.

41. Duan, X.; Wang, H.; Ji, Z.; Cui, Y.; Yang, Y.; Qian, G., A novel metal-organic framework for high storage and separation of acetylene at room temperature. J. Solid State Chem. 2016, 241, 152-156.

42. Duan, X.; Zhang, Q.; Cai, J.; Yang, Y.; Cui, Y.; He, Y.; Wu, C.; Krishna, R.; Chen, B.; Qian, G., A new metal-organic framework with potential for adsorptive separation of methane from carbon dioxide, acetylene, ethylene, and ethane established by simulated breakthrough experiments. J. Mat. Chem. A 2014, 2 (8), 2628-2633.

43. Gao, J.; Qian, X.; Lin, R.-B.; Krishna, R.; Wu, H.; Zhou, W.; Chen, B., Mixed Metal-Organic Framework with Multiple Binding Sites for Efficient C2H2/CO2 Separation. Angew. Chem. Int. Ed. 2020, 59 (11), 4396-4400.

44. Ye, Y.; Ma, Z.; Lin, R.-B.; Krishna, R.; Zhou, W.; Lin, Q.; Zhang, Z.; Xiang, S.; Chen, B., Pore Space Partition within a Metal-Organic Framework for Highly Efficient $\mathrm{C}_{2} \mathrm{H}_{2} / \mathrm{CO}_{2}$ Separation. J. Am. Chem. Soc. 2019, 141 (9), 4130-4136. 
45. Fan, W.; Yuan, S.; Wang, W.; Feng, L.; Liu, X.; Zhang, X.; Wang, X.; Kang, Z.; Dai, F.; Yuan, D.; Sun, D.; Zhou, H.-C., Optimizing Multivariate Metal-Organic Frameworks for Efficient C2H2/CO2 Separation. J. Am. Chem. Soc. 2020.

46. Li, L.; Wang, J.; Zhang, Z.; Yang, Q.; Yang, Y.; Su, B.; Bao, Z.; Ren, Q., Inverse Adsorption Separation of CO2/C2H2 Mixture in Cyclodextrin-Based Metal-Organic Frameworks. ACS Appl. Mater. Interfaces 2019, 11 (2), 2543-2550.

47. Foo, M. L.; Matsuda, R.; Hijikata, Y.; Krishna, R.; Sato, H.; Horike, S.; Hori, A.; Duan, J.; Sato, Y.; Kubota, Y.; Takata, M.; Kitagawa, S., An Adsorbate Discriminatory Gate Effect in a Flexible Porous Coordination Polymer for Selective Adsorption of $\mathrm{CO}_{2}$ over $\mathrm{C}_{2} \mathrm{H}_{2}$. J.Am. Chem. Soc. 2016, 138 (9), 3022-3030.

48. Duan, J.; Higuchi, M.; Foo, M. L.; Horike, S.; Rao, K. P.; Kitagawa, S., A Family of Rare Earth Porous Coordination Polymers with Different Flexibility for $\mathrm{CO}_{2} / \mathrm{C}_{2} \mathrm{H}_{4}$ and $\mathrm{CO}_{2} / \mathrm{C}_{2} \mathrm{H}_{6}$ Separation. Inorg. Chem. 2013, 52 (14), 8244-8249.

49. Yang, W.; Davies, A. J.; Lin, X.; Suyetin, M.; Matsuda, R.; Blake, A. J.; Wilson, C.; Lewis, W.; Parker, J. E.; Tang, C. C.; George, M. W.; Hubberstey, P.; Kitagawa, S.; Sakamoto, H.; Bichoutskaia, E.; Champness, N. R.; Yang, S.; Schröder, M., Selective CO2 uptake and inverse CO2/C2H2 selectivity in a dynamic bifunctional metal-organic framework. Chemical Science 2012, 3 (10), $2993-2999$.

50. Eguchi, R.; Uchida, S.; Mizuno, N., Inverse and High $\mathrm{CO}_{2} / \mathrm{C}_{2} \mathrm{H}_{2}$ Sorption Selectivity in Flexible Organic-Inorganic lonic Crystals. Angew. Chem., Int. Ed. 2012, 51 (7), 1635-1639.

51. Horike, S.; Kishida, K.; Watanabe, Y.; Inubushi, Y.; Umeyama, D.; Sugimoto, M.; Fukushima, T.; Inukai, M.; Kitagawa, S., Dense coordination network capable of selective CO2 capture from C1 and C2 hydrocarbons. J. Am. Chem. Soc. 2012, 134 (24), $9852-5$.

52. Noro, S.-i.; Tanaka, D.; Sakamoto, H.; Shimomura, S.; Kitagawa, S.; Takeda, S.; Uemura, K.; Kita, H.; Akutagawa, T.; Nakamura, T., Selective Gas Adsorption in One-Dimensional, Flexible Cull Coordination Polymers with Polar Units. Chem. Mater. 2009, 21 (14), $3346-$ 3355.

53. Krishna, R., Methodologies for evaluation of metal-organic frameworks in separation applications. RSC Adv. 2015, 5 (64), $52269-52295$.

54. Subraveti, S. G.; Pai, K. N.; Rajagopalan, A. K.; Wilkins, N. S.; Rajendran, A.; Jayaraman, A.; Alptekin, G., Cycle design and optimization of pressure swing adsorption cycles for pre-combustion $\mathrm{CO}_{2}$ capture. Appl. Energy 2019, $254,113624$.

55. Yanai, N.; Kitayama, K.; Hijikata, Y.; Sato, H.; Matsuda, R.; Kubota, Y.; Takata, M.; Mizuno, M.; Uemura, T.; Kitagawa, S., Gas detection by structural variations of fluorescent guest molecules in a flexible porous coordination polymer. Nat. Mater. 2011, 10, 787.

56. Qazvini, O. T.; Fatemi, S., Modeling and simulation pressure-temperature swing adsorption process to remove mercaptan from humid natural gas; a commercial case study. Sep. Purif. Technol. 2015, 139, 88-103.

57. Mukherjee, S.; Sikdar, N.; O’Nolan, D.; Franz, D. M.; Gascón, V.; Kumar, A.; Kumar, N.; Scott, H. S.; Madden, D. G.; Kruger, P. E., Trace CO2 capture by an ultramicroporous physisorbent with low water affinity. Sci. Adv. 2019, 5 (11), eaax9171.

58. Masala, A.; Vitillo, J. G.; Mondino, G.; Grande, C. A.; Blom, R.; Manzoli, M.; Marshall, M.; Bordiga, S., CO2 Capture in Dry and Wet Conditions in UTSA-16 Metal-Organic Framework. ACS Appl. Mater. Interfaces 2017, 9 (1), 455-463. 
Entry for the Table of Contents

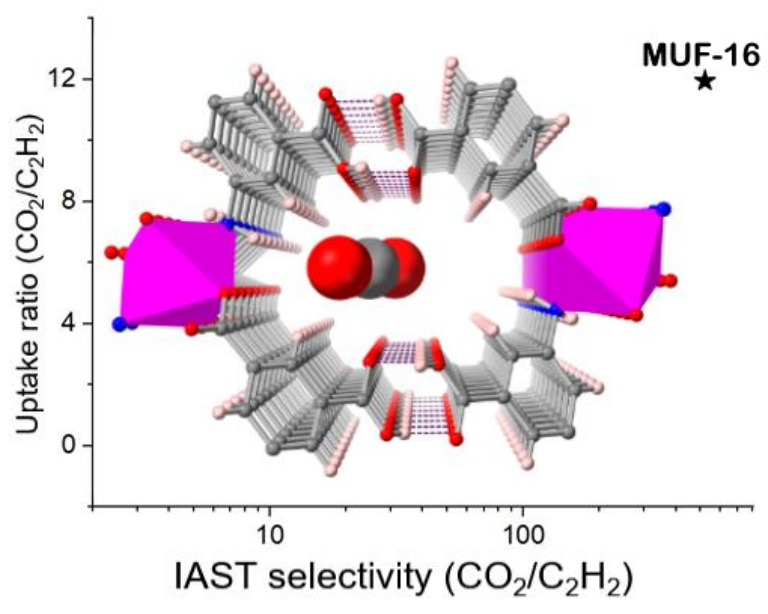




\title{
Supplementary Materials for
}

\section{Selective Capture of Carbon Dioxide from Hydrocarbons Using a Metal-Organic Framework: Relevance to the Purification of Natural Gas and Acetylene}

\author{
Omid T. Qazvini ${ }^{1,2}$ and Shane G. Telfer ${ }^{*}, 1$ \\ ${ }^{1}$ MacDiarmid Institute for Advanced Materials and Nanotechnology, School of Fundamental Sciences, Massey \\ University, Palmerston North, New Zealand. \\ ${ }^{2}$ Department of Chemical Engineering and Analytical Science, The University of Manchester, Oxford Road, \\ Manchester M13 9PL, UK.
}

\section{Contents}

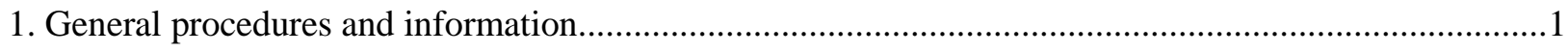

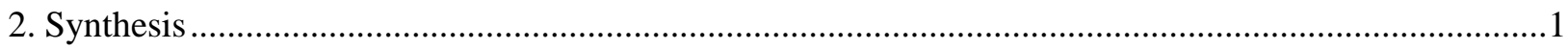

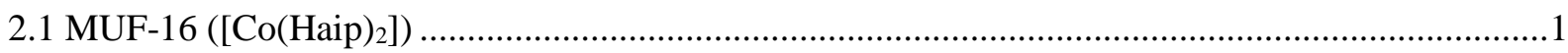

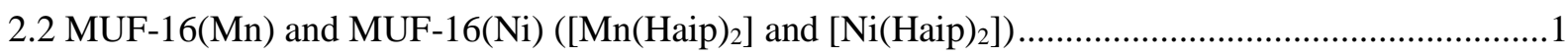

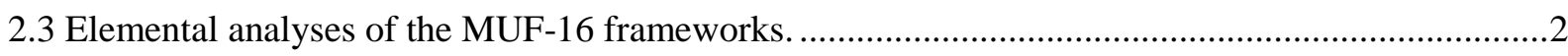

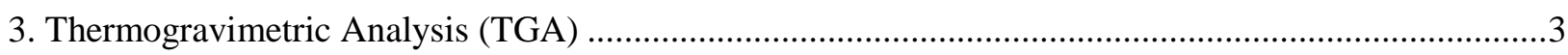

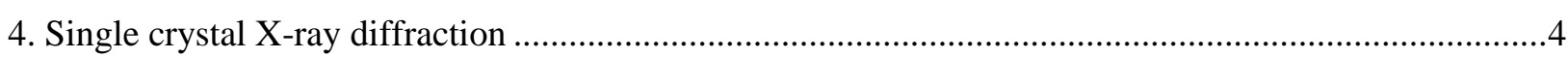

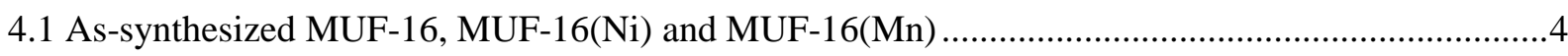

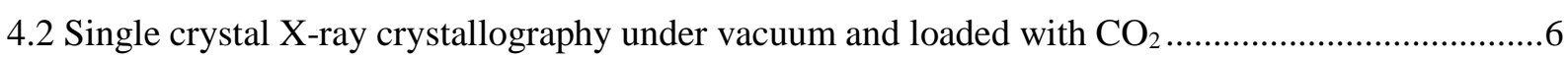

4.3 Refinement details for guest-free and $\mathrm{CO}_{2}$-loaded MUF-16(Mn) ................................................

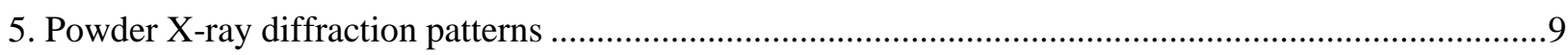

6. Textural properties and low-pressure gas adsorption measurements...................................................11

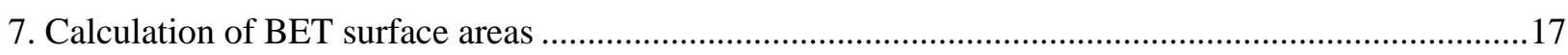

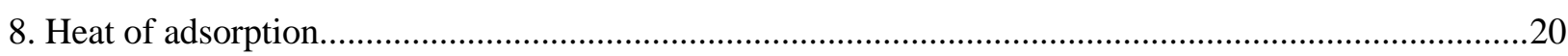

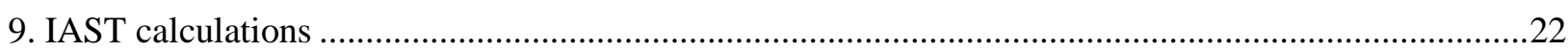

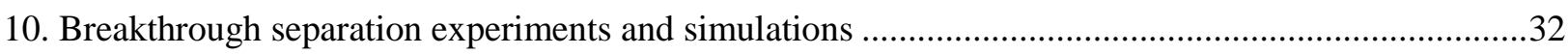

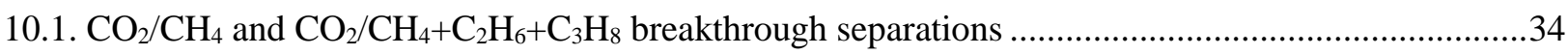

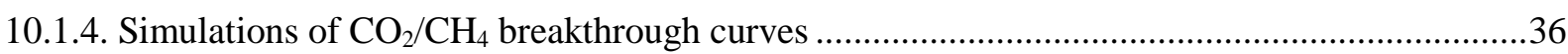

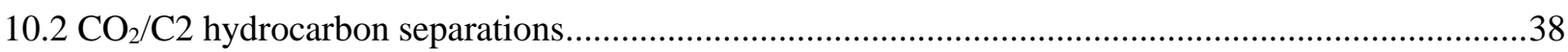

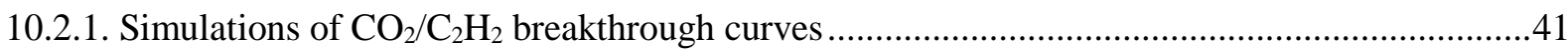

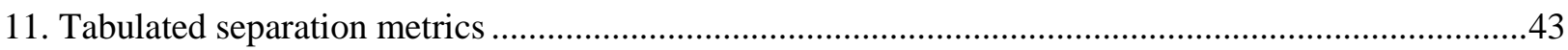

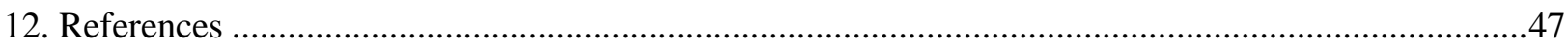




\section{General procedures and information}

All starting compounds and solvents were used as received from commercial sources without further purification unless otherwise noted. Elemental analyses were performed by the Campbell Microanalytical Laboratory at the University of Otago, New Zealand.

\section{Synthesis}

\subsection{MUF-16 ([Co(Haip)2])}

\section{Small-scale synthesis:}

A mixture of $\mathrm{Co}(\mathrm{OAc})_{2} \cdot 4 \mathrm{H}_{2} \mathrm{O}(0.625 \mathrm{~g}, 2.5 \mathrm{mmol})$, 5-aminoisophthalic acid (1.8 g, $\left.10 \mathrm{mmol}\right)$, methanol $(80 \mathrm{~mL})$ and water $(5 \mathrm{ml})$ were sonicated for $20 \mathrm{~min}$ in a sealed $1000 \mathrm{~mL}$ Schott bottle, which was then heated in a pre-heated oven at $85^{\circ} \mathrm{C}$ for 2 hours under autogenous pressure. After cooling the oven to room temperature, the resulting pink crystals were isolated by decanting off the mother liquor, washed with methanol several times and dried under vacuum at $130{ }^{\circ} \mathrm{C}$ for $20 \mathrm{~h}$. Yield: $0.98 \mathrm{~g}(94 \%$ based on cobalt) of guest-free MUF-16.

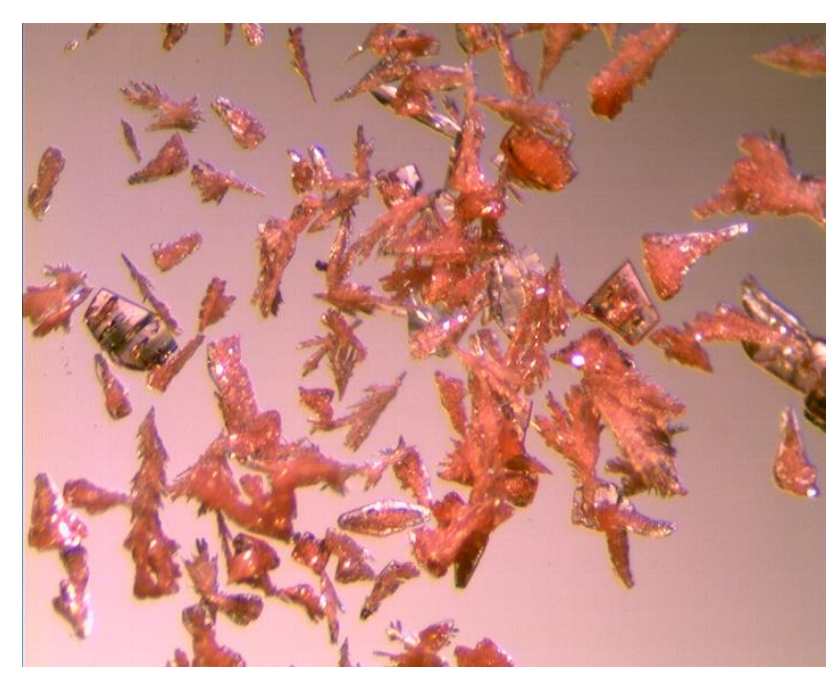

Fig. S1. Crystal of MUF-16.

\subsection{MUF-16(Mn) and MUF-16(Ni) ([Mn(Haip)2] and [Ni(Haip)2])}

A mixture of $\mathrm{M}\left(\mathrm{ClO}_{4}\right)_{2} \cdot 6 \mathrm{H}_{2} \mathrm{O}$ (where $\mathrm{M}=\mathrm{Mn}$ or $\mathrm{Ni}$ ) (1.25 mmol), 5-aminoisophthalic acid (2.50 mmol, $0.45 \mathrm{~g})$, and $\mathrm{NH}_{4} \mathrm{NO}_{3}(2.50 \mathrm{mmol}, 0.20 \mathrm{~g})$ with a mixed-solvent of $\mathrm{CH}_{3} \mathrm{CN}(20 \mathrm{~mL})$ and $\mathrm{CH}_{3} \mathrm{OH}(15$ $\mathrm{mL}$ ) were sonicated for $20 \mathrm{~min}$ and sealed in a $100 \mathrm{~mL}$ Teflon-lined stainless-steel reaction vessel and heated at $160{ }^{\circ} \mathrm{C}$ for two days under autogenous pressure. After cooling the oven to room temperature, the resulting brownish-coloured crystals were isolated by decanting off the mother liquor, then washed 
with methanol several times and dried under vacuum at $130{ }^{\circ} \mathrm{C}$ for $20 \mathrm{~h}$. Yields: $0.21 \mathrm{~g}(40 \%$ based on $\mathrm{Mn}$ ) of guest free MUF-16(Mn), and $0.28 \mathrm{~g}$ (53\% based on Ni) of guest-free MUF-16(Ni).

2.3 Elemental analyses of the MUF-16 frameworks.

\begin{tabular}{lccc}
\hline & C: calcd./found & $\mathrm{H}$ : calcd./found & N: calcd./found \\
\hline MUF-16 $\cdot \mathrm{H}_{2} \mathrm{O}$ & $43.95 / 43.49$ & $3.23 / 3.23$ & $6.41 / 6.40$ \\
MUF-16(Mn) $\cdot \mathrm{H}_{2} \mathrm{O}$ & $44.36 / 44.05$ & $3.26 / 3.42$ & $6.47 / 6.64$ \\
MUF-16(Ni) $\cdot \mathrm{H}_{2} \mathrm{O}$ & $43.98 / 44.18$ & $3.23 / 3.57$ & $6.41 / 6.90$ \\
\hline
\end{tabular}




\section{Thermogravimetric Analysis (TGA)}

Freshly prepared MOF samples were washed with $\mathrm{MeOH}$, and then activated at $130{ }^{\circ} \mathrm{C}$ under vacuum for 10 hours. Samples were exposed to air for one hour and then transferred to an aluminium sample pan. Measurements were then commenced under an $\mathrm{N}_{2}$ flow with a heating rate of $5{ }^{\circ} \mathrm{C} / \mathrm{min}$.

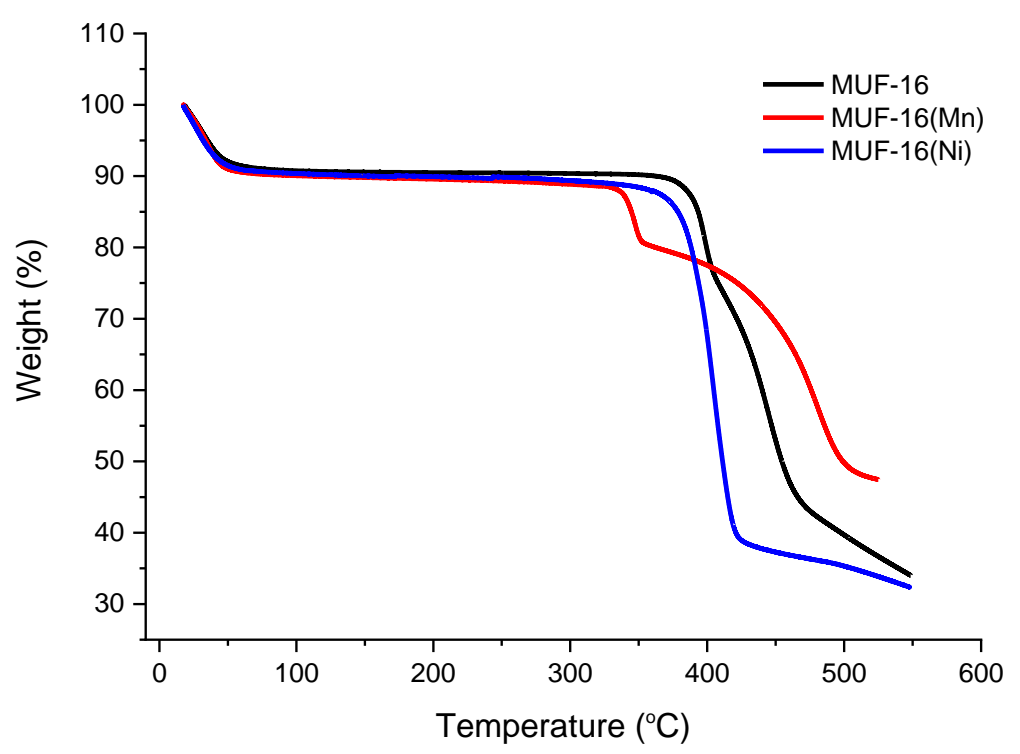

Fig. S2. TGA curves of MUF-16, MUF-16(Mn), and MUF-16(Ni) under $\mathrm{N}_{2}$. 


\section{Single crystal X-ray diffraction}

A Rigaku Spider diffractometer equipped with a MicroMax MM007 rotating anode generator $\left(\mathrm{Cu}_{\alpha}\right.$ radiation, $1.54180 \AA$ ), high-flux Osmic multilayer mirror optics, and a curved image plate detector was used to collect SCXRD data.

\subsection{As-synthesized MUF-16, MUF-16(Ni) and MUF-16(Mn)}

\section{General}

MOF crystals were analysed after removing them from methanol. Room temperature data collections produced better refinement statistics than low temperature data collections. All atoms were found in the electron density difference map. All atoms were refined anisotropically, except hydrogen atoms and certain of the water molecules in the pores (as specified below). The structures of solvated MUF-16 ${ }^{1}$ and MUF-16(Mn $)^{2}$ have been reported previously.

MUF-16

$\mathrm{O} 15$ of an occluded $\mathrm{H}_{2} \mathrm{O}$ molecule was refined isotropically. Despite numerous data collections, the wR $\mathrm{R}_{2}$ value remained high due to an inherent lack of precise ordering in the material. A small $\left(1.95 \mathrm{eA}^{-3}\right)$ electron density peak remained near the Co site.

$M U F-16(N i)$

The crystals diffracted to a resolution of just $1.0 \AA$ thus the calculated $\sin \left(\theta_{\max }\right) /$ wavelength is 0.4999 . This limited the number of data and produced a relatively low data: parameter ratio (7.3) and low precision on the $\mathrm{C}-\mathrm{C}$ bonds. Despite numerous data collections, the $\mathrm{wR}_{2}$ value remained high due to an inherent lack of precise ordering in the material. And a small $\left(1.55 \mathrm{eA}^{-3}\right)$ electron density peak remained near the Ni site.

A solvent mask was calculated and 124 electrons were found in a volume of $308 \AA^{3}$ in one void per unit cell. This is consistent with the presence of three disordered water molecules per asymmetric unit, which account for 120 electrons per unit cell. 
Table S1. Crystal data and structure refinement details for MUF-16, MUF-16(Mn) and MUF-16(Ni).

\begin{tabular}{|c|c|c|c|}
\hline & MUF-16 & MUF-16(Mn) & MUF-16(Ni) \\
\hline Formula & $\mathrm{Co}(\text { Haip })_{2} \cdot 2 \mathrm{H}_{2} \mathrm{O}$ & $\mathrm{Mn}(\text { Haip })_{2} \cdot 3 \mathrm{H}_{2} \mathrm{O}$ & $\mathrm{Ni}(\text { Haip })_{2} \cdot 3 \mathrm{H}_{2} \mathrm{O}$ \\
\hline CCDC deposition no. & 1948901 & 1948902 & 1948903 \\
\hline Empirical formula & $\mathrm{C}_{16} \mathrm{H}_{16} \mathrm{CoN}_{2} \mathrm{O}_{10}$ & $\mathrm{C}_{16} \mathrm{H}_{18} \mathrm{MnN}_{2} \mathrm{O}_{11}$ & $\mathrm{C}_{16} \mathrm{H}_{18} \mathrm{~N}_{2} \mathrm{NiO}_{11}$ \\
\hline Formula weight & 455.24 & 471.28 & 473.3 \\
\hline Temperature / K & 292 & 292 & 293.0 \\
\hline Crystal system & monoclinic & monoclinic & monoclinic \\
\hline Space group & $\mathrm{I} 2 / \mathrm{a}$ & $I 2 / a$ & $\mathrm{I} 2 / \mathrm{a}$ \\
\hline a / $\AA$ & $15.3514(15)$ & $25.2367(14)$ & $15.4963(11)$ \\
\hline $\mathrm{b} / \AA$ & $4.4232(4)$ & $4.57990(10)$ & $4.5780(2)$ \\
\hline c / $\AA$ & $25.614(4)$ & $15.4895(11)$ & $25.230(2)$ \\
\hline$\alpha /{ }^{\circ}$ & 90 & 90 & 90 \\
\hline$\beta / \circ$ & $94.294(10)$ & $96.046(8)$ & $96.177(8)$ \\
\hline$\gamma / \circ$ & 90 & 90 & 90 \\
\hline Volume / $\AA^{3}$ & $1734.4(4)$ & $1780.34(17)$ & $1779.5(2)$ \\
\hline $\mathrm{Z}$ & 4 & 4 & 4 \\
\hline$\rho_{\text {calc }} / \mathrm{g} \mathrm{cm}^{-3}$ & 1.743 & 1.758 & 1.564 \\
\hline$\mu / \mathrm{mm}^{-1}$ & 8.357 & 6.682 & 2.020 \\
\hline $\mathrm{F}(000)$ & 932.0 & 972.0 & 856.0 \\
\hline Resolution range for data/ $\AA$ & 0.81 & 0.81 & 1.0 \\
\hline Reflections collected & 7472 & 14132 & 6610 \\
\hline Independent reflections & $1594\left[\mathrm{R}_{\mathrm{int}}=0.0918, \mathrm{R}_{\text {sigma }}=0.0917\right]$ & $1668\left[\mathrm{R}_{\text {int }}=0.1054, \mathrm{R}_{\text {sigma }}=0.1158\right]$ & $925\left[\mathrm{R}_{\mathrm{int}}=0.0917, \mathrm{R}_{\mathrm{sigma}}=0.0852\right]$ \\
\hline Data/restraints/parameters & $1594 / 2 / 136$ & $1668 / 1 / 149$ & $925 / 0 / 126$ \\
\hline Goodness-of-fit on F2 & 1.301 & 1.152 & 1.649 \\
\hline Final $R$ indices $[I>2 \sigma(I)]$ & $\mathrm{R}_{1}=0.1185, \mathrm{wR}_{2}=0.3035$ & $\mathrm{R}_{1}=0.0740, \mathrm{wR}_{2}=0.1821$ & $\mathrm{R}_{1}=0.1517, \mathrm{wR}_{2}=0.3672$ \\
\hline Final $\mathrm{R}$ indices [all data] & $\mathrm{R}_{1}=0.1576, \mathrm{wR}_{2}=0.3785$ & $\mathrm{R}_{1}=0.1350, \mathrm{wR}_{2}=0.2421$ & $\mathrm{R}_{1}=0.2061, \mathrm{wR}_{2}=0.4467$ \\
\hline Largest diff. peak/hole / e $\AA^{-3}$ & $0.93 /-1.26$ & $0.57 /-0.51$ & $0.77 /-0.83$ \\
\hline
\end{tabular}




\subsection{Single crystal $\mathrm{X}$-ray crystallography under vacuum and loaded with $\mathrm{CO}_{2}$}

Capillary SCXRD was performed for a single crystal of MUF-16(Mn) both under vacuum and loaded with $\mathrm{CO}_{2}$ at around 1.1 bar and $20^{\circ} \mathrm{C}$ based on the following steps:

First a single crystal was chosen with an appropriate size $(\sim 0.1 \times 0.1 \times 0.1 \mathrm{~mm})$ and soaked in ethanol. A small capillary tube with around $0.2 \mathrm{~mm}$ in diameter and $50 \mathrm{~mm}$ in length (which is open at both ends) was made by burning and shaping the neck of a glass pipette (referred to as the 'home-made capillary'). The home-made capillary was then used to trap the crystal inside it. Normally, the crystal flowed through the capillary carried by the ethanol stream.

The home-made capillary was then transferred into a standard $0.3 \mathrm{~mm}$ capillary. A long capillary $(0.2$ $\mathrm{mm}$ in diameter) was used to push the home-made capillary to the very bottom of the $0.3 \mathrm{~mm}$ capillary. Around 6 or 7 crystals of cobalt chloride hydrate were then transferred to the $0.3 \mathrm{~mm}$ capillary and placed on the top of the home-made capillary. The cobalt chloride was used a visual indicator of the level of water vapour in the capillary based on its pink $\rightarrow$ blue colour change upon dehydration.

The top of the $0.3 \mathrm{~mm}$ capillary was then covered by glass wool to avoid the elutriation of cobalt chloride crystals during activation.

The capillary assembly was then connected to an adsorption apparatus (Quantachrome-Autosorb-iQ2) using appropriate Swagelok fittings (Fig. S3) and was kept under vacuum and a temperature of $140{ }^{\circ} \mathrm{C}$ for around 5 hours so that the vacuum level reached 0.0008 torr. At this point the cobalt chloride crystals were blue in colour (anhydrous).

The capillary was flame sealed to trap the crystal under vacuum. Alternatively, the capillary was filled with $\mathrm{CO}_{2}$ to a pressure of 1.2 bar and then flame sealed.

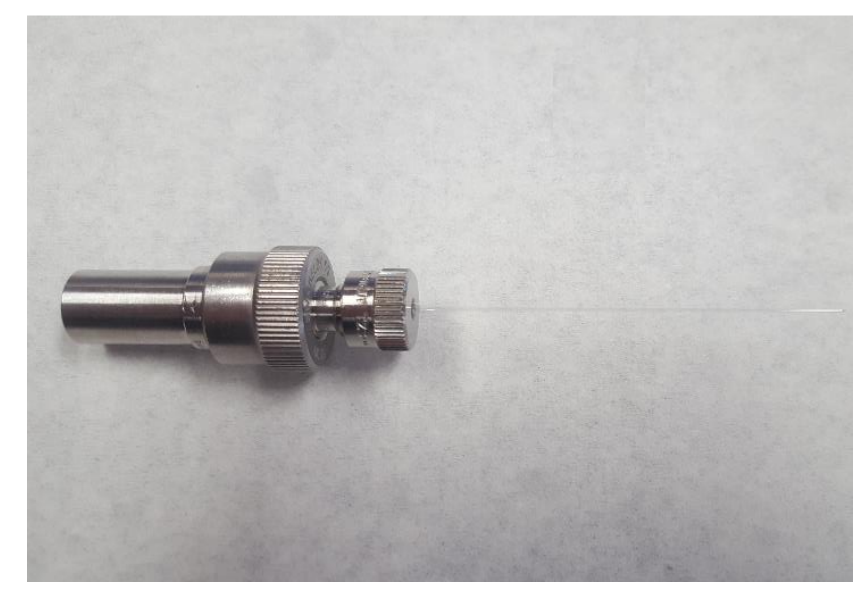

Fig. S3. Swagelok fittings for connecting capillary to Quantachrome-Autosorb-iQ2. 


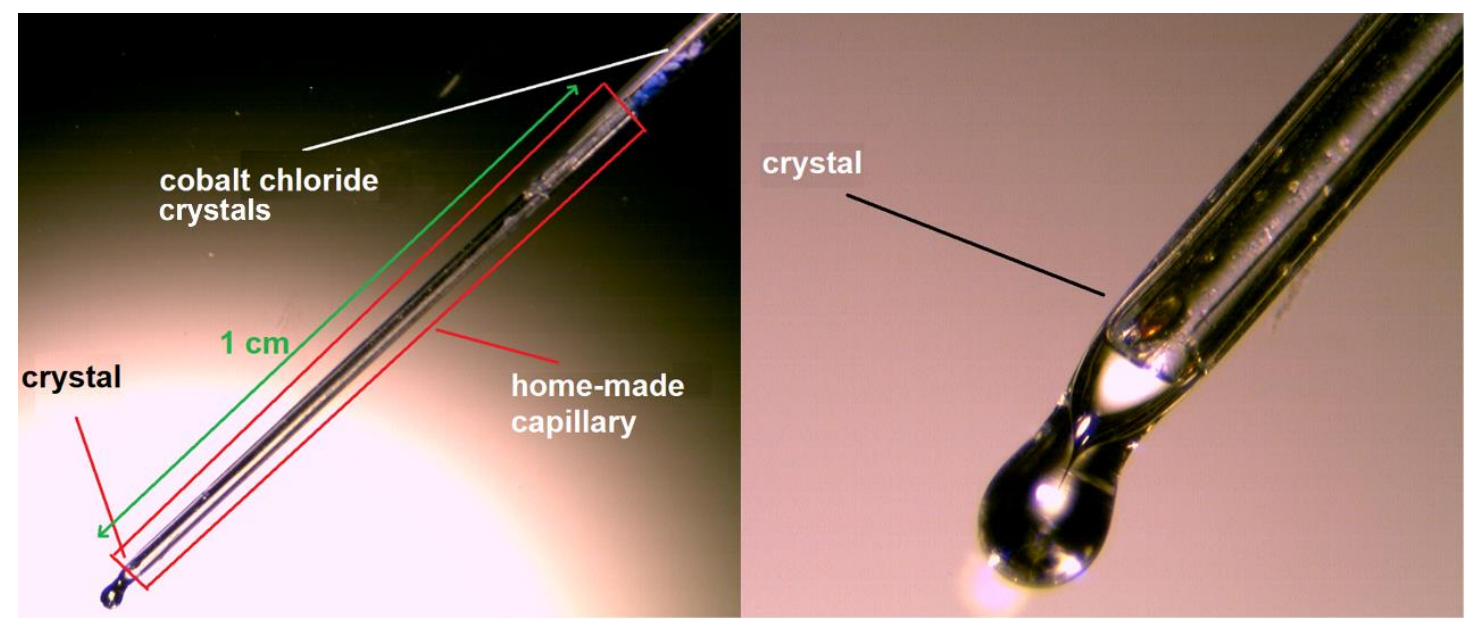

Fig. S4. Schematic and dimensions of capillaries used for SCXRD.

\subsection{Refinement details for guest-free and $\mathrm{CO}_{2}$-loaded MUF-16(Mn)}

\section{General}

Certain reflections were omitted from the refinement process since they were mismeasured due to the presence of the glass capillary. All non-hydrogen atoms were found in the Fourier difference map.

MUF-16(Mn) in vacuo

The crystals diffracted to a resolution of just $0.90 \AA$ thus the calculated $\sin \left(\theta_{\max }\right) /$ wavelength is 0.555 .

\section{MUF-16(Mn) under $\mathrm{CO}_{2}$}

The crystals diffracted to a resolution of just $1.08 \AA$ thus the calculated $\sin \left(\theta_{\text {max }}\right) /$ wavelength is 0.463 . This limited the number of data and produced a relatively low data: parameter ratio (5.3) and low precision on the $\mathrm{C}-\mathrm{C}$ bonds.

A strong electron density peak was observed in the middle of the pore and two weaker areas of electron density towards the pore surface. The central dense area was assigned to be an oxygen (O15) with a fixed occupancy of 1 (lowing for its location on a special position), while the other two areas were ascribed to oxygen $(\mathrm{O} 16)$ and carbon $(\mathrm{C} 17)$ atoms with fixed occupancies of 0.5 . This describes two disordered $\mathrm{CO}_{2}$ molecules that occupy one of two sites. The two molecules share an $\mathrm{O}$ atom. Overall, this equates to one $\mathrm{CO}_{2}$ molecule per $\mathrm{Mn}$ centre which is in agreement with the adsorption isotherm. The $\mathrm{C}=\mathrm{O}$ bond lengths were restrained to $1.16 \AA$ and the $\mathrm{O}=\mathrm{C}=\mathrm{O}$ angle to $180^{\circ}$. The $\mathrm{C}$ and $\mathrm{O}$ atoms of the $\mathrm{CO}_{2}$ were refined isotropically. 
Table S2. SCXRD data and refinement details of guest-free and $\mathrm{CO}_{2}$-loaded MUF-16(Mn).

\begin{tabular}{|c|c|c|}
\hline & MUF-16(Mn) in vacuo & MUF-16(Mn) under $\mathrm{CO}_{2}(1.1$ bar) \\
\hline Formula & Mn(Haip) $)_{2}$ & $\mathrm{Mn}$ (Haip) $)_{2} \cdot \mathrm{CO}_{2}$ \\
\hline CCDC deposition no. & 1948905 & 1948904 \\
\hline Empirical formula & $\mathrm{C}_{16} \mathrm{H}_{12} \mathrm{MnN}_{2} \mathrm{O}_{8}$ & $\mathrm{C}_{17} \mathrm{H}_{12} \mathrm{MnN}_{2} \mathrm{O}_{10}$ \\
\hline Formula weight & 415.22 & 459.23 \\
\hline Temperature/K & 292 & 292 \\
\hline Crystal system & monoclinic & monoclinic \\
\hline Space group & $I 2 / \mathrm{a}$ & $I 2 / \mathrm{a}$ \\
\hline $\mathrm{a} / \AA ̊ \AA$ & $15.4872(11)$ & $15.5719(10)$ \\
\hline $\mathrm{b} / \AA ̊ \AA$ & $4.51930(10)$ & $4.52010(10)$ \\
\hline $\mathrm{c} / \AA$ & $25.4913(13)$ & $25.438(2)$ \\
\hline$\alpha /^{\circ}$ & 90 & 90 \\
\hline$\beta /{ }^{\circ}$ & $97.080(16)$ & $97.108(8)$ \\
\hline$\gamma /{ }^{\circ}$ & 90 & 90 \\
\hline Volume $/ \AA^{3}$ & $1770.56(17)$ & $1776.7(2)$ \\
\hline $\mathrm{Z}$ & 4 & 4 \\
\hline$\rho_{\text {calc }} / \mathrm{g} \mathrm{cm}^{-3}$ & 1.558 & 1.717 \\
\hline$\mu / \mathrm{mm}^{-1}$ & 6.512 & 6.646 \\
\hline $\mathrm{F}(000)$ & 844.0 & 932.0 \\
\hline Data range for refinement/ $\AA$ & 0.90 & 1.08 \\
\hline Reflections collected/ind. & $7515 / 1214\left[R_{\text {int }}=0.1632, R_{\sigma}=0.1964\right]$ & $8177 / 713\left[\mathrm{R}_{\text {int }}=0.1104, \mathrm{R}_{\sigma}=0.0804\right]$ \\
\hline Data/restraints/parameters & $1214 / 0 / 129$ & $713 / 90 / 136$ \\
\hline Goodness-of-fit on $\mathrm{F}^{2}$ & 0.862 & 1.216 \\
\hline Final $\mathrm{R}$ indexes $[\mathrm{I}>=2 \sigma(\mathrm{I})]$ & $\mathrm{R}_{1}=0.0510, \mathrm{wR}_{2}=0.0954$ & $\mathrm{R}_{1}=0.0868, \mathrm{wR}_{2}=0.2280$ \\
\hline Final $\mathrm{R}$ indexes [all data] & $\mathrm{R}_{1}=0.1341, \mathrm{wR}_{2}=0.1112$ & $\mathrm{R}_{1}=0.1278, \mathrm{wR}_{2}=0.2915$ \\
\hline Largest diff. peak/hole / e $\AA^{-3}$ & $0.35 /-0.48$ & $0.56 /-0.58$ \\
\hline
\end{tabular}




\section{Powder X-ray diffraction patterns}

The data were obtained from freshly prepared MOF samples that had been washed several times with $\mathrm{MeOH}$. MOF crystals were analysed right after removing them from $\mathrm{MeOH}$. The two-dimensional images of the Debye rings were integrated with 2DP to give $2 \theta$ vs I diffractograms. Predicted powder patterns were generated from single crystal structures using Mercury.

For aging experiments on the frameworks, after washing as-synthesized samples several times with $\mathrm{MeOH}$, they were activated and were aged in air at $70-85 \%$ relative humidity or water at $20{ }^{\circ} \mathrm{C}$.

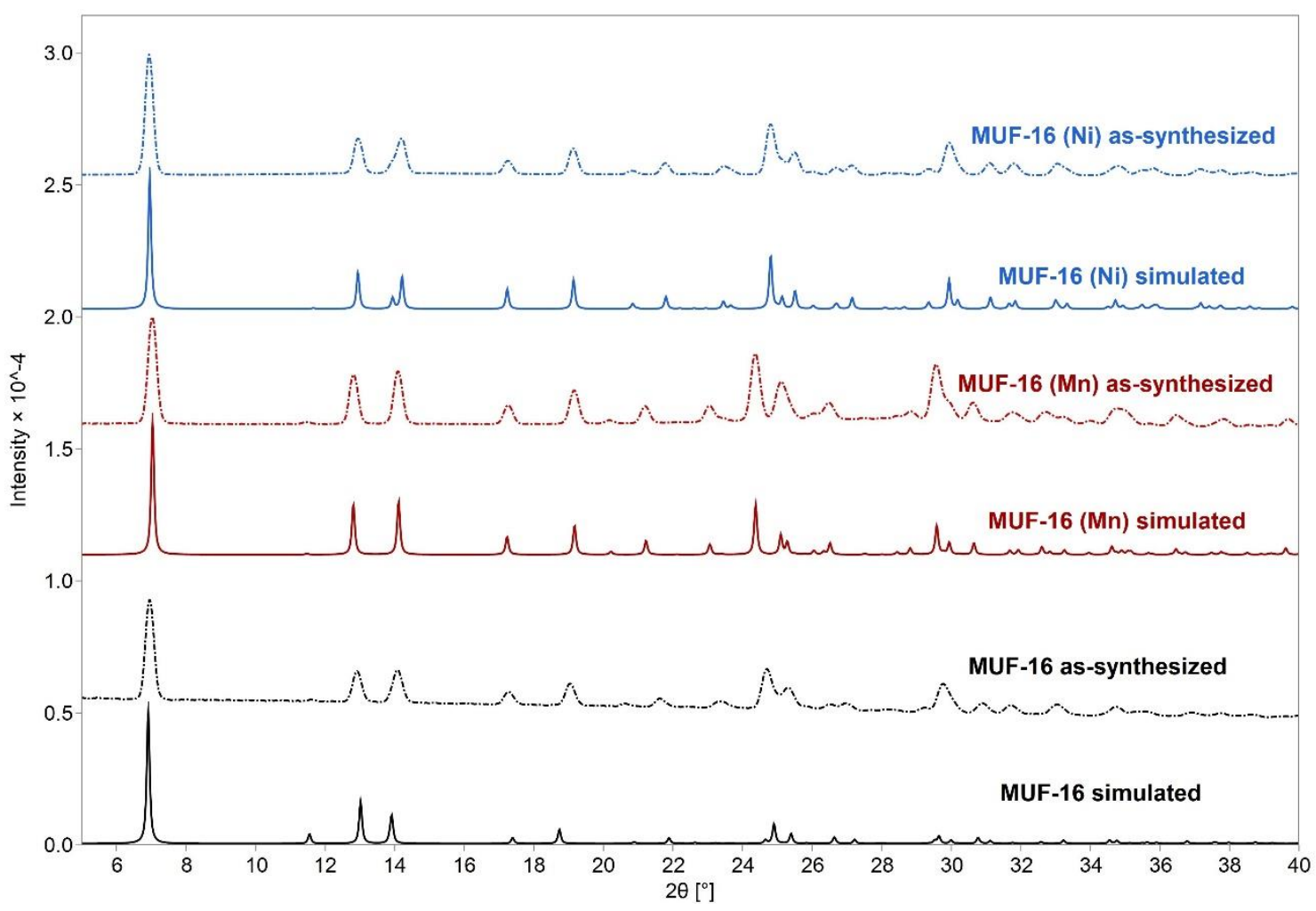

Fig. S5. PXRD patterns of MUF-16, MUF-16(Mn) and MUF-(Ni) with comparisons between measurements on as-synthesized bulk samples and diffractograms predicted from SCXRD structures. 


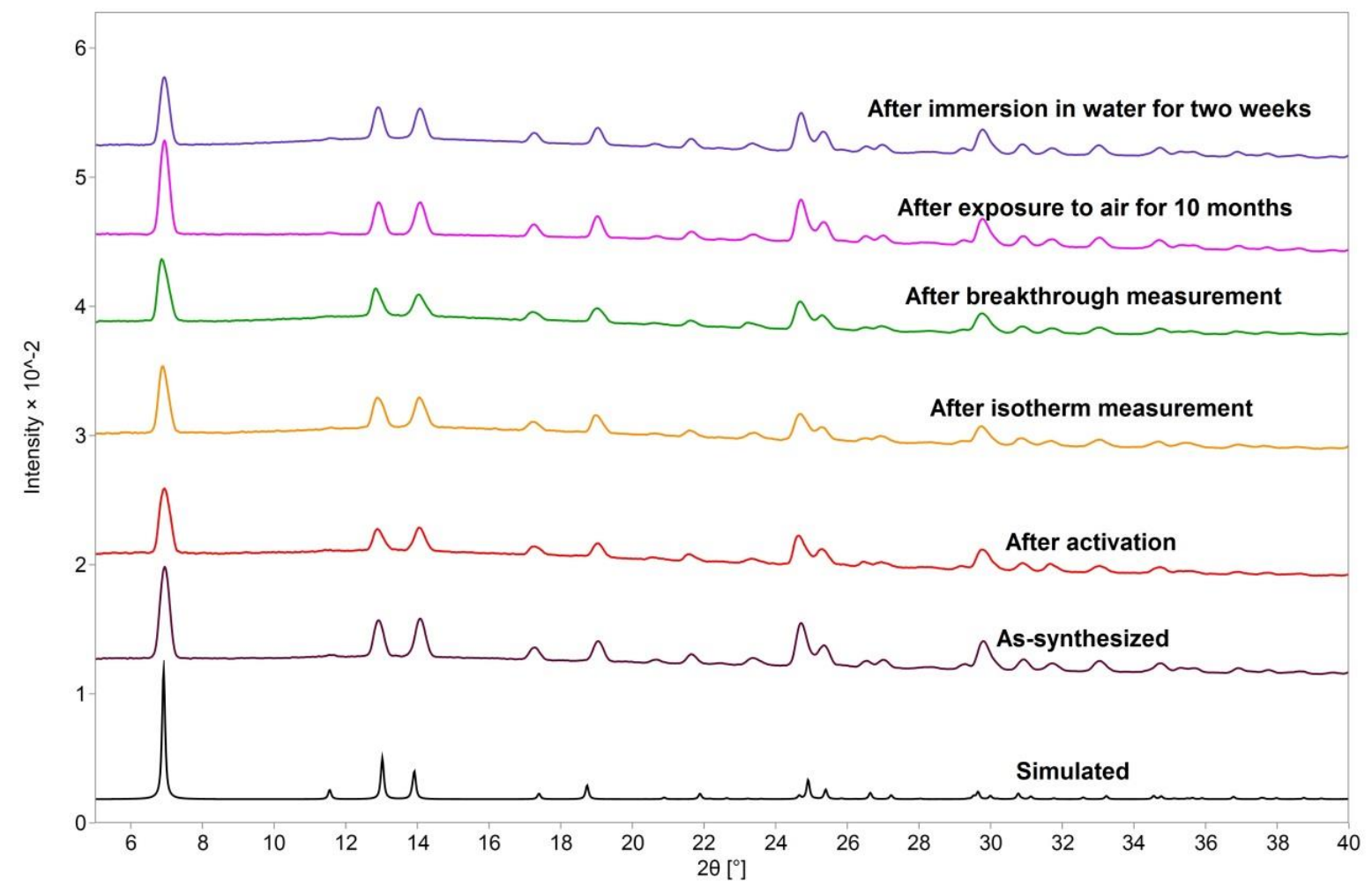

Fig. S6. PXRD patterns of MUF-16 showing that its structure remains unchanged after activation at $130{ }^{\circ} \mathrm{C}$ under vacuum, after isotherm measurements, after breakthrough experiments, after exposure to an air with relative humidity of $>80 \%$ for at least 12 months and after immersion in water for two weeks.

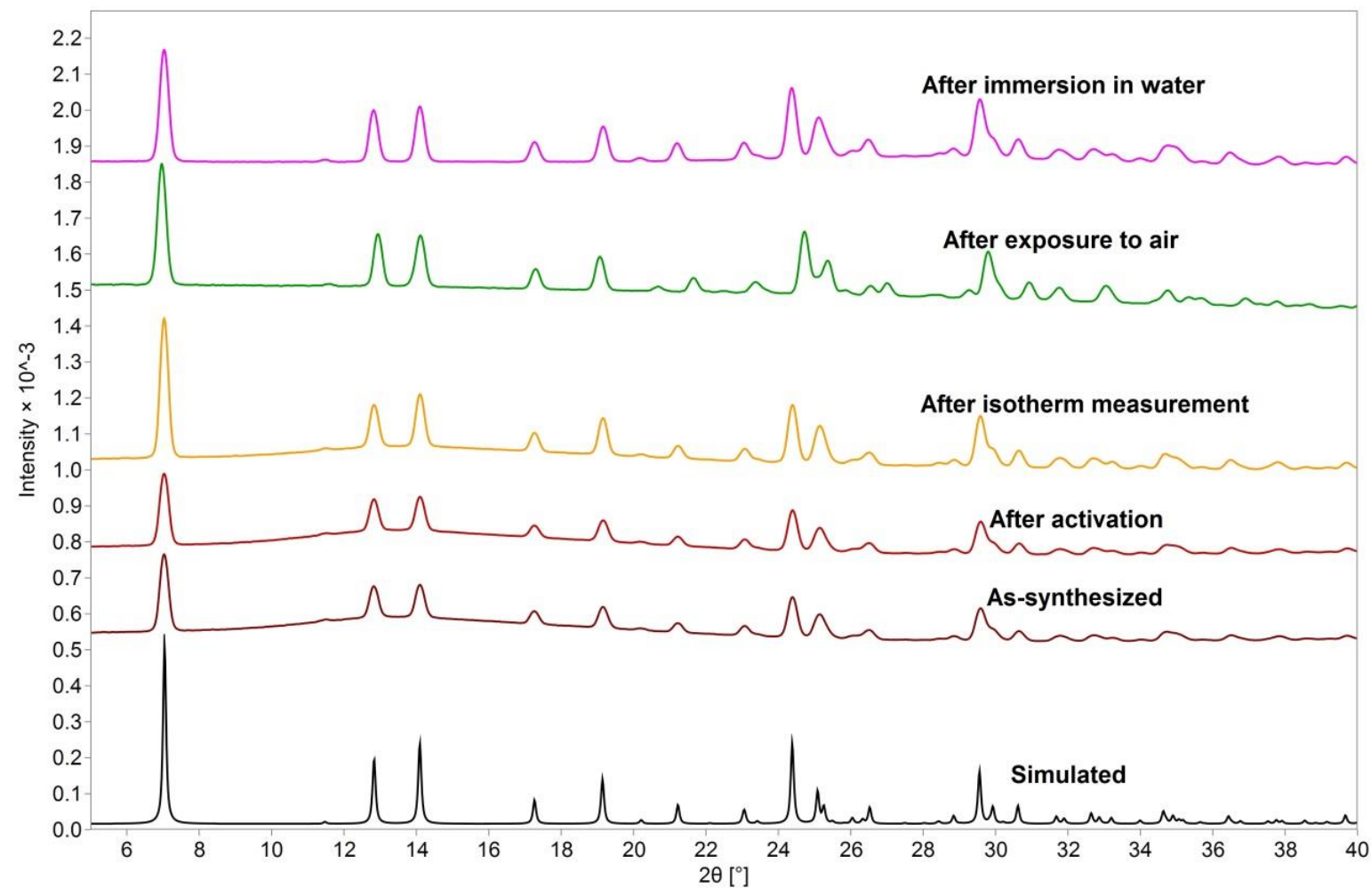

Fig. S7. PXRD patterns of MUF-16(Mn) showing that its structure remains unchanged after activation at $130{ }^{\circ} \mathrm{C}$ under vacuum, after isotherm measurements, after exposure to an air with relative humidity of $>80 \%$ for at least 12 months and after immersion in water for 2 weeks. 


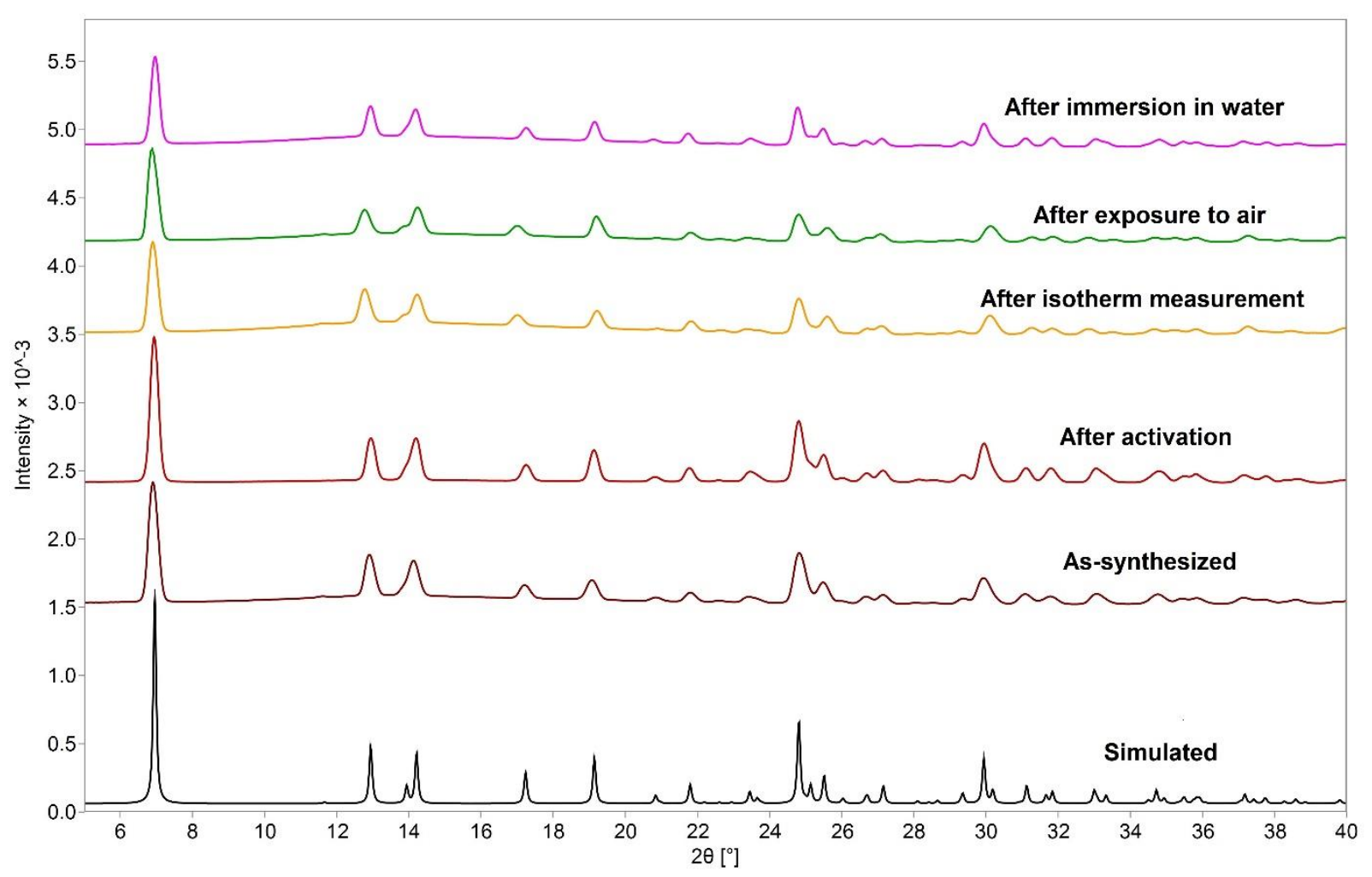

Fig. S8. PXRD patterns of MUF-16(Ni) showing that its structure remains unchanged after activation at $130{ }^{\circ} \mathrm{C}$ under vacuum, after isotherm measurements, after exposure to an air with relative humidity of $>80 \%$ for at least 12 months and after immersion in water for 2 weeks.

\section{Textural properties and low-pressure gas adsorption measurements}

Single crystal structures of MUF-16, MUF-16(Mn) and MUF-16(Ni) were used directly for all the calculations and simulations without modification except removal of occluded solvent, where relevant. The Zeo $++^{3}$ code and RASPA $2^{4}$ were used to calculate their pore volumes and surface areas with the use of $\mathrm{H}_{2}$ and $\mathrm{He}$ probes, respectively. 
Table S3. Some calculated and experimentally determined properties of the MUF-16 family.

\begin{tabular}{lccc}
\hline & MUF-16 & MUF-16(Mn) & MUF-16(Ni) \\
\hline Geometric surface area $\left(\mathrm{m}^{2} / \mathrm{g}\right.$, Zeo++) & 313 & 315 & 313 \\
BET surface area $\left(\mathrm{m}^{2} / \mathrm{g}\right.$, from experimental $\mathrm{N}_{2}$ isotherm/77 K) & 214 & 205 & 204 \\
Calculated void fraction $(\%$, RASPA2) & 17.3 & 17.0 & 16.7 \\
Calculated pore volume $\left(\mathrm{cm}^{3} / \mathrm{g}\right.$, RASPA2) & 0.10 & 0.11 & 0.11 \\
Pore volume $\left(\mathrm{cm}^{3} / \mathrm{g}\right.$, from experimental $\mathrm{N}_{2}$ isotherm $\left./ 77 \mathrm{~K}\right)$ & 0.11 & 0.12 & 0.11 \\
\hline
\end{tabular}

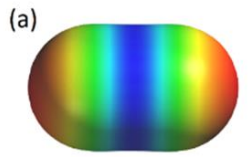

(c)

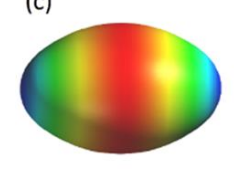

(d)
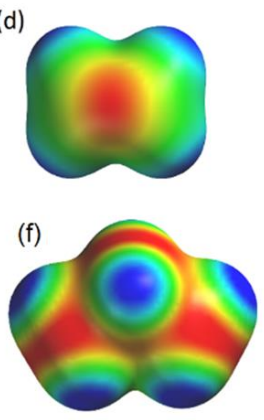

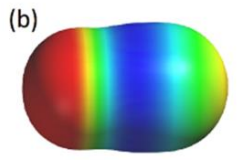

(e)
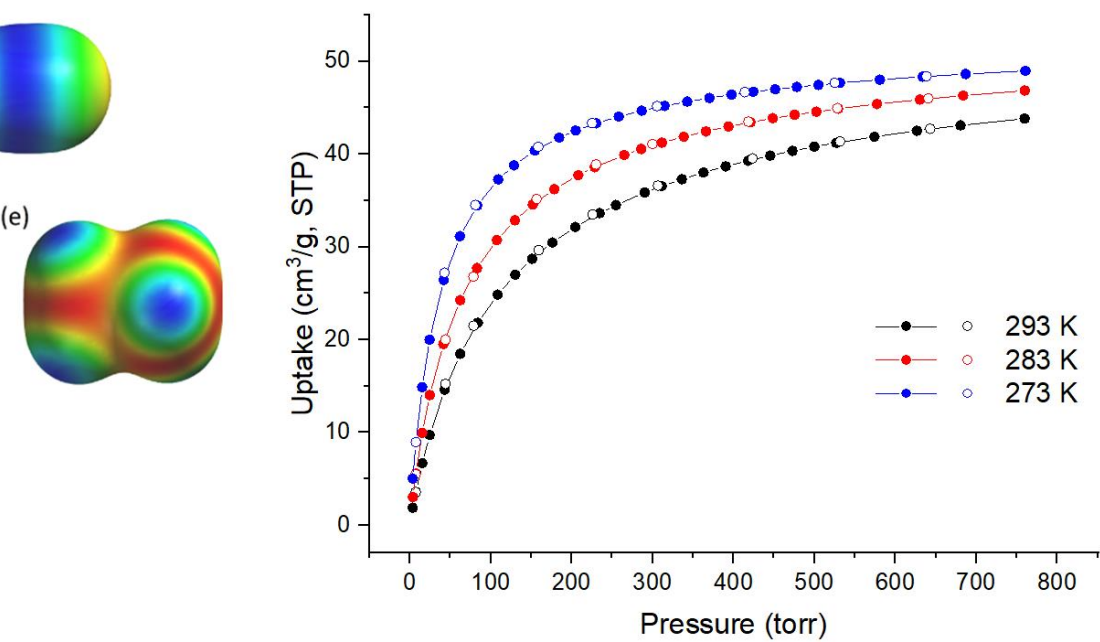

Fig. S9. Left: Electrostatic potential maps of (a) $\mathrm{CO}_{2}$, (b) $\left(\mathrm{N}_{2} \mathrm{O}\right.$ ) (c) $\mathrm{C}_{2} \mathrm{H}_{2}$, (d) $\mathrm{C}_{2} \mathrm{H}_{4}$, (e) $\mathrm{C}_{2} \mathrm{H}_{6}$ and (f) $\mathrm{C}_{3} \mathrm{H}_{8}$ Blue/green = positive; red/orange = negative; Right: Volumetric adsorption isotherms of $\mathrm{N}_{2} \mathrm{O}$ measured at different temperatures for MUF-16.

Table S4. Physicochemical characteristics of different gasses relevant to their separation. ${ }^{5-8}$

\begin{tabular}{|c|c|c|c|c|c|}
\hline & $\begin{array}{l}\text { Boiling point } \\
(\mathbf{K})\end{array}$ & $\begin{array}{c}\text { Molecular } \\
\text { dimensions (A) }\end{array}$ & $\begin{array}{c}\text { Polarizability } \\
\left(\AA^{\mathbf{3}}\right)\end{array}$ & $\begin{array}{c}\text { Dipole } \\
\text { moment } \\
\times \mathbf{1 0}^{18} / \mathrm{esu} \mathbf{~ c m}^{2} \\
\end{array}$ & $\begin{array}{c}\text { Quadrupole } \\
\text { moment } \\
\times 10^{26} / \mathrm{esu} \mathbf{~ c m}^{2}\end{array}$ \\
\hline $\mathrm{CO}_{2}$ & 216.5 & $3.18 \times 3.33 \times 5.36$ & 2.91 & 0 & -4.3 \\
\hline $\mathrm{CH}_{4}$ & 111.66 & $3.82 \times 3.94 \times 4.10$ & 2.59 & 0 & 0 \\
\hline $\mathrm{C}_{2} \mathrm{H}_{2}$ & 188.4 & $3.32 \times 3.34 \times 5.7$ & $3.33-3.93$ & 0 & +7.5 \\
\hline $\mathrm{C}_{2} \mathrm{H}_{4}$ & 169.4 & $3.28 \times 4.18 \times 4.84$ & 4.25 & 0 & +1.5 \\
\hline $\mathrm{C}_{2} \mathrm{H}_{6}$ & 184.5 & $3.81 \times 4.82 \times 4.08$ & $4.43-4.47$ & 0 & +0.65 \\
\hline $\mathrm{C}_{3} \mathrm{H}_{8}$ & 231.0 & $6.80 \times 4.20 \times 3.80$ & $6.29-6.37$ & 0.084 & - \\
\hline $\mathrm{C}_{3} \mathrm{H}_{6}$ & 225.4 & - & 6.26 & 0.366 & - \\
\hline
\end{tabular}




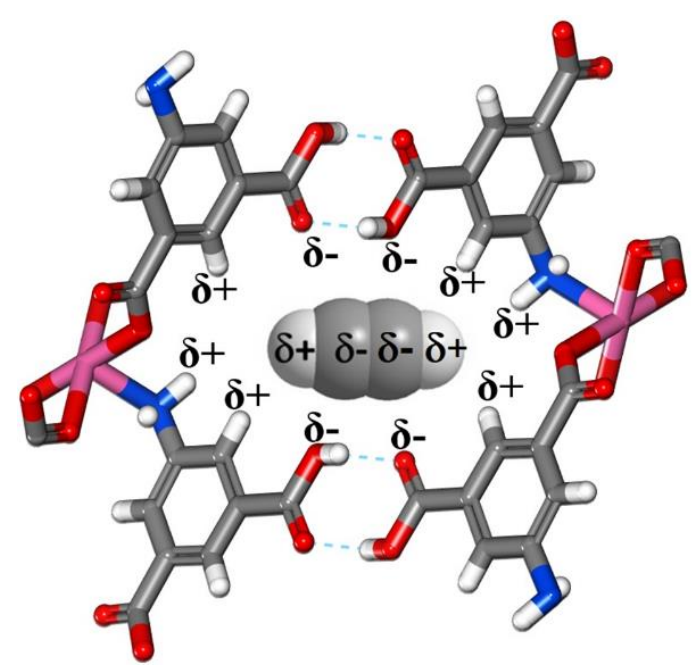

Fig. S10. Schematic of electrostatic potential distribution on the pore surface of MUF-16 leads to repulsive interactions with guest $\mathrm{C}_{2} \mathrm{H}_{2}$ molecules if they occupy the sites crystallographically observed for the binding of $\mathrm{CO}_{2}$.

For adsorption measurements, as-synthesized samples were washed with anhydrous methanol several times and 50-1000 mg was transferred into a pre-dried and weighed sample tube. Large sample quantities $(\sim 1 \mathrm{~g})$ were used to measure isotherms of the weakly-adsorbing gases to ensure that the recorded uptake measurements were reliable. To activate the sample, it was heated at rate of $10^{\circ} \mathrm{C} / \mathrm{min}$ to a temperature of $130{ }^{\circ} \mathrm{C}$ under a dynamic vacuum with a turbomolecular pump for 20 hours.

Table S5. Uptake capacity of MUF-16 for $\mathrm{CO}_{2}$ at $293 \mathrm{~K}$ and 1 bar.

\begin{tabular}{lcccc}
\hline & $\begin{array}{c}\text { Uptake } \\
(\mathbf{w t} \%)\end{array}$ & $\begin{array}{c}\text { Molecules of } \mathrm{CO}_{2} \text { per unit } \\
\text { cell }\end{array}$ & $\begin{array}{c}\text { Molecules of } \mathbf{C O}_{2} \text { per } \\
\text { metal }\end{array}$ & $\begin{array}{c}\text { Fraction of void volume } \\
\text { occupied by } \mathbf{C O}_{2}{ }^{*}\end{array}$ \\
\hline MUF-16 & 9.38 & 3.57 & 0.89 & 0.67 \\
MUF-16(Ni) & 9.41 & 3.58 & 0.89 & 0.68 \\
MUF-16(Mn) & 9.90 & 3.74 & 0.93 & 0.70 \\
\hline
\end{tabular}

*The fraction of the total free volume of MUF-16 that is occupied by adsorbate molecules. This was calculated from the accessible void fraction given by RASPA2 software (Table S3), the molecular volume of the $\mathrm{CO}_{2}$ adsorbates $(56.75$ $\AA^{3} /$ molecule) and the total number of adsorbate molecules. 
Fig. S11. Volumetric adsorption (filled circles) and desorption (open circles) isotherms of $\mathrm{CO}_{2}$ at different temperatures for MUF-16.

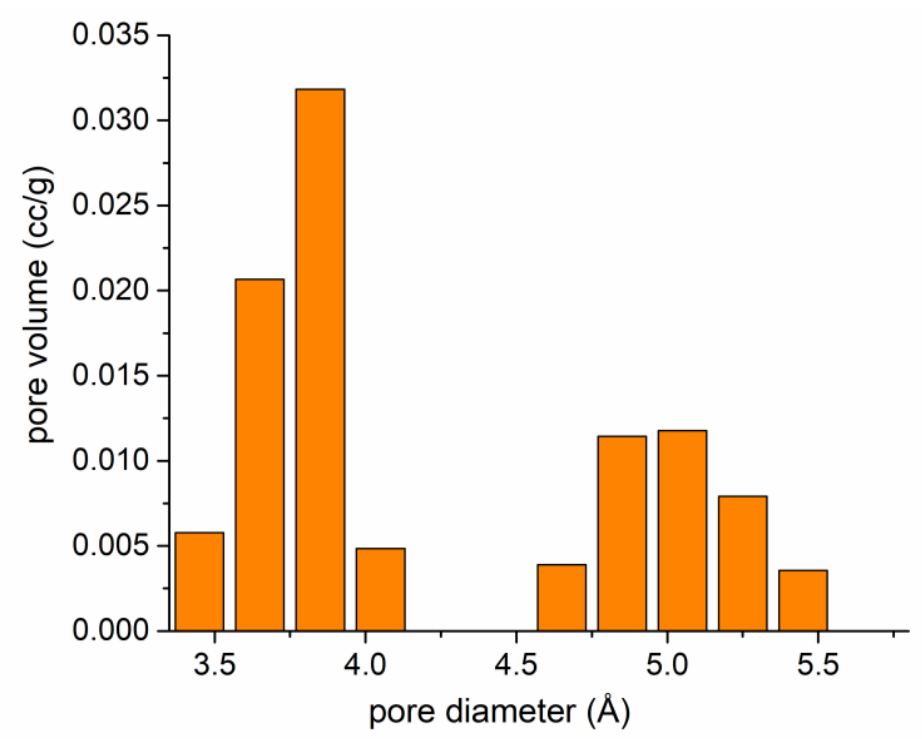

Fig. S12. Pore size distribution of MUF-16 calculated from its $\mathrm{CO}_{2}$ adsorption isotherm at $273 \mathrm{~K}$ using a NLDFT method. 
Fig. S13. $\mathrm{CO}_{2}$ adsorption isotherms $(293 \mathrm{~K})$ of as-synthesized MUF-16 after four consecutive adsorption-desorption cycles, after exposing it to air with $\sim 80 \%$ humidity for 6 months, and after immersion in water for 48 hours.

Fig. S14. Volumetric adsorption (filled circles) and desorption (open circles) isotherms of $\mathrm{N}_{2}$ for MUF-16 (black), MUF-16(Mn) (red) and MUF-16(Ni) (blue) measured at $77 \mathrm{~K}$. 
Fig. S15. Volumetric adsorption (filled circles) and desorption (open circles) isotherms $\mathrm{C}_{2} \mathrm{H}_{2}$ (red), $\mathrm{C}_{2} \mathrm{H}_{6}$ (blue) and $\mathrm{CH}_{4}$ (purple) measured at $195 \mathrm{~K}$ for MUF-16.

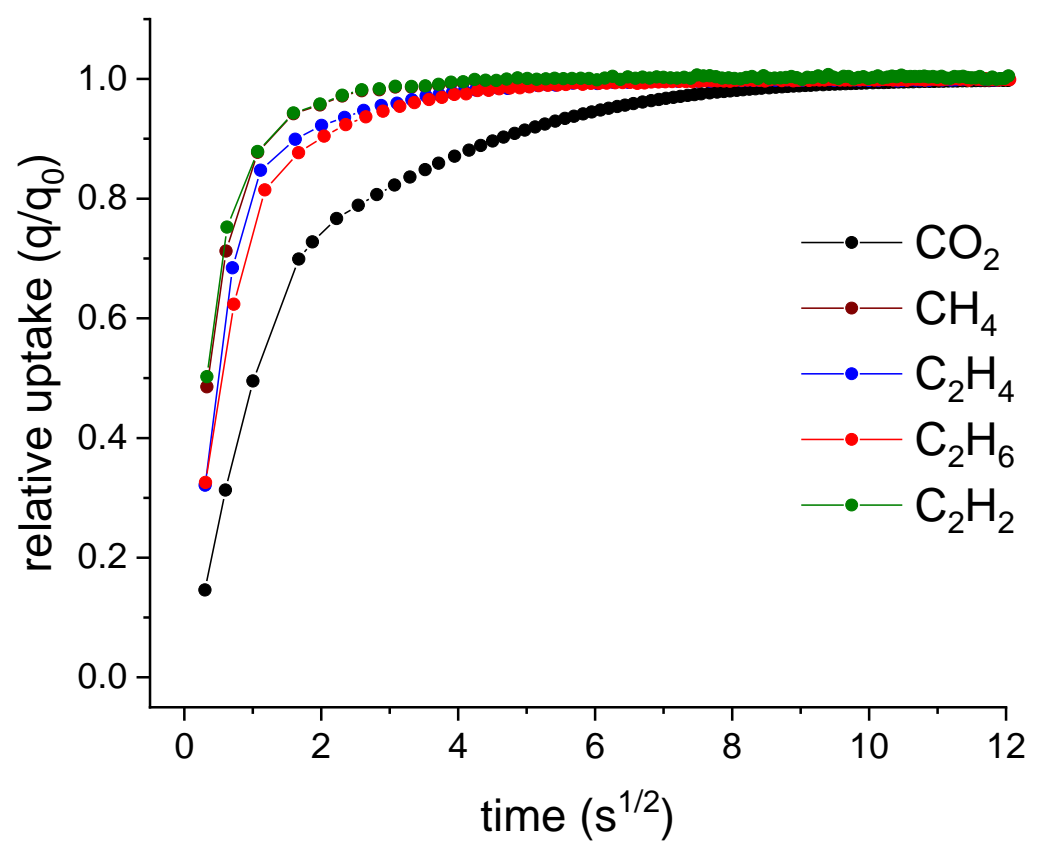

Fig. S16. Kinetic profiles of different gas uptake by MUF-16 at $293 \mathrm{~K}$ upon exposing an evacuated sample to a dose of gas equal to its measured total adsorption of that gas at 1 bar. $\mathrm{q}$ is the amount of uptake at time $\mathrm{t}$ and $\mathrm{q}_{0}$ is the final uptake amount. 


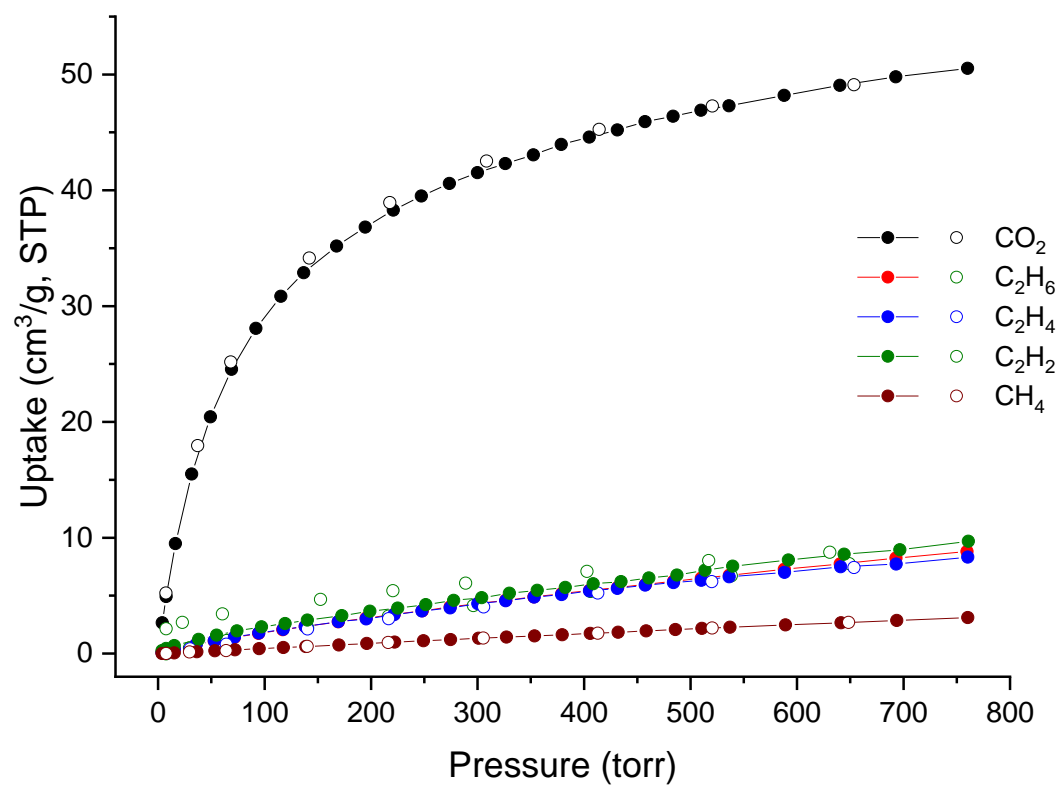

Fig. S17. Volumetric adsorption (filled circles) and desorption (open circles) isotherms of different gases by MUF-16(Mn) at $293 \mathrm{~K}$.

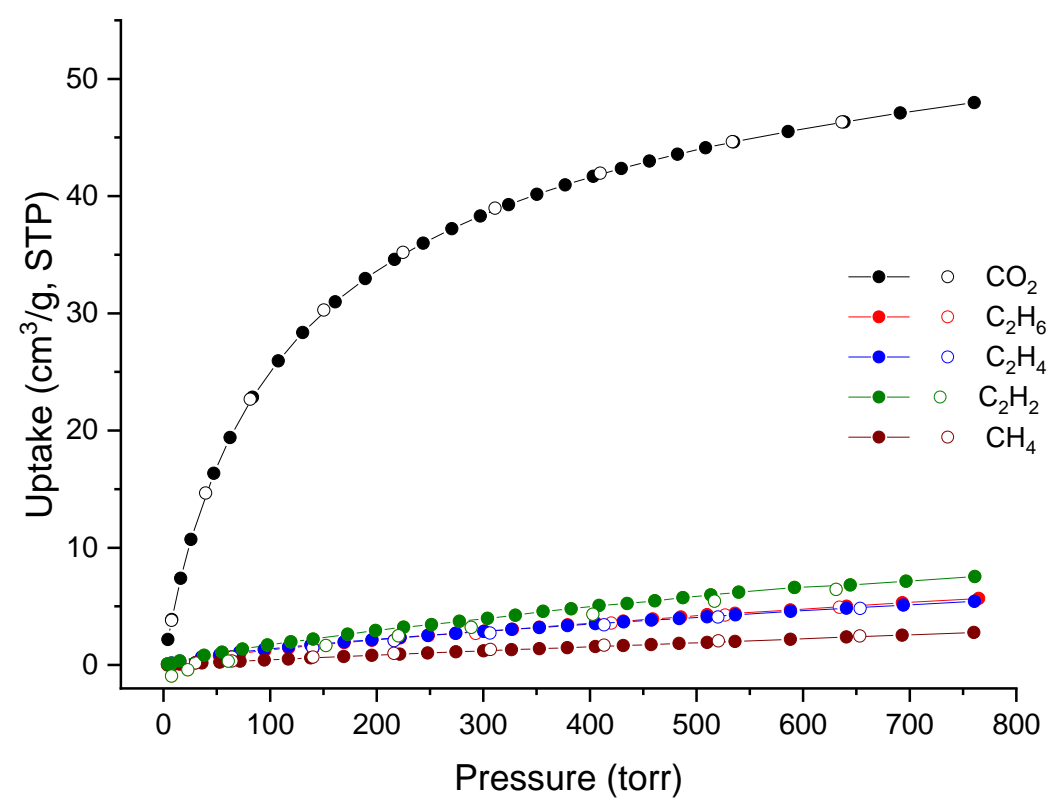

Fig. S18. Volumetric adsorption (filled circles) and desorption (open circles) isotherms of different gases by MUF-16(Ni) at $293 \mathrm{~K}$.

\section{Calculation of BET surface areas}

BET surface areas were calculated from $\mathrm{N}_{2}$ adsorption isotherms at $77 \mathrm{~K}$ according to the following procedures ${ }^{9}$ : 
1) The isotherm region where $v\left(1-P / P_{0}\right)$ increases versus $P / P_{0}$, where $v$ is the amount of $\mathrm{N}_{2}$ adsorbed, was identified.

2) Within this isotherm region, sequential data points that led to a positive intercept in the plot of $\frac{P / P_{0}}{v\left(1-P / P_{0}\right)}$ against $P / P_{0}$, were found. This plot yields a slope $a$, and a positive intercept $b$. The amount of gas molecules adsorbed in the initial monolayer is $v_{m}=\frac{1}{a+b}$.

3) The BET surface area was calculated according to the following equation:

$A_{B E T}=v_{m}\left(\mathrm{~cm}^{3} \mathrm{~g}^{-1}\right) * \frac{1(\mathrm{~mol})}{22400\left(\mathrm{~cm}^{3}\right)} * \sigma_{0}\left(\AA^{2}\right) * N_{A}\left(\mathrm{~mol}^{-1}\right) * 10^{-20}\left(\frac{\mathrm{m}^{2}}{\AA^{2}}\right)$

Where $\mathrm{N}_{\mathrm{A}}$ is Avogadro's constant, and $\sigma_{0}$ is the cross-sectional area of a $\mathrm{N}_{2}$ molecule, which is $16.2 \AA^{2}$.
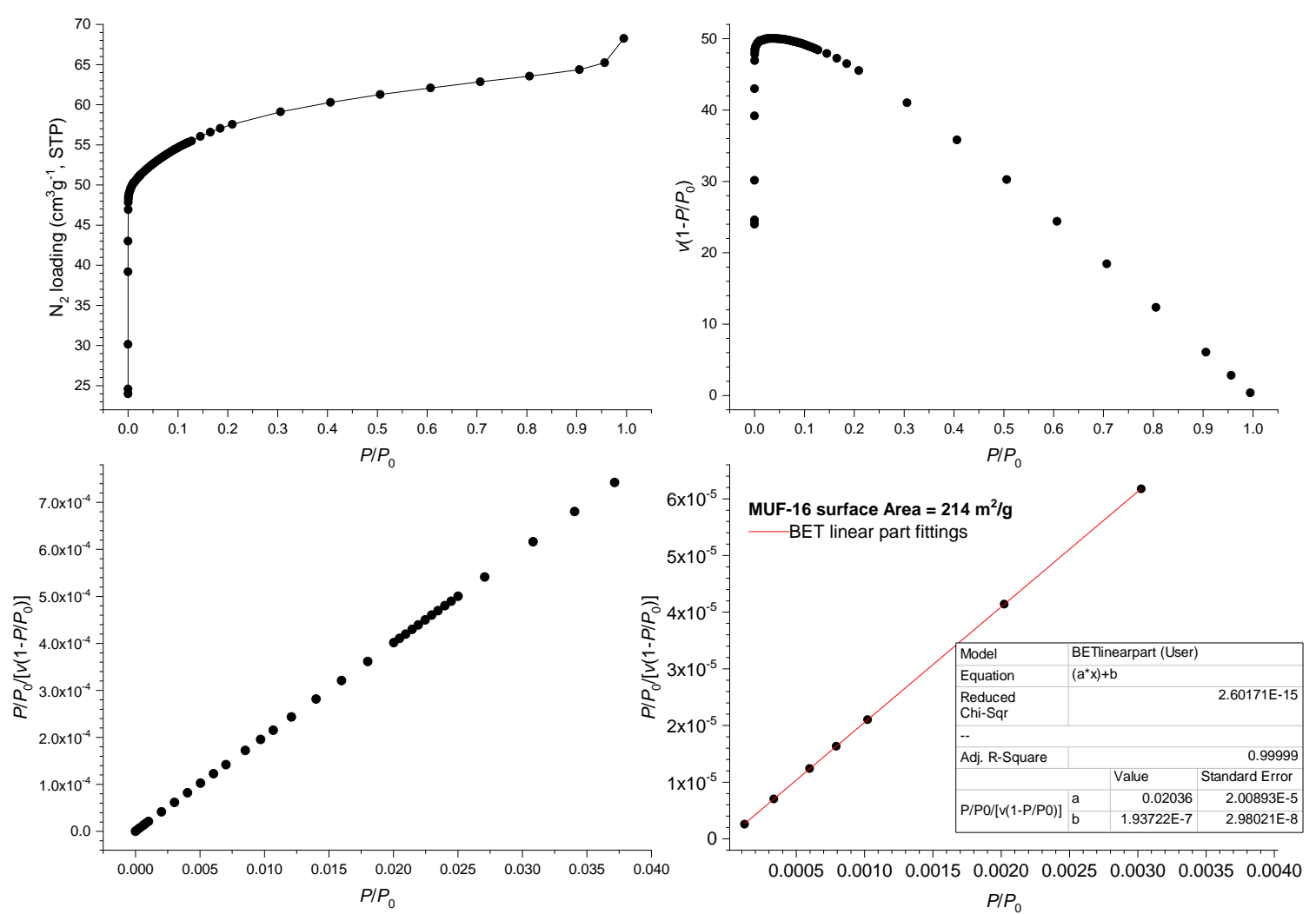

Fig. S19. $\mathrm{N}_{2}$ adsorption isotherm at $77 \mathrm{~K}$ and BET surface area plots for MUF-16. 

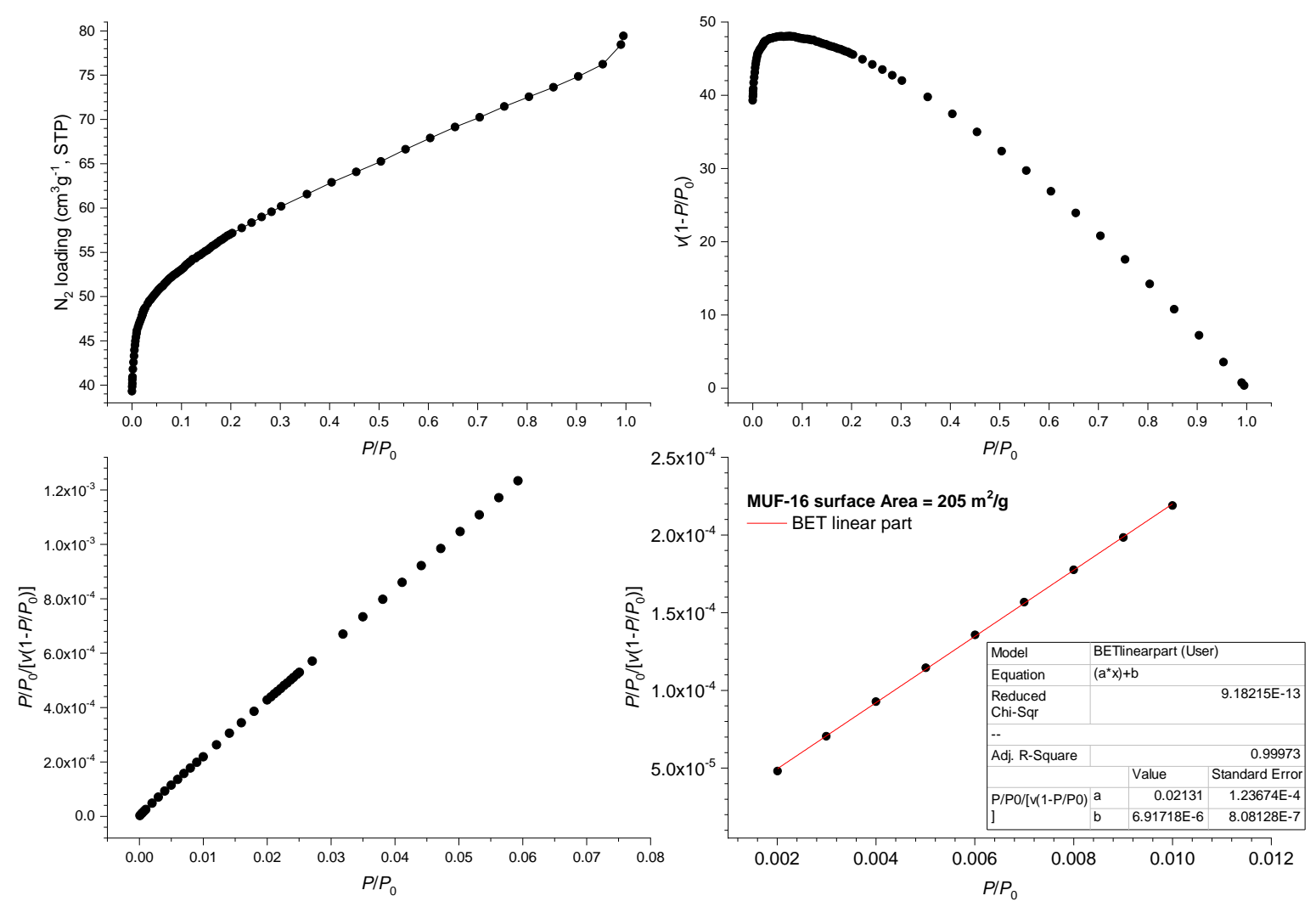

Fig. S20. $\mathrm{N}_{2}$ adsorption isotherm at $77 \mathrm{~K}$ and BET surface area plots for MUF-16(Mn).
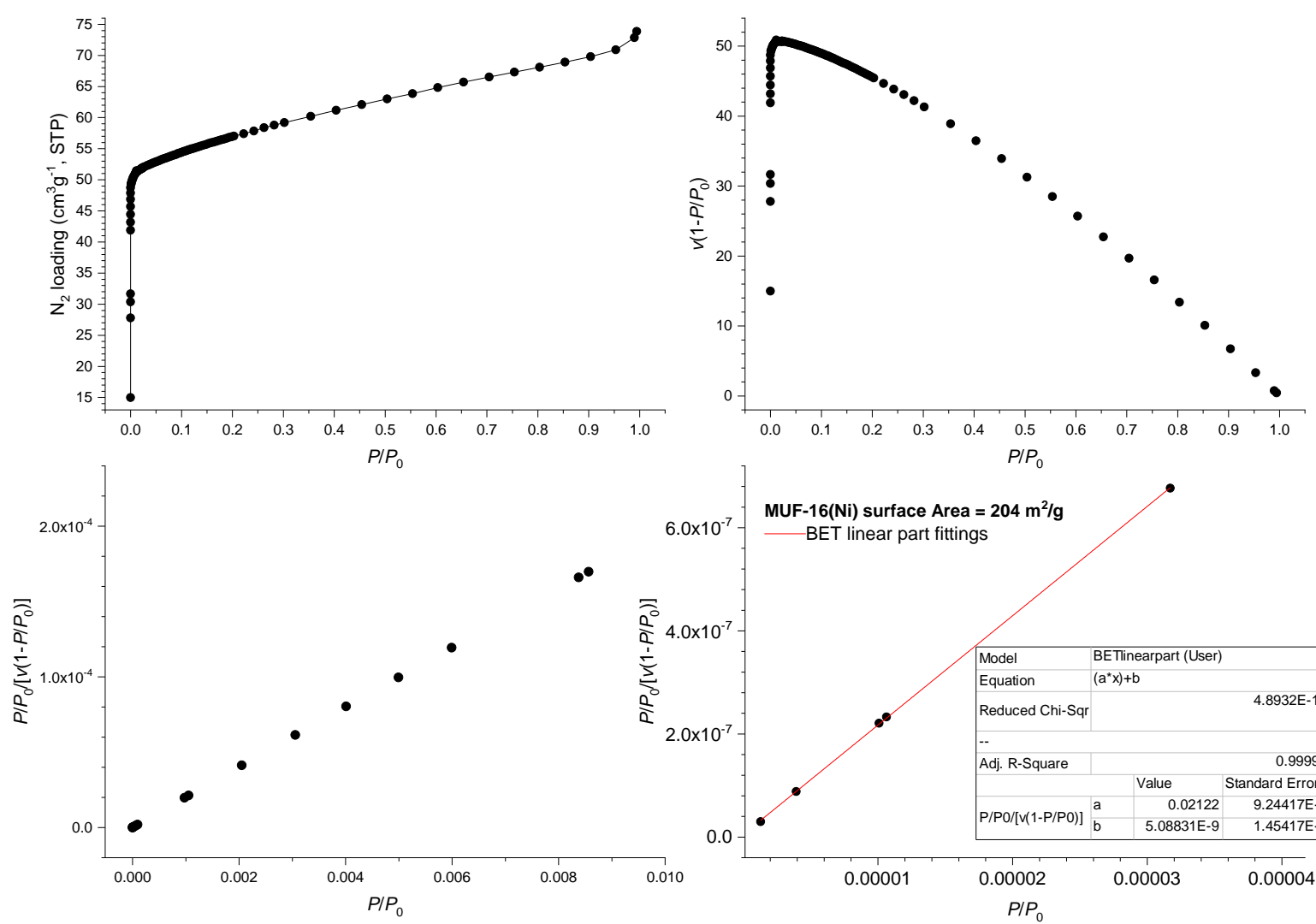

MUF-16(Ni) surface Area $=204 \mathrm{~m}^{2} / \mathrm{g}$ $6.0 \times 10^{-7}-\frac{\text { MUF-16(Ni) surface Area }=}{\text { BET linear part fittings }}$

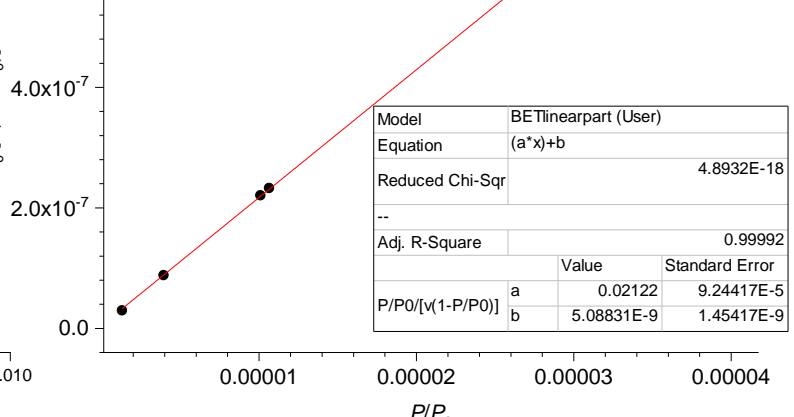

Fig. S21. $\mathrm{N}_{2}$ adsorption isotherm at $77 \mathrm{~K}$ and BET surface area plots for MUF-16(Ni). 


\section{Heat of adsorption}

Isosteric heat of adsorption $\left(\mathrm{Q}_{\mathrm{st}}\right)^{10}$ values were calculated from isotherms measured at $293 \mathrm{~K}, 298 \mathrm{~K}$ and $303 \mathrm{~K}$ for $\mathrm{CO}_{2}$. The isotherms were first fit to a viral equation:

$\ln P=\ln N+\frac{1}{T} \sum_{i=0}^{m} a_{i} N^{i}+\sum_{i=0}^{n} b_{i} N^{i}$

Where $N$ is the amount of gas adsorbed at the pressure $P, a$ and $b$ are virial coefficients, $m$ and $n$ are the number of coefficients require to adequately describe the isotherm. To calculate $\mathrm{Q}_{\mathrm{st}}$, the fitting parameters from the above equation were input in to the following equation:

$Q_{s t}=-R \sum_{i=0}^{m} a_{i} N^{i}$

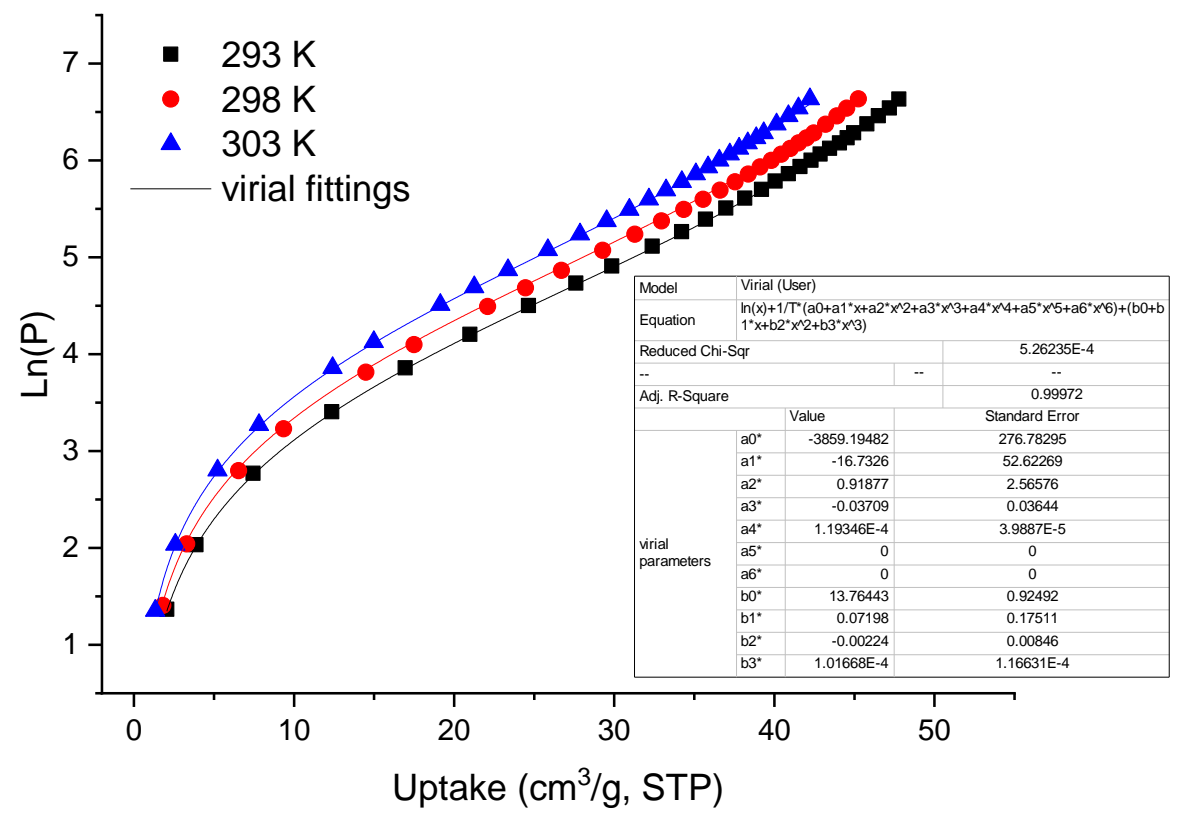

Fig. S22. Virial equation fits for $\mathrm{CO}_{2}$ adsorption isotherms of MUF-16. 


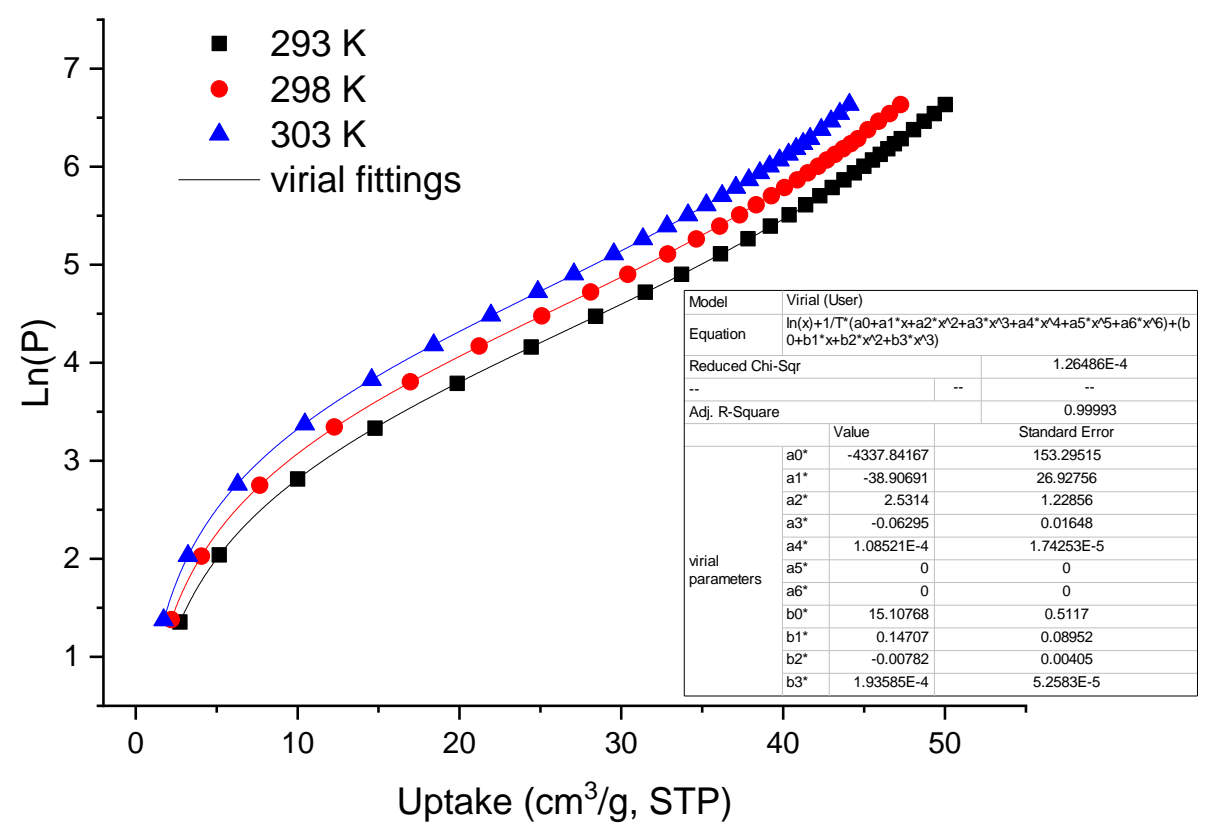

Fig. S23. Virial equation fits for $\mathrm{CO}_{2}$ adsorption isotherms of MUF-16(Mn).

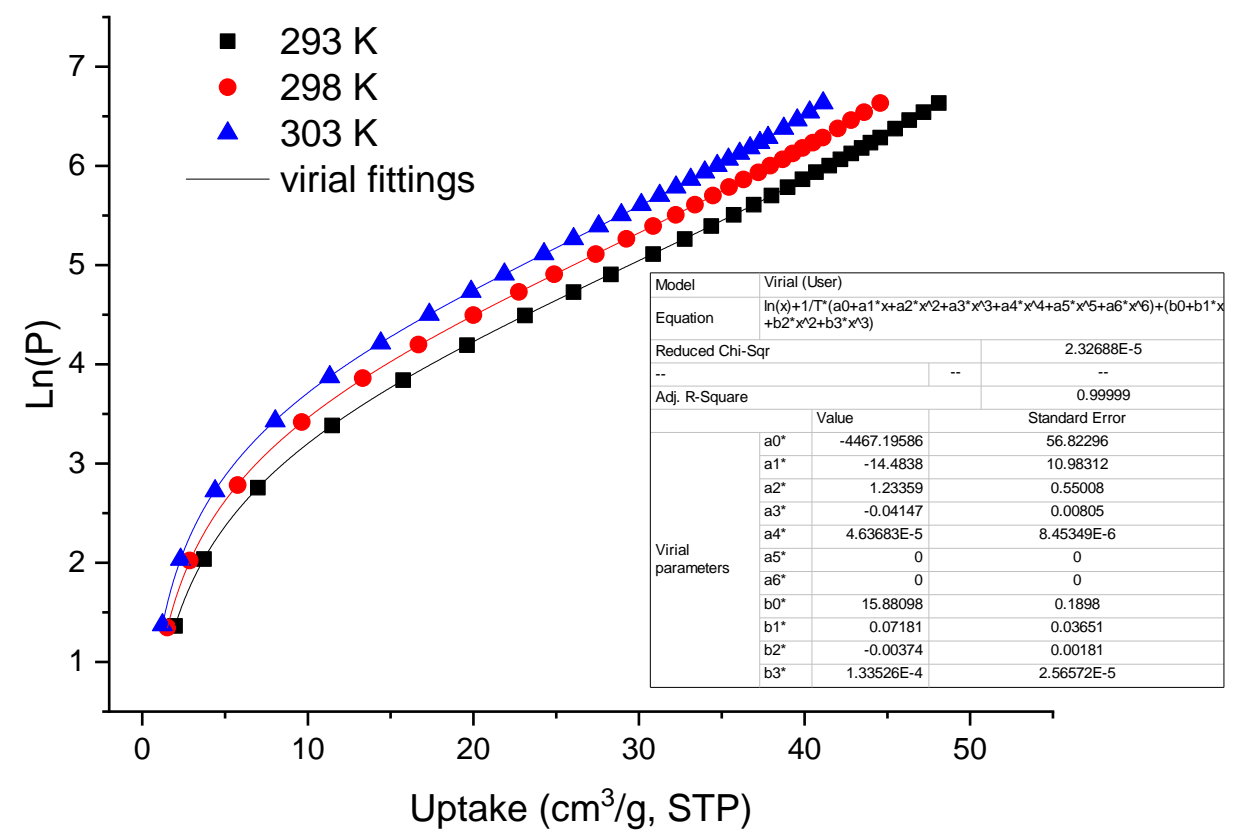

Fig. S24. Virial equation fits for $\mathrm{CO}_{2}$ adsorption isotherms of MUF-16(Ni).

Table S6. $Q_{\text {st }}$ values at low coverage for MUF-16 with various gases.

\begin{tabular}{llllll}
\hline gas & $\mathbf{C O}_{2}$ & $\mathbf{C}_{2} \mathrm{H}_{6}$ & $\mathbf{C}_{2} \mathbf{H}_{4}$ & $\mathbf{C}_{2} \mathbf{H}_{2}$ & $\mathbf{C H}_{4}$ \\
\hline $\mathbf{Q}_{\text {st }}(\mathrm{kJ} / \mathrm{mol})$ & 32.3 & 24.8 & 24.9 & 25.8 & 18.6 \\
\hline
\end{tabular}




\section{IAST calculations}

Mixed gas adsorption isotherms and gas selectivities for different mixtures of $\mathrm{CO}_{2} / \mathrm{C}_{2} \mathrm{H}_{2}, \mathrm{CO}_{2} / \mathrm{C}_{2} \mathrm{H}_{4}$, $\mathrm{CO}_{2} / \mathrm{C}_{2} \mathrm{H}_{6}, \mathrm{CO}_{2} / \mathrm{N}_{2}, \mathrm{CO}_{2} / \mathrm{CH}_{4}$ and $\mathrm{CO}_{2} / \mathrm{H}_{2}$ at $293 \mathrm{~K}$ were calculated based on the ideal adsorbed solution theory (IAST) proposed by Myers and Prausnitz ${ }^{11}$. In order to predict the sorption performance of MUF16 toward the separation of binary mixed gases, the single-component adsorption isotherms were first fit to a Dual Site Langmuir or a Dual Site Langmuir Freundlich model, as below:

$q=\frac{q_{1} b_{1} P}{1+b_{1} P}+\frac{q_{2} b_{2} P}{1+b_{2} P}$

$q=\frac{q_{1} b_{1} P^{1 / t_{1}}}{1+b_{1} P^{1 / t_{1}}}+\frac{q_{2} b_{2} P^{1 / t_{2}}}{1+b_{2} P^{1 / t_{2}}}$

Where $\mathrm{q}$ is the uptake of a gas; $\mathrm{P}$ is the equilibrium pressure and $\mathrm{q}_{1}, \mathrm{~b}_{1}, \mathrm{t}_{1}, \mathrm{q}_{2}, \mathrm{~b}_{2}$ and $\mathrm{t}_{2}$ are constants. These parameters were subsequently used for the IAST calculations.

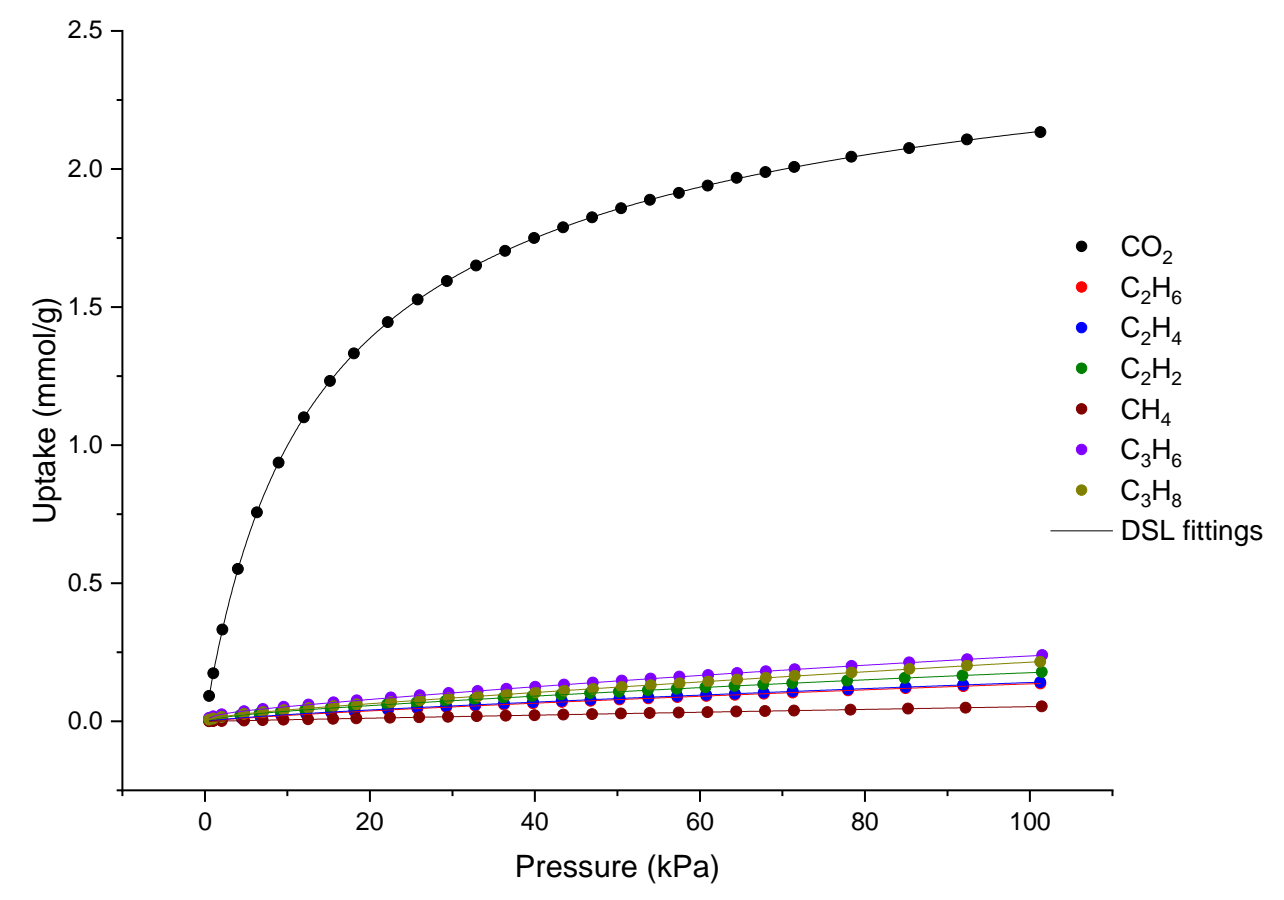

\begin{tabular}{|c|c|c|c|c|c|c|c|}
\hline Model & \multicolumn{7}{|c|}{ DSL (User) } \\
\hline Equation & & & & $q 1^{*} b 1^{*} x /\left(1+b 1^{*} x\right)+q 2^{*} b 2$ & ${ }^{2} x /\left(1+b 2^{*} x\right)$ & & \\
\hline Plot & $\mathrm{CO} 2$ & $\mathrm{C} 2 \mathrm{H} 6$ & $\mathrm{C} 2 \mathrm{H} 4$ & $\mathrm{C} 2 \mathrm{H} 2$ & $\mathrm{CH} 4$ & $\mathrm{C} 3 \mathrm{H} 6$ & $\mathrm{C} 3 \mathrm{H} 8$ \\
\hline $\mathrm{q} 1$ & $1.92197 \pm 0.03622$ & $0.01903 \pm 7.58427 \mathrm{E}-4$ & $0.90455 \pm 0.02194$ & $0.84858 \pm 0.02172$ & $-1.37048 \mathrm{E}-4 \pm 2.62012 \mathrm{E}-5$ & $0.92327 \pm 0.02031$ & $0.02582 \pm 8.46918 \mathrm{E}-4$ \\
\hline b1 & $0.09147 \pm 0.00142$ & $0.06919 \pm 0.00295$ & $0.00155 \pm 4.83418 E-5$ & $0.00219 \pm 7.32671 \mathrm{E}-5$ & $2.40335 \pm 2.41269$ & $0.00289 \pm 8.52827 E-5$ & $0.38985 \pm 0.03262$ \\
\hline q2 & $0.71591 \pm 0.02029$ & $0.91643 \pm 0.02976$ & $0.02077 \pm 4.66874 \mathrm{E}-4$ & $0.02486 \pm 4.712 E-4$ & $0.63958 \pm 0.01292$ & $0.03023 \pm 4.69954 \mathrm{E}-4$ & $2.11273 \pm 0.21651$ \\
\hline b2 & $0.01264 \pm 0.0014$ & $0.00149 \pm 6.32966 \mathrm{E}-5$ & $0.09736 \pm 0.00278$ & $0.29065 \pm 0.01171$ & $9.04454 \mathrm{E}-4 \pm 2.00076 \mathrm{E}-5$ & $0.92871 \pm 0.04824$ & $9.83565 E-4 \pm 1.13365 E-4$ \\
\hline Reduced C & $2.547 \mathrm{E}-6$ & 4.27057E-9 & $4.09689 \mathrm{E}-9$ & $3.87189 \mathrm{E}-8$ & 1.11837E-9 & $1.63183 E-7$ & $2.34956 \mathrm{E}-7$ \\
\hline R-Square (COD) & 0.99999 & 1 & 1 & 0.99999 & 1 & 0.99997 & 0.99994 \\
\hline Adj. R-Square & 0.99999 & 1 & 1 & 0.99998 & 1 & 0.99996 & 0.99994 \\
\hline
\end{tabular}

Fig. S25 Dual-site Langmuir fits of various adsorption isotherms for MUF-16 at 293 K. 


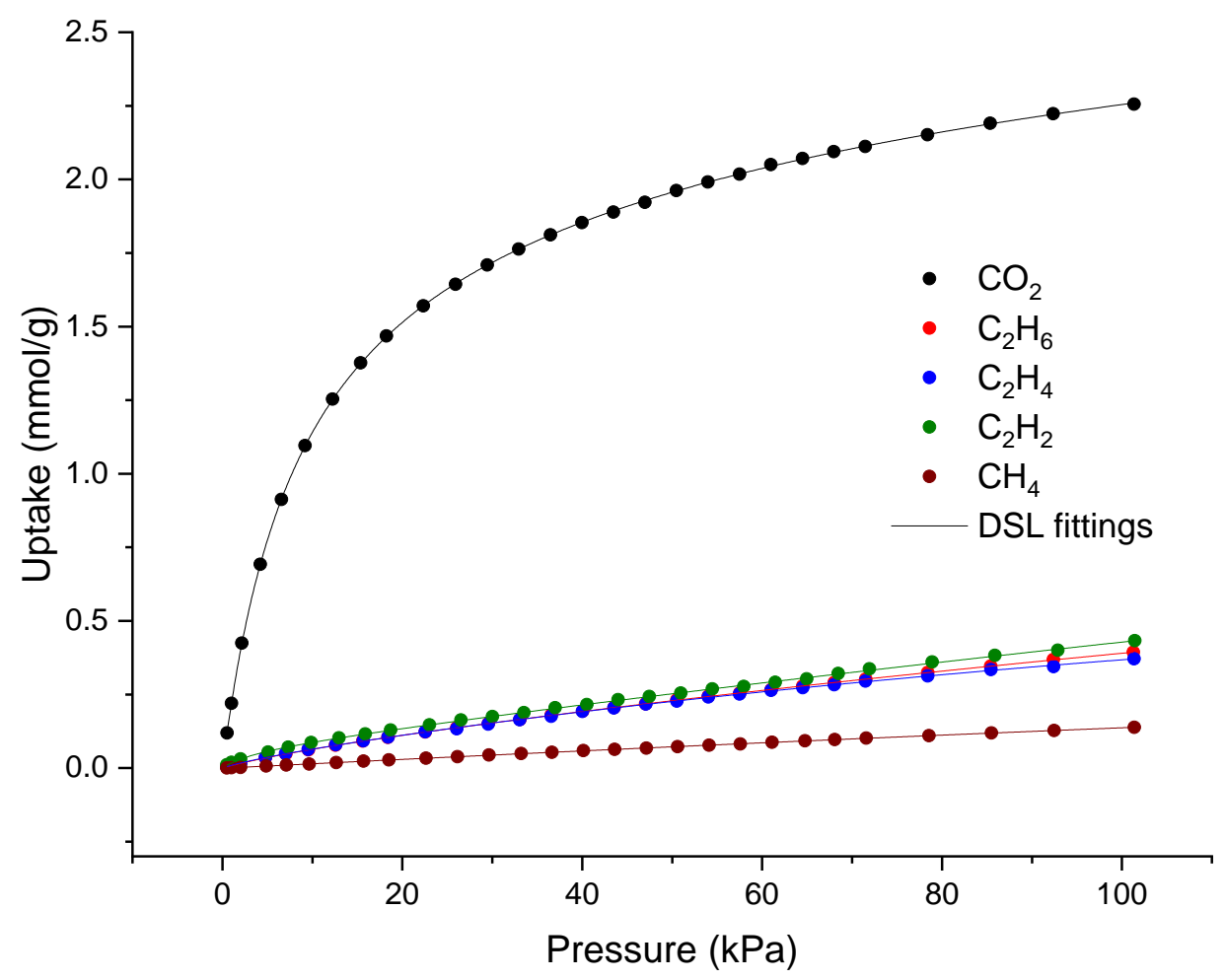

\begin{tabular}{|c|c|c|c|c|c|}
\hline Model & \multicolumn{5}{|c|}{ DSL (User) } \\
\hline Equation & \multicolumn{5}{|c|}{$\mathrm{q}^{*} \mathrm{~b} 1^{*} \mathrm{x} /\left(1+\mathrm{b} 1^{*} \mathrm{x}\right)+\mathrm{q} 2^{*} \mathrm{~b} 2^{*} \mathrm{x} /\left(1+\mathrm{b} 2^{*} \mathrm{x}\right)$} \\
\hline Plot & $\mathrm{CO} 2$ & $\mathrm{C} 2 \mathrm{H} 6$ & $\mathrm{C} 2 \mathrm{H} 4$ & $\mathrm{C} 2 \mathrm{H} 2$ & $\mathrm{CH} 4$ \\
\hline$q 1$ & $1.94289 \pm 0.0227$ & $0.04806 \pm 0.00391$ & $1.11314 \pm 0.0652$ & $3.94913 \pm 1.20449$ & $1.20612 \pm 0.06748$ \\
\hline b1 & $0.12229 \pm 0.00169$ & $0.09141 \pm 0.009$ & $0.00448 \pm 4.81593 \mathrm{E}-$ & $0.00102 \pm 3.53725 \mathrm{E}-$ & $0.00129 \pm 8.15601 \mathrm{E}-5$ \\
\hline q2 & $1.14216 \pm 0.04571$ & $2.04938 \pm 0.09902$ & $0.02464 \pm 0.00777$ & $0.06637 \pm 0.00631$ & $-8.32165 \mathrm{E}-4 \pm 2.43966 \mathrm{E}$ \\
\hline b2 & $0.0067 \pm 8.46612 \mathrm{E}-$ & $0.00204 \pm 1.38007 \mathrm{E}-$ & $0.20141 \pm 0.10616$ & $0.24669 \pm 0.04921$ & $10.03567 \pm 38.12063$ \\
\hline Reduced Chi-Sq & $6.81414 \mathrm{E}-6$ & $2.15657 \mathrm{E}-7$ & $3.7049 \mathrm{E}-6$ & $6.09794 \mathrm{E}-6$ & $1.33437 \mathrm{E}-7$ \\
\hline R-Square (COD) & 0.99998 & 0.99999 & 0.99973 & 0.99963 & 0.99993 \\
\hline Adj. R-Square & 0.99998 & 0.99998 & 0.99969 & 0.99958 & 0.99992 \\
\hline
\end{tabular}

Fig. S26. Dual-site Langmuir fits of various adsorption isotherms for MUF-16(Mn) at $293 \mathrm{~K}$. 


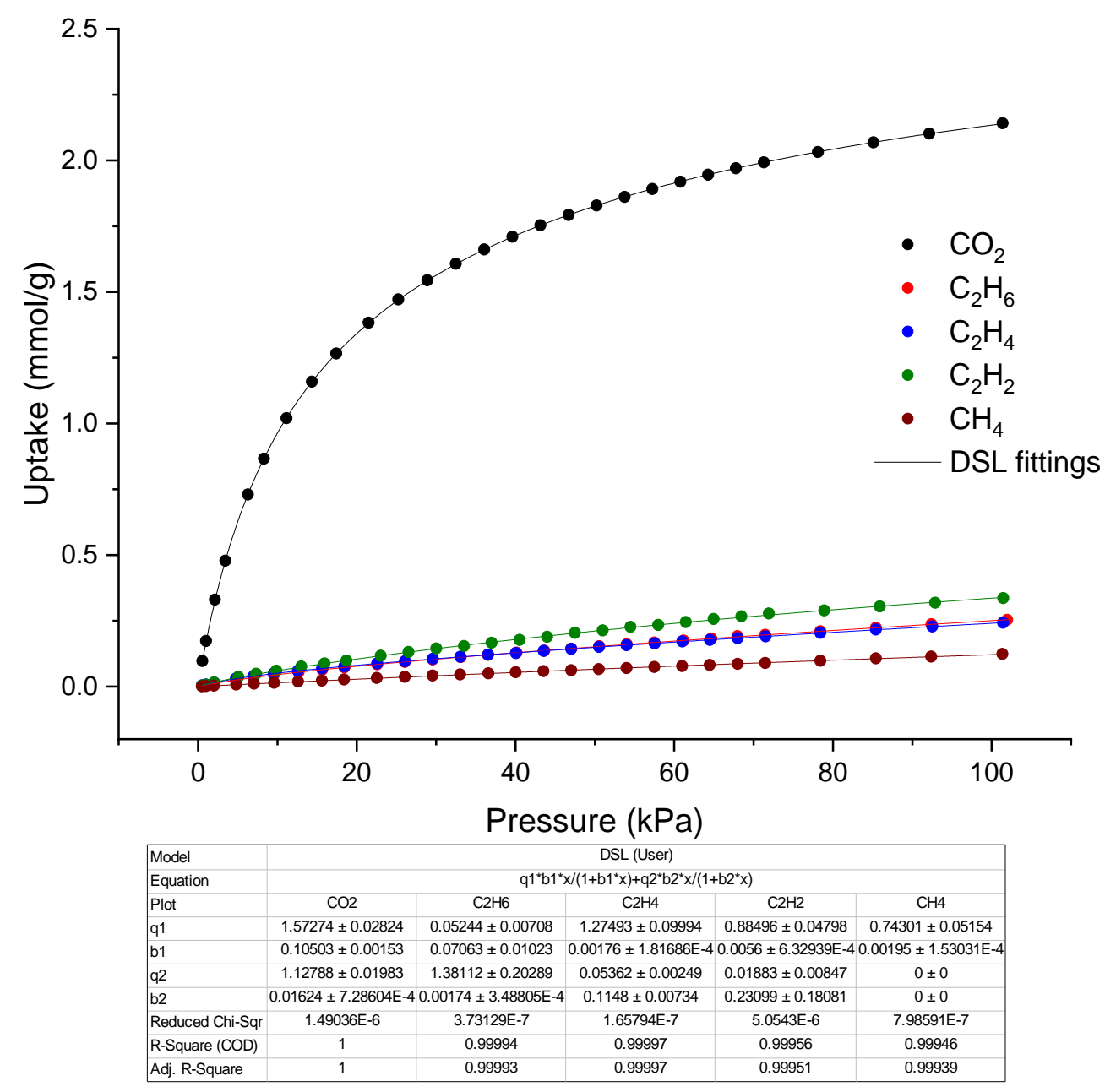

Fig. S27. Dual-site Langmuir fits of various adsorption isotherms for MUF-16(Ni) at $293 \mathrm{~K}$. 


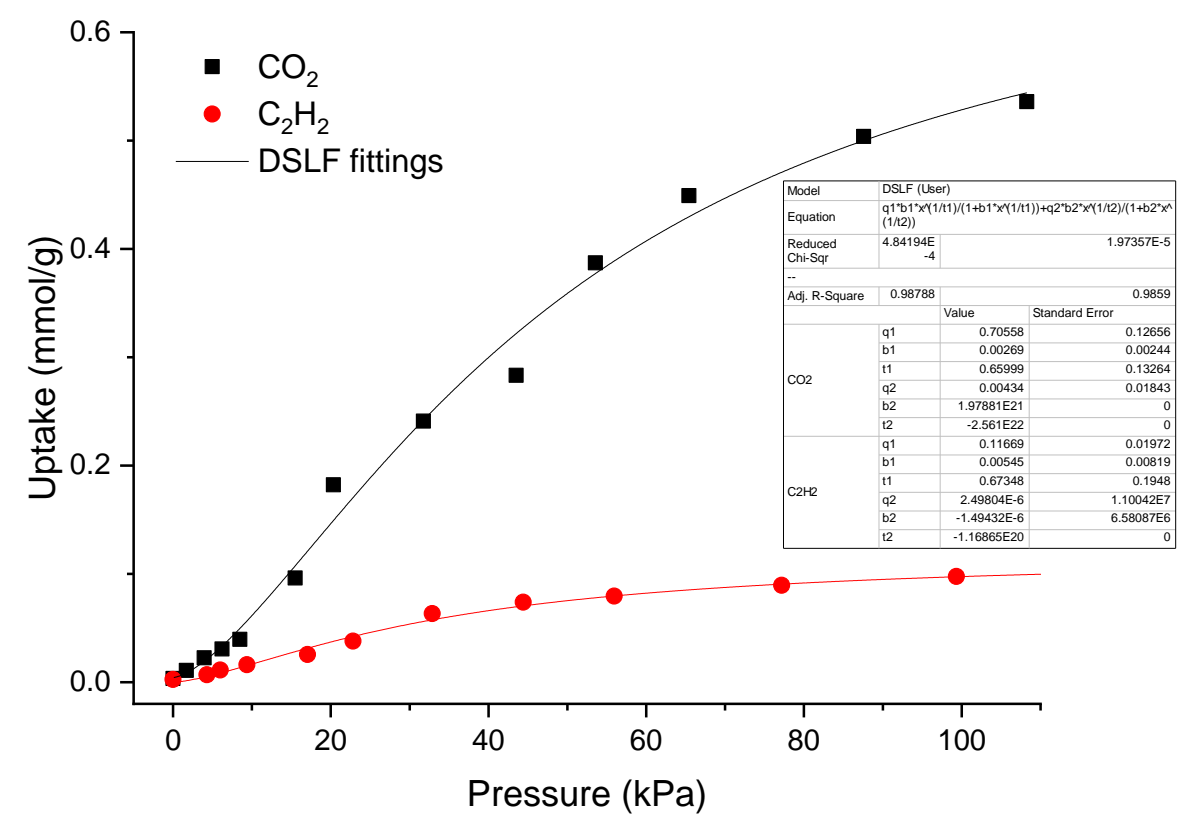

Fig. S28. Dual-site Langmuir Freundlich fits for $\mathrm{K}_{2}\left[\mathrm{Cr}_{3} \mathrm{O}(\mathrm{OOCH})_{6}(4 \text {-ethylpyridine })_{3}\right]_{2}\left[\alpha-\mathrm{SiW}_{12} \mathrm{O}_{40}\right]$ at $278 \mathrm{~K}$. Isotherm data were extracted from ${ }^{6}$ using a digitizer software.

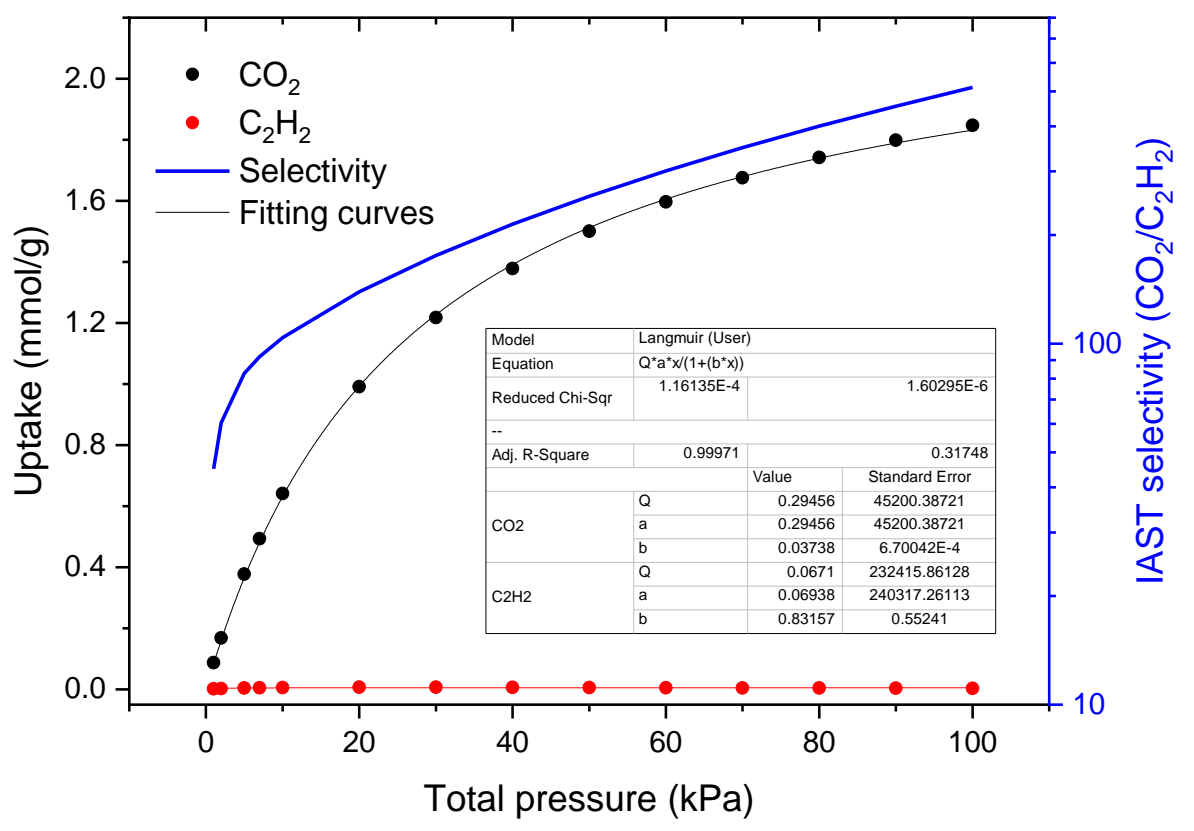

Fig. S29. Mixed-gas isotherms and selectivity of MUF-16 predicted by IAST for a mixture of 50/50 $\mathrm{CO}_{2} / \mathrm{C}_{2} \mathrm{H}_{2}$ at $293 \mathrm{~K}$. 


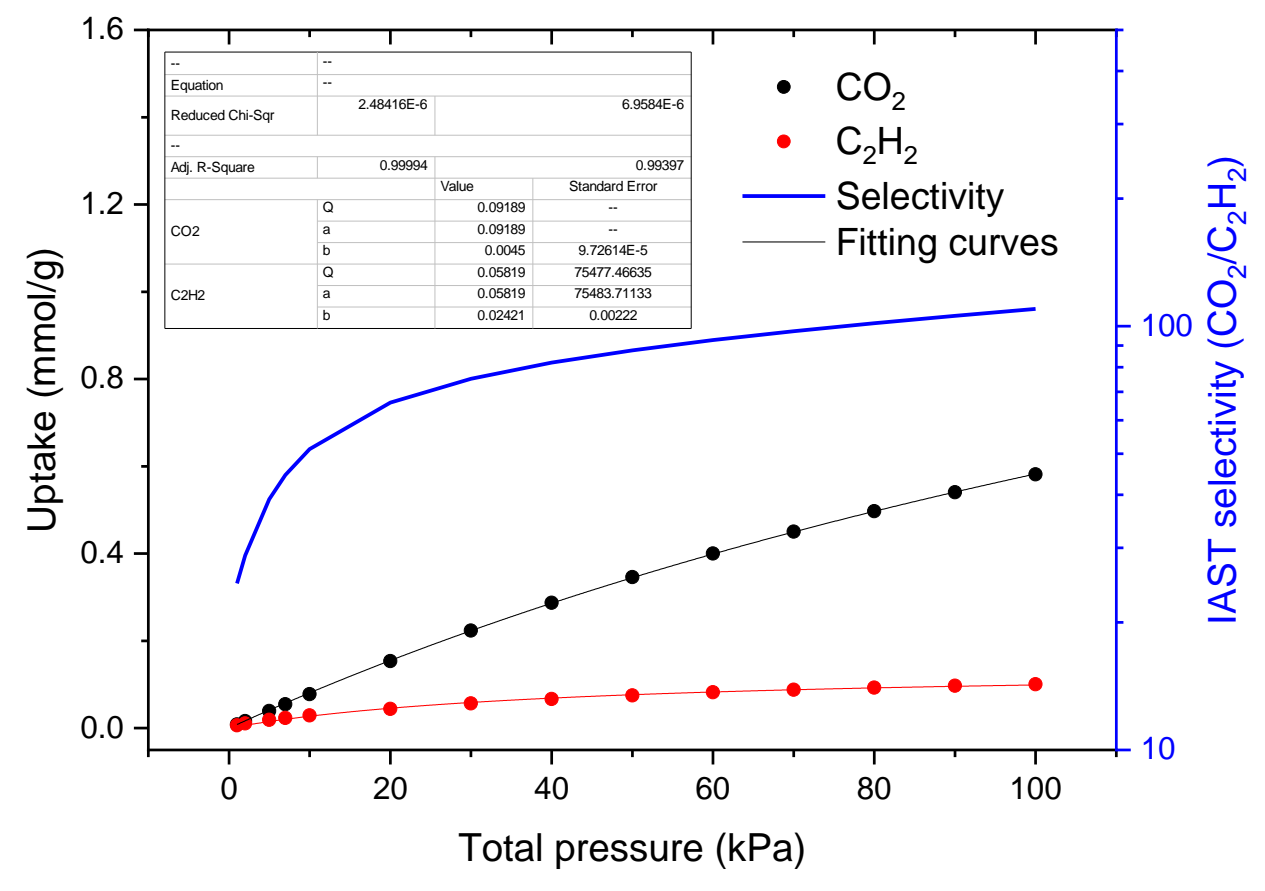

Fig. S30. Mixed-gas isotherms and selectivity of MUF-16 predicted by IAST for a mixture of 5/95 $\mathrm{CO}_{2} / \mathrm{C}_{2} \mathrm{H}_{2}$ at $293 \mathrm{~K}$.

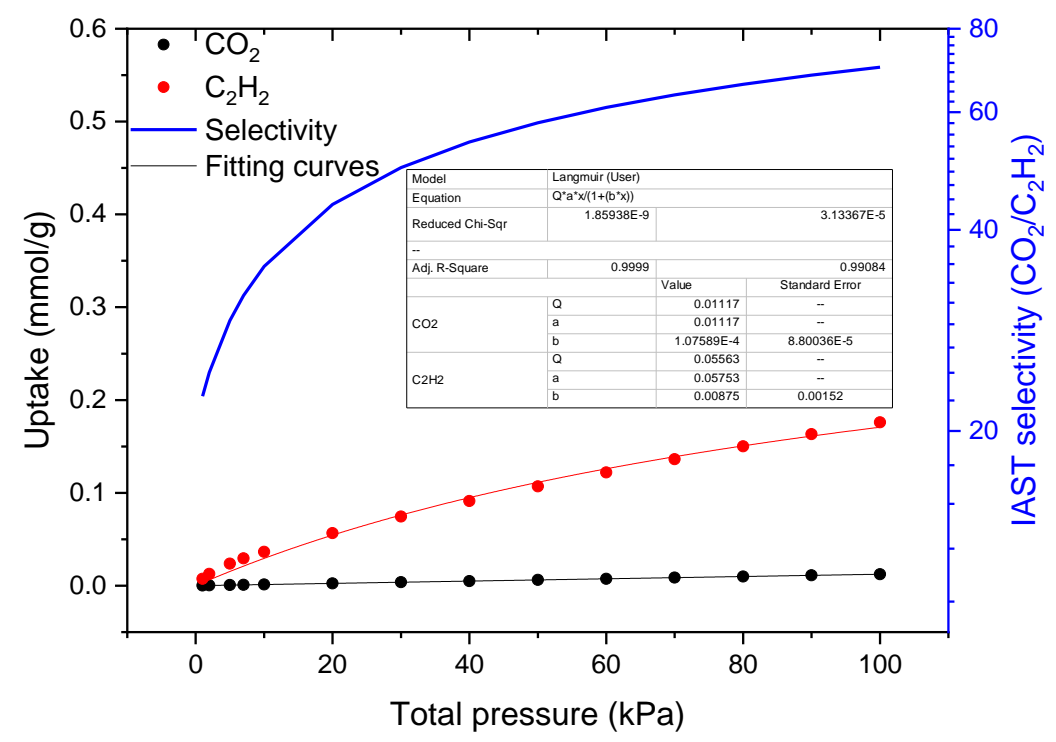

Fig. S31. Mixed-gas isotherms and selectivity of MUF-16 predicted by IAST for a mixture of 0.1/99.9 $\mathrm{CO}_{2} / \mathrm{C}_{2} \mathrm{H}_{2}$ at $293 \mathrm{~K}$. 


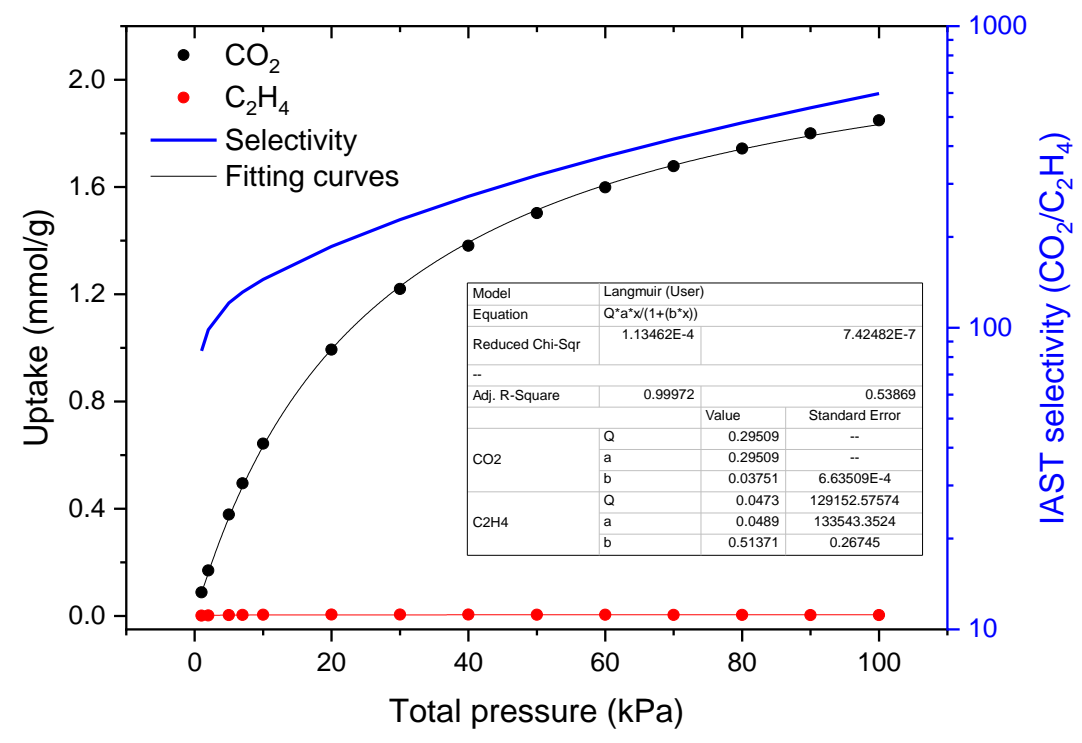

Fig. S32. Mixed-gas isotherms and selectivity of MUF-16 predicted by IAST for a mixture of 50/50 $\mathrm{CO}_{2} / \mathrm{C}_{2} \mathrm{H}_{4}$ at $293 \mathrm{~K}$.

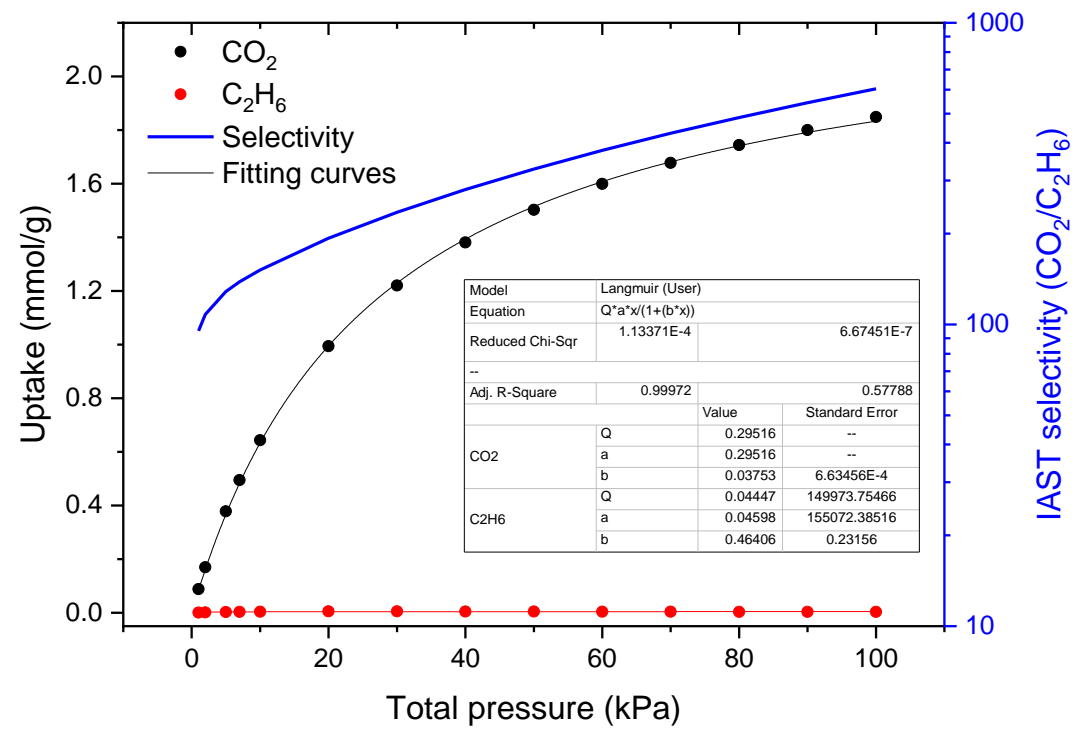

Fig. S33. Mixed-gas isotherms and selectivity of MUF-16 predicted by IAST for a mixture of 50/50 $\mathrm{CO}_{2} / \mathrm{C}_{2} \mathrm{H}_{6}$ at $293 \mathrm{~K}$. 


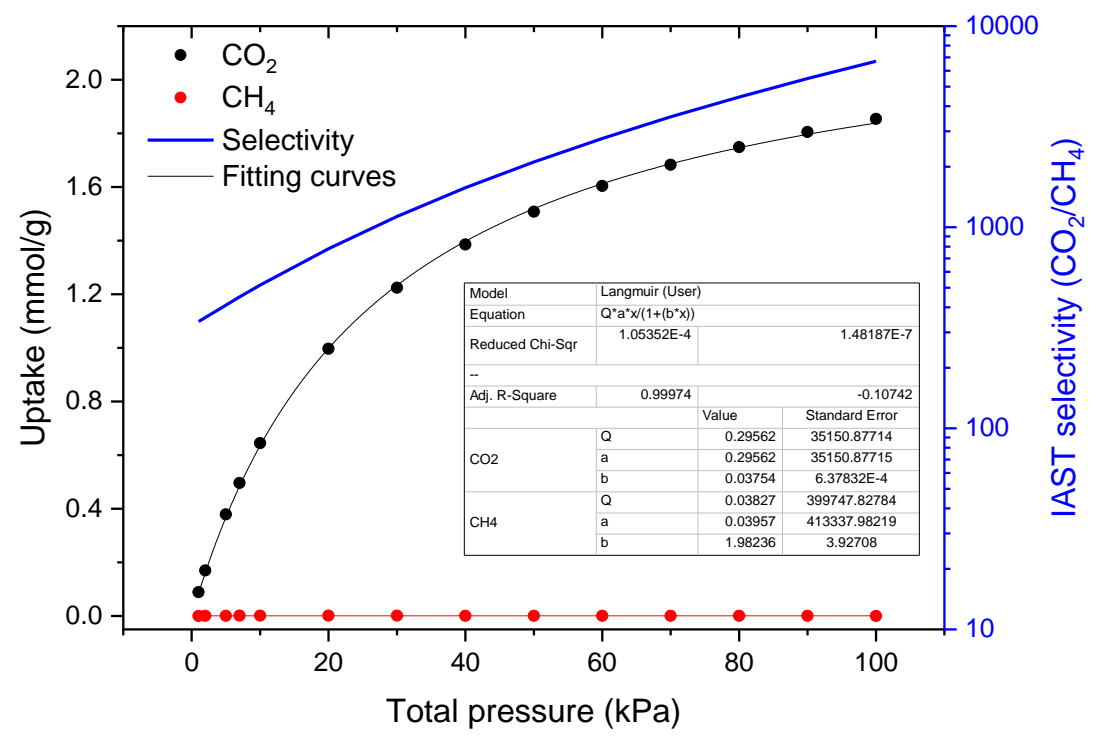

Fig. S34. Mixed-gas isotherms and selectivity of MUF-16 predicted by IAST for a mixture of 50/50 $\mathrm{CO}_{2} / \mathrm{CH}_{4}$ at $293 \mathrm{~K}$.

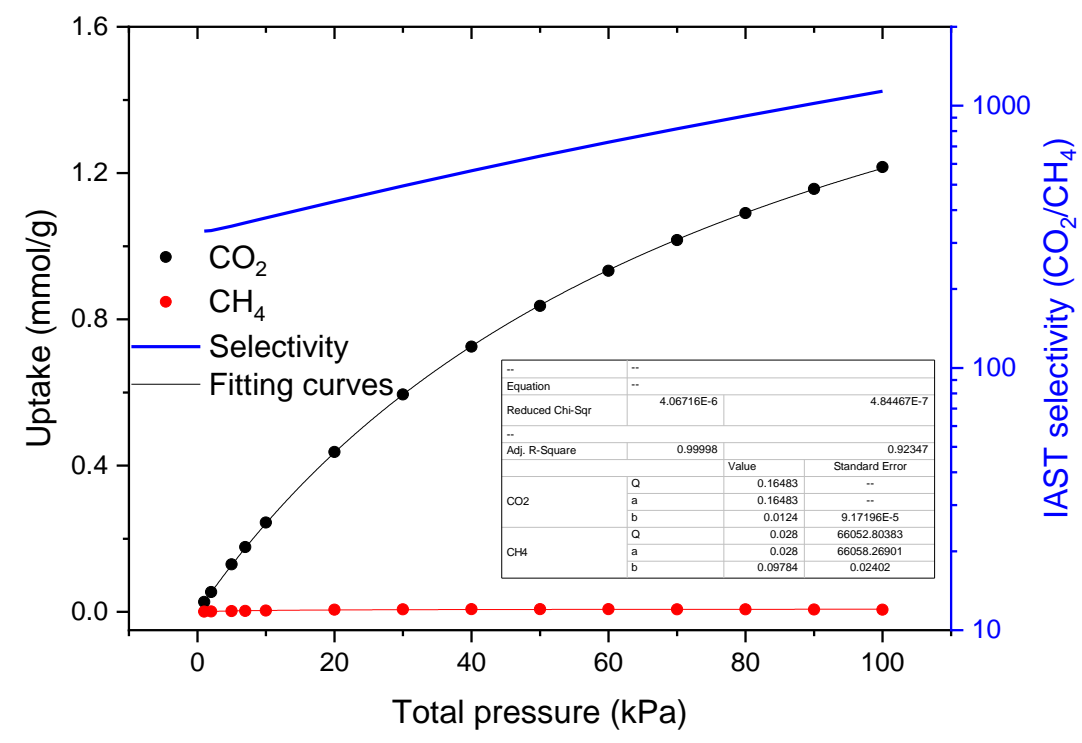

Fig. S35. Mixed-gas isotherms and selectivity of MUF-16 predicted by IAST for a mixture of 15/85 $\mathrm{CO}_{2} / \mathrm{CH}_{4}$ at $293 \mathrm{~K}$. 


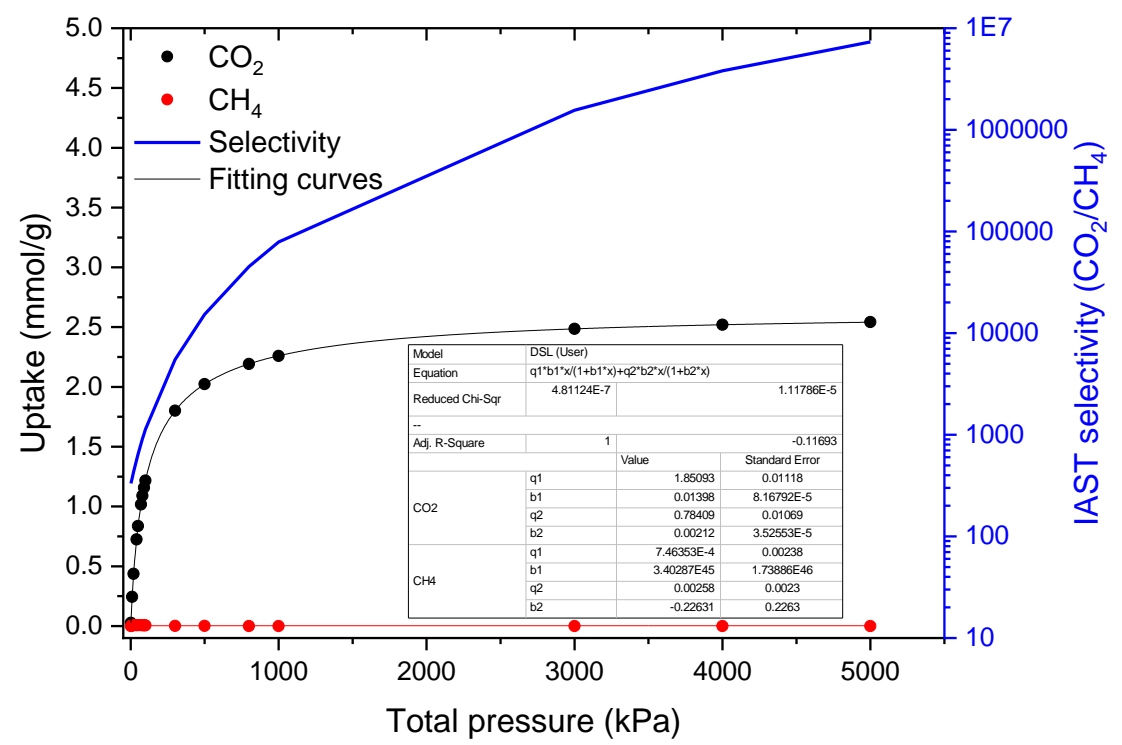

Fig. S36. Mixed-gas isotherms and selectivity of MUF-16 predicted by IAST for a mixture of 15/85 $\mathrm{CO}_{2} / \mathrm{CH}_{4}$ at $293 \mathrm{~K}$ up to 50 bar.

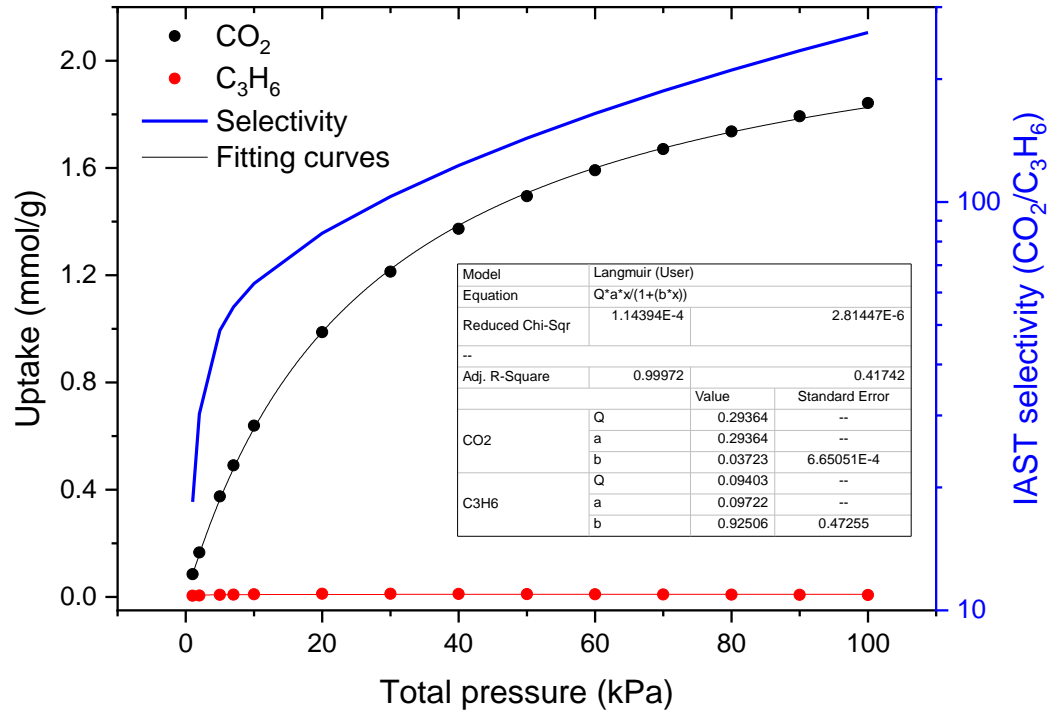

Fig. S37. Mixed-gas isotherms and selectivity of MUF-16 predicted by IAST for a mixture of 50/50 $\mathrm{CO}_{2} / \mathrm{C}_{3} \mathrm{H}_{6}$ at $293 \mathrm{~K}$. 


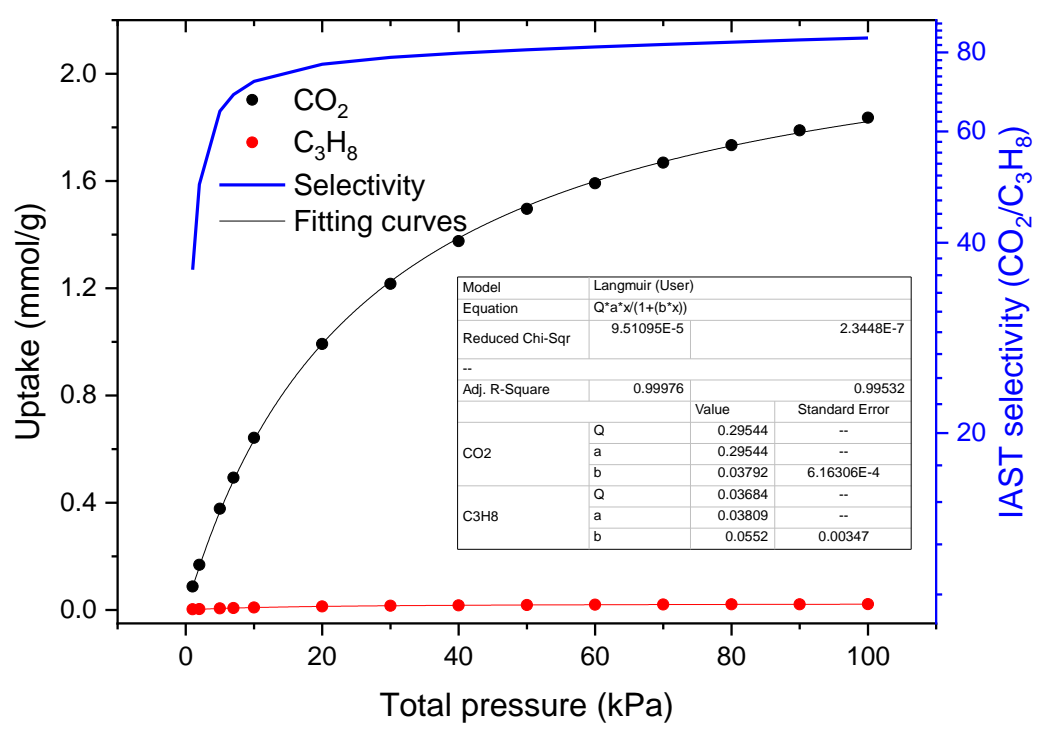

Fig. S38. Mixed-gas isotherms and selectivity of MUF-16 predicted by IAST for a mixture of 50/50 $\mathrm{CO}_{2} / \mathrm{C}_{3} \mathrm{H}_{8}$ at $293 \mathrm{~K}$.

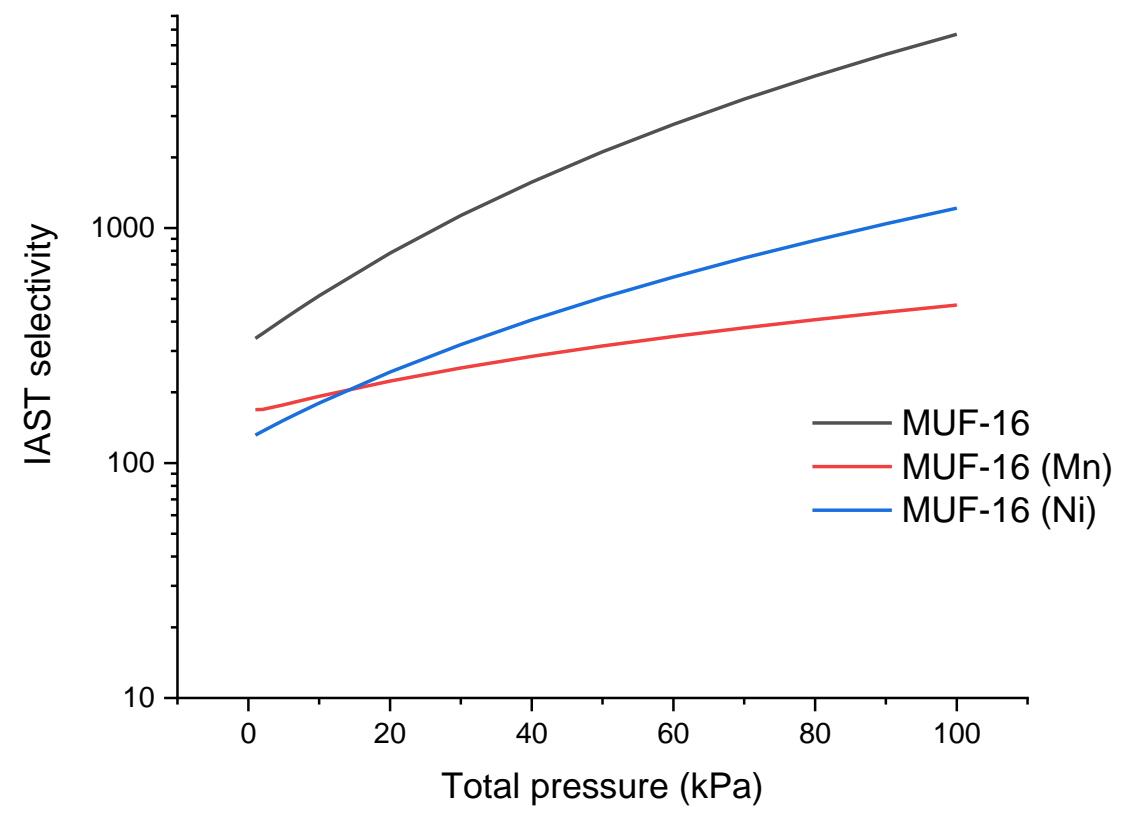

Fig. S39. IAST selectivity for a 50/50 mixture of $\mathrm{CO}_{2} / \mathrm{CH}_{4}$ at $293 \mathrm{~K}$ for the MUF-16 family. 


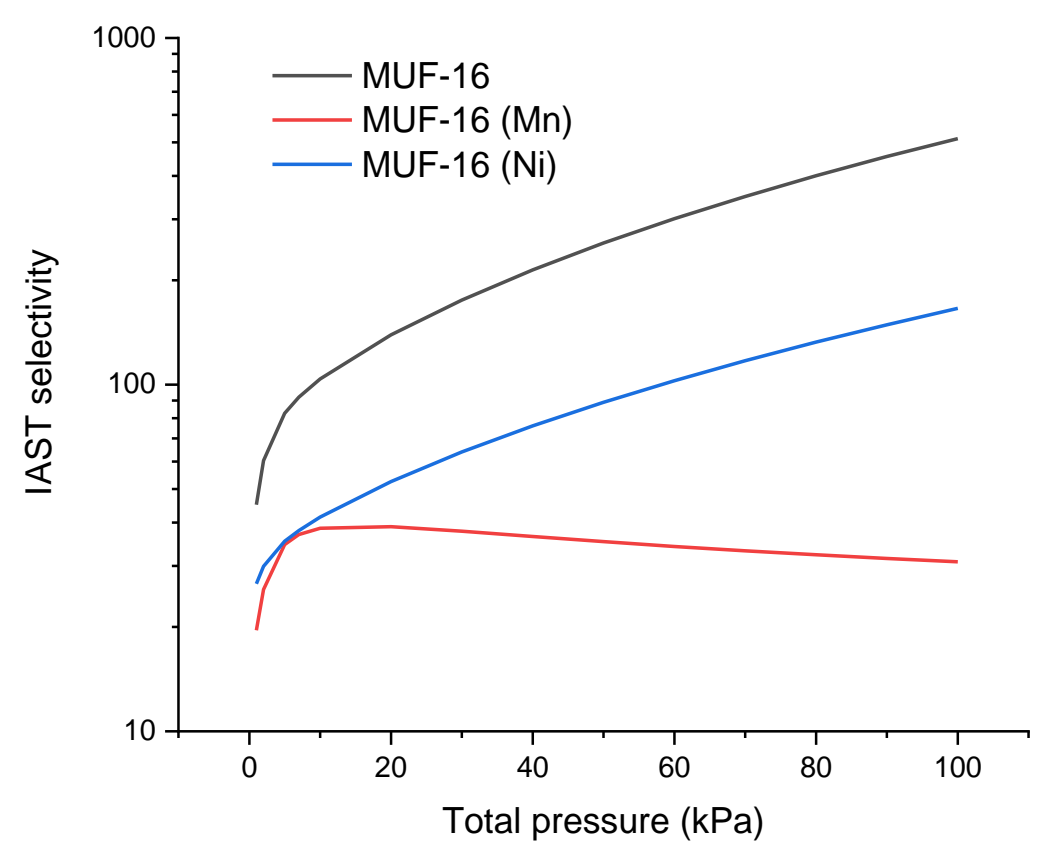

Fig. S40. IAST selectivity for a 50/50 mixture of $\mathrm{CO}_{2} / \mathrm{C}_{2} \mathrm{H}_{2}$ at $293 \mathrm{~K}$ for the MUF-16 family.

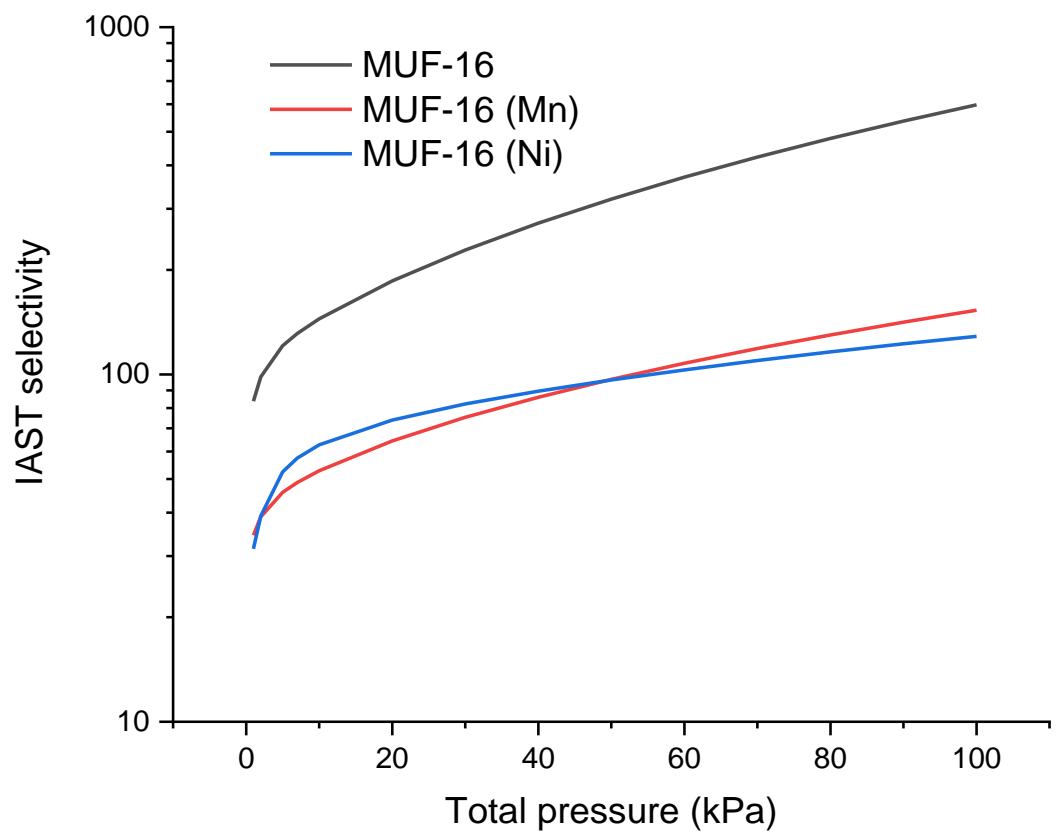

Fig. S41. IAST selectivity for a 50/50 mixture of $\mathrm{CO}_{2} / \mathrm{C}_{2} \mathrm{H}_{4}$ at $293 \mathrm{~K}$ for the MUF-16 family. 


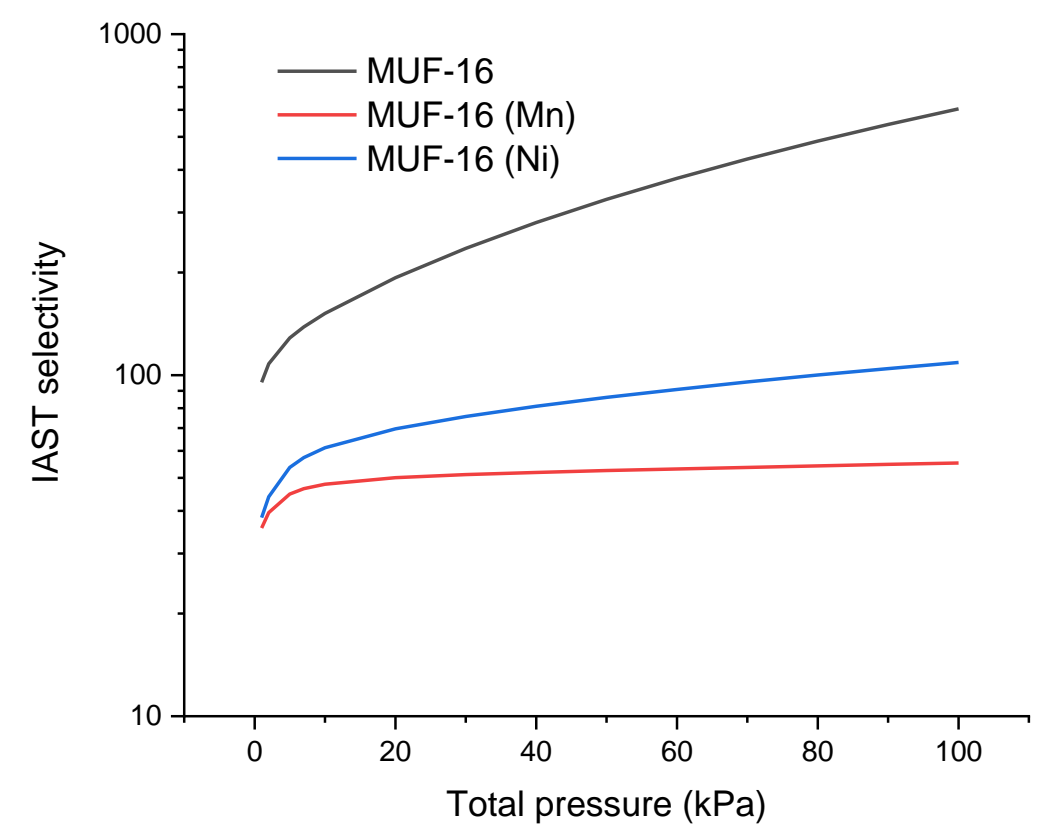

Fig. S42. IAST selectivity for a 50/50 mixture of $\mathrm{CO}_{2} / \mathrm{C}_{2} \mathrm{H}_{6}$ at $293 \mathrm{~K}$ for the MUF-16 family.

\section{Breakthrough separation experiments and simulations}

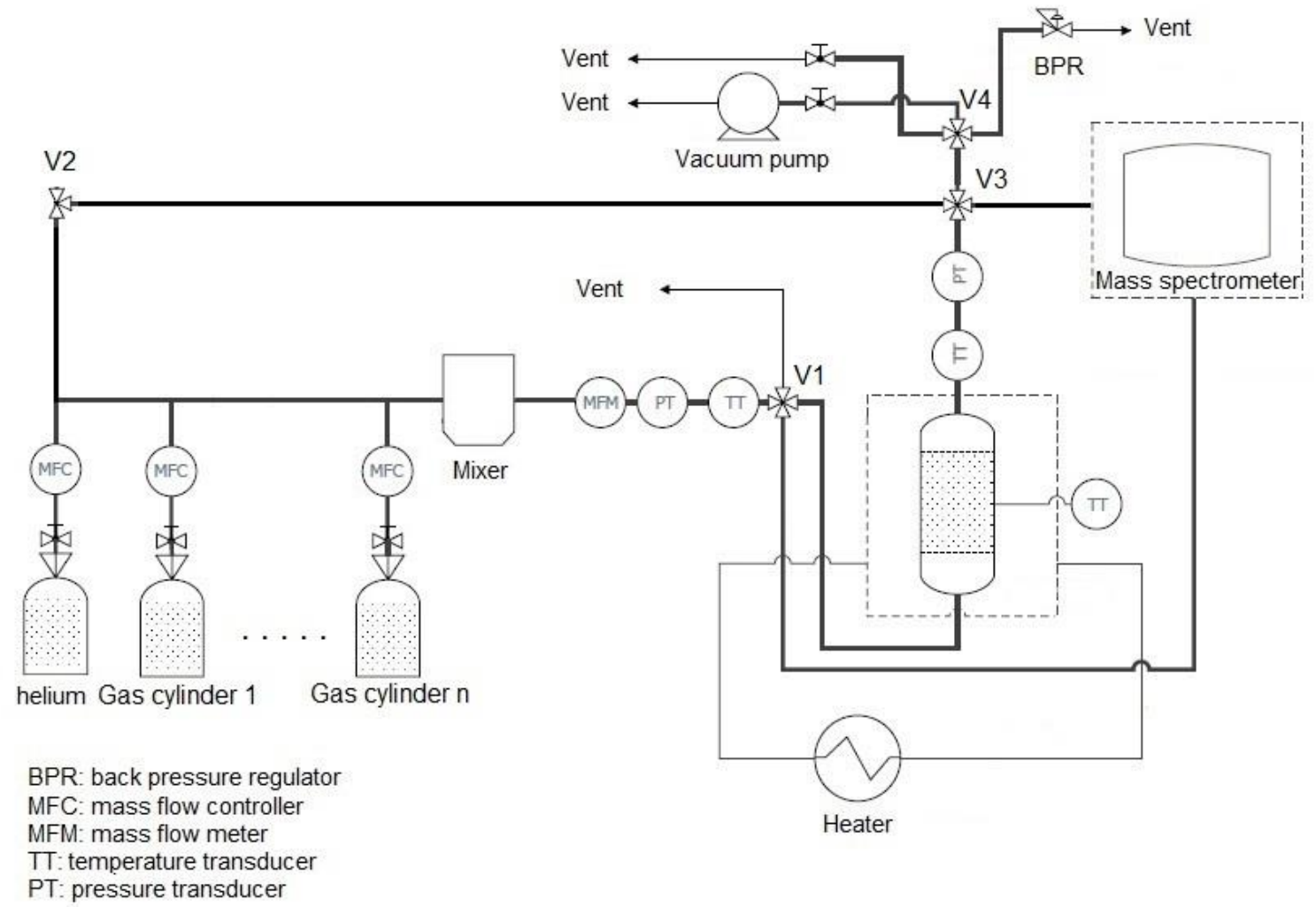

Fig. S43. A schematic of the experimental column breakthrough setup. 
Table S7. Summary of inlet gas feed streams, outlet compositions and associated data for experimental breakthrough tests using a MUF-16 adsorbent bed.

\begin{tabular}{|c|c|c|c|c|c|c|c|c|}
\hline Gas mixture & $\begin{array}{c}\text { Total } \\
\text { pressure } \\
\text { (bar) }\end{array}$ & $\begin{array}{l}\text { Inlet } \mathrm{CO}_{2} \\
\text { partial } \\
\text { pressure } \\
\text { (bar) }\end{array}$ & $\begin{array}{c}\text { Flowrate } \\
\left(\mathrm{mL}_{\mathbf{N}} / \mathbf{m i n}\right)\end{array}$ & $\begin{array}{l}\text { Upper limit for } \mathrm{CO}_{2} \\
\text { concentration in } \\
\text { effluent (ppmv) }\end{array}$ & $\begin{array}{c}\text { Breakthrough } \\
\text { point of } \mathrm{CO}_{2} \\
(\mathrm{~min})\end{array}$ & $\begin{array}{c}\mathrm{CO}_{2} \text { concentration in } \\
\text { effluent at } \\
\text { breakthrough point } \\
(\mathrm{ppmv})\end{array}$ & $\begin{array}{c}\text { Dynamic } \\
\text { adsorption } \\
\text { capacity } \\
(\mathrm{mmol} / \mathrm{g})\end{array}$ & $\begin{array}{l}\text { Equilibrium } \\
\text { adsorption } \\
\text { capacity } \\
\text { (mmol/g) }\end{array}$ \\
\hline $\mathrm{CO}_{2} / \mathrm{CH}_{4}(50 / 50)$ & 1 & 0.5 & 6 & 500 & 10.6 & 600 & 1.53 & 1.85 \\
\hline $\mathrm{CO}_{2} / \mathrm{CH}_{4}(15 / 85)$ & 1 & 0.15 & 6 & 520 & 25.6 & 600 & 1.13 & 1.23 \\
\hline $\mathrm{CO}_{2} / \mathrm{CH}_{4}(15 / 85)$ & 9 & 0.15 & 6 & 360 & 44.8 & 600 & 2.01 & - \\
\hline $\begin{array}{l}\mathrm{CO}_{2} / \mathrm{CH}_{4}+\mathrm{C}_{2} \mathrm{H}_{6}+\mathrm{C}_{3} \mathrm{H}_{8} \\
(15 / 80 / 4 / 1)\end{array}$ & 1 & 0.15 & 6 & 520 & 24.6 & 600 & 1.09 & 1.23 \\
\hline $\begin{array}{l}\mathrm{CO}_{2} / \mathrm{CH}_{4}+\mathrm{C}_{2} \mathrm{H}_{6}+\mathrm{C}_{3} \mathrm{H}_{8} \\
(15 / 80 / 4 / 1)\end{array}$ & 9 & 0.15 & 6 & 390 & 42.5 & 600 & 1.93 & - \\
\hline $\mathrm{CO}_{2} / \mathrm{C}_{2} \mathrm{H}_{2}(50 / 50)^{*}$ & 1 & 0.33 & 6 & 500 & 12.3 & 600 & 1.23 & 1.64 \\
\hline $\mathrm{CO}_{2} / \mathrm{C}_{2} \mathrm{H}_{2}(5 / 95)$ & 1 & 0.035 & 6.85 & 540 & 15.1 & 600 & 0.18 & 0.46 \\
\hline $\mathrm{CO}_{2} / \mathrm{C}_{2} \mathrm{H}_{4}(50 / 50)^{*}$ & 1 & 0.33 & 6 & 500 & 11.9 & 600 & 1.19 & 1.64 \\
\hline $\mathrm{CO}_{2} / \mathrm{C}_{2} \mathrm{H}_{6}(50 / 50)^{*}$ & 1 & 0.33 & 6 & 500 & 12.2 & 600 & 1.22 & 1.64 \\
\hline
\end{tabular}

$* 2 \mathrm{~mL} / \mathrm{min}$ of helium was used as carrier gas in this experiment. 


\section{1. $\mathrm{CO}_{2} / \mathrm{CH}_{4}$ and $\mathrm{CO}_{2} / \mathrm{CH}_{4}+\mathrm{C}_{2} \mathrm{H}_{6}+\mathrm{C}_{3} \mathrm{H}_{8}$ breakthrough separations}

Activated MUF-16 (0.9 g) was placed in an adsorption column $(6.4 \mathrm{~mm}$ in diameter $\times 11 \mathrm{~cm}$ in length) to form a fixed bed. The adsorbent was activated at $130{ }^{\circ} \mathrm{C}$ under high vacuum for 7 hours and then the column was left under vacuum for another 3 hours while being cooled to $20{ }^{\circ} \mathrm{C}$. The column was then purged under a $20 \mathrm{~mL} / \mathrm{min}$ flow of $\mathrm{He}$ gas for $1 \mathrm{hr}$ at 1.1 bar prior to the breakthrough experiment. A gas mixture containing $\mathrm{CO}_{2} / \mathrm{CH}_{4}$ or $\mathrm{CO}_{2} / \mathrm{CH}_{4}+\mathrm{C}_{2} \mathrm{H}_{6}+\mathrm{C}_{3} \mathrm{H}_{8}$ was introduced to the column at 1.1 bar and 9 bar for $\mathrm{CO}_{2} / \mathrm{CH}_{4}$ and $\left.\mathrm{CO}_{2} / \mathrm{CH}_{4}+\mathrm{C}_{2} \mathrm{H}_{6}+\mathrm{C}_{3} \mathrm{H}_{8}\right)$ and $20{ }^{\circ} \mathrm{C}$.

A feed flowrate of $6 \mathrm{~mL} / \mathrm{min}$ was set. The operating pressure was controlled at 1.1 or 9 bar with a backpressure regulator. The outlet composition was continuously monitored by a SRS UGA200 mass spectrometer. The $\mathrm{CO}_{2}$ was deemed to have broken through from the column when its concentration reached 600 ppmv.

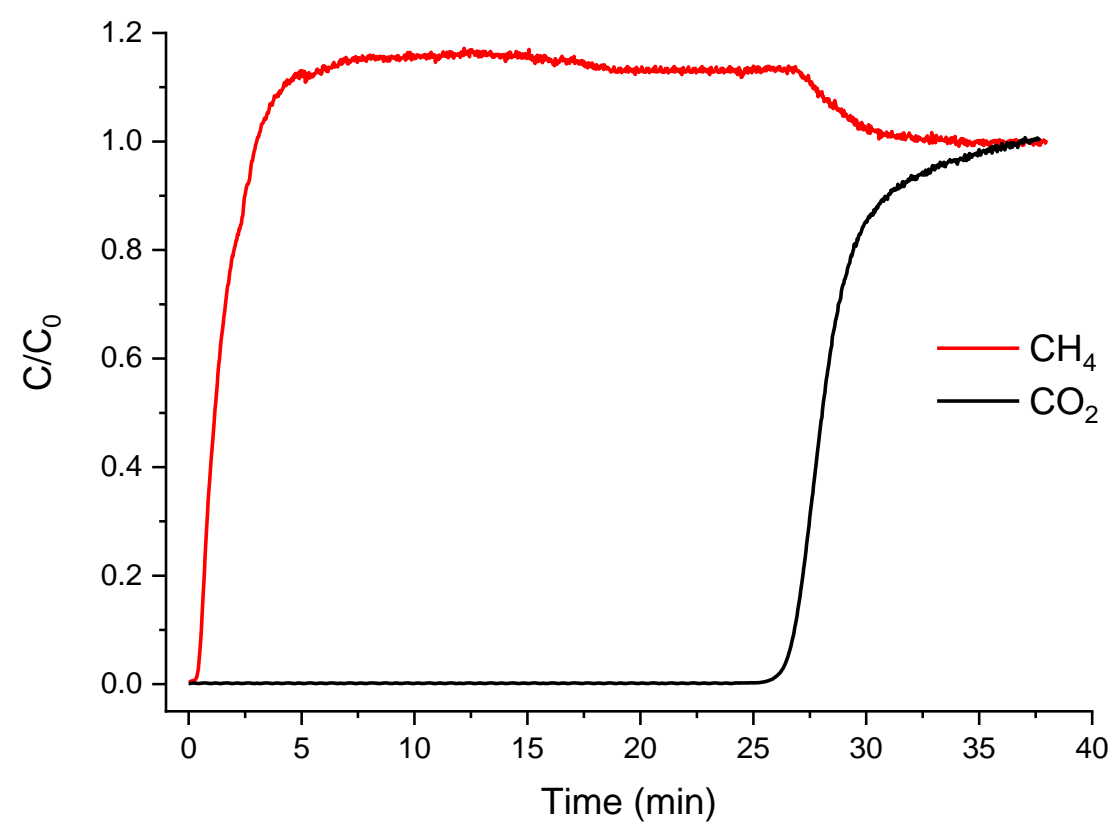

Fig. S44. Experimental breakthrough curves for a mixture of $15 / 85 \mathrm{CO}_{2} / \mathrm{CH}_{4}$ at 1.1 bar and $293 \mathrm{~K}$ in an adsorption column packed with MUF-16. 


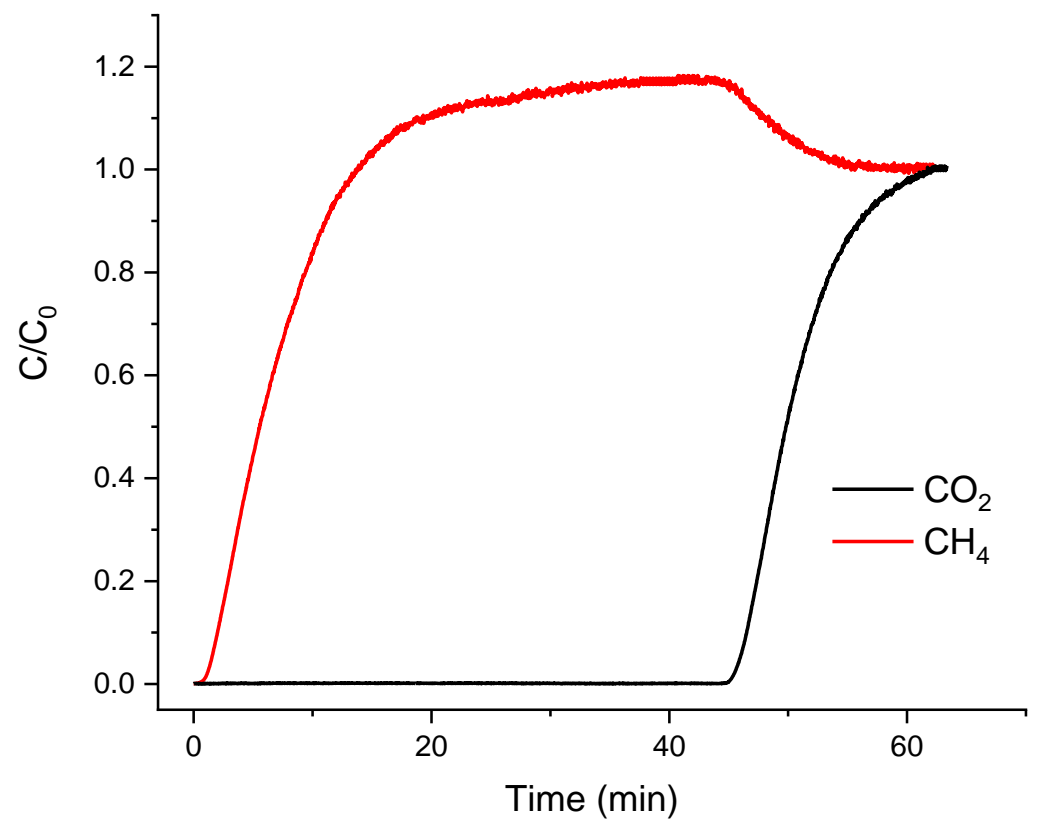

Fig. S45. Experimental breakthrough curves for a mixture of $15 / 85 \mathrm{CO}_{2} / \mathrm{CH}_{4}$ at 9 bar and $293 \mathrm{~K}$ in an adsorption column packed with MUF-16.

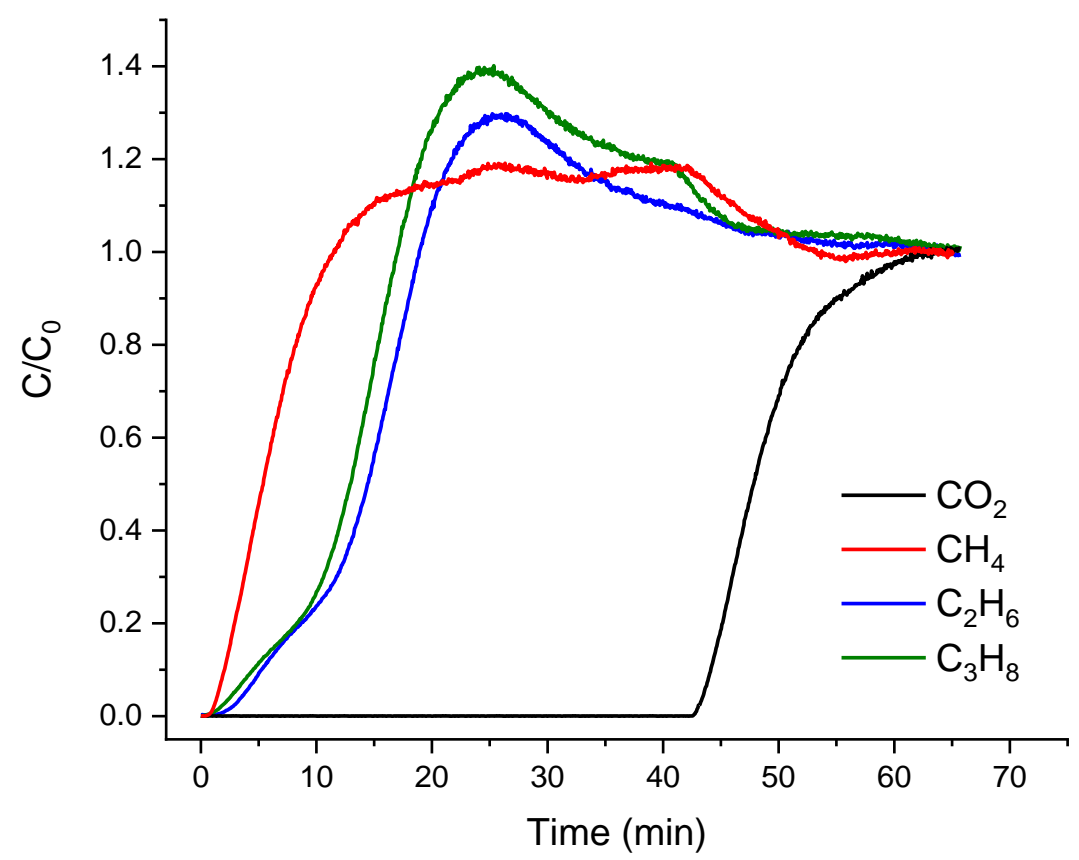

Fig. S46. Experimental breakthrough curves for a mixture of $15 / 80 / 4 / 1 \mathrm{CO}_{2} / \mathrm{CH}_{4} / \mathrm{C}_{2} \mathrm{H}_{6} / \mathrm{C}_{3} \mathrm{H}_{8}$ at 9 bar and $293 \mathrm{~K}$ in an adsorption column packed with MUF-16. 


\subsubsection{Simulations of $\mathrm{CO}_{2} / \mathrm{CH}_{4}$ breakthrough curves}

The simulation of breakthrough curves was carried out using a previously reported method. ${ }^{12,13}$ A value for the mass transfer coefficient $(\mathrm{k})$ was obtained by empirical tuning the steepness of the predicted breakthrough curves to match the experimental curve. The mass transfer coefficient tuned in this way was later used to predict breakthrough curves for other feed mixtures and operating pressures. A summary of adsorption column parameters and feed characterizations are presented in Table S8.

Table S8. Adsorption column parameters and feed characterizations used for the simulations for MUF16.

\begin{tabular}{ll}
\hline Adsorption bed & Feed \\
Length: $110 \mathrm{~mm}$ & Flow rate: $6 \mathrm{~mL} / \mathrm{min}$ \\
Diameter: $6.4 \mathrm{~mm}$ & Temperature: $293 \mathrm{~K}$ \\
Amount of adsorbent in the bed: $0.9 \mathrm{~g}$ & Pressure: $1.1 \mathrm{bar}$ \\
Adsorbent density: $1.674 \mathrm{~g} / \mathrm{cm}^{3}$ & Carrier gas flow rate: No carrier gas was used \\
Adsorbent average radius: $0.2 \mathrm{~mm}$ & \\
$\mathrm{k}_{\mathrm{CO} 2}: 0.029 \mathrm{~s}^{-1}$ & \\
$\mathrm{k}_{\mathrm{CH} 4}: 0.00021 \mathrm{~s}^{-1}$ & \\
\hline
\end{tabular}

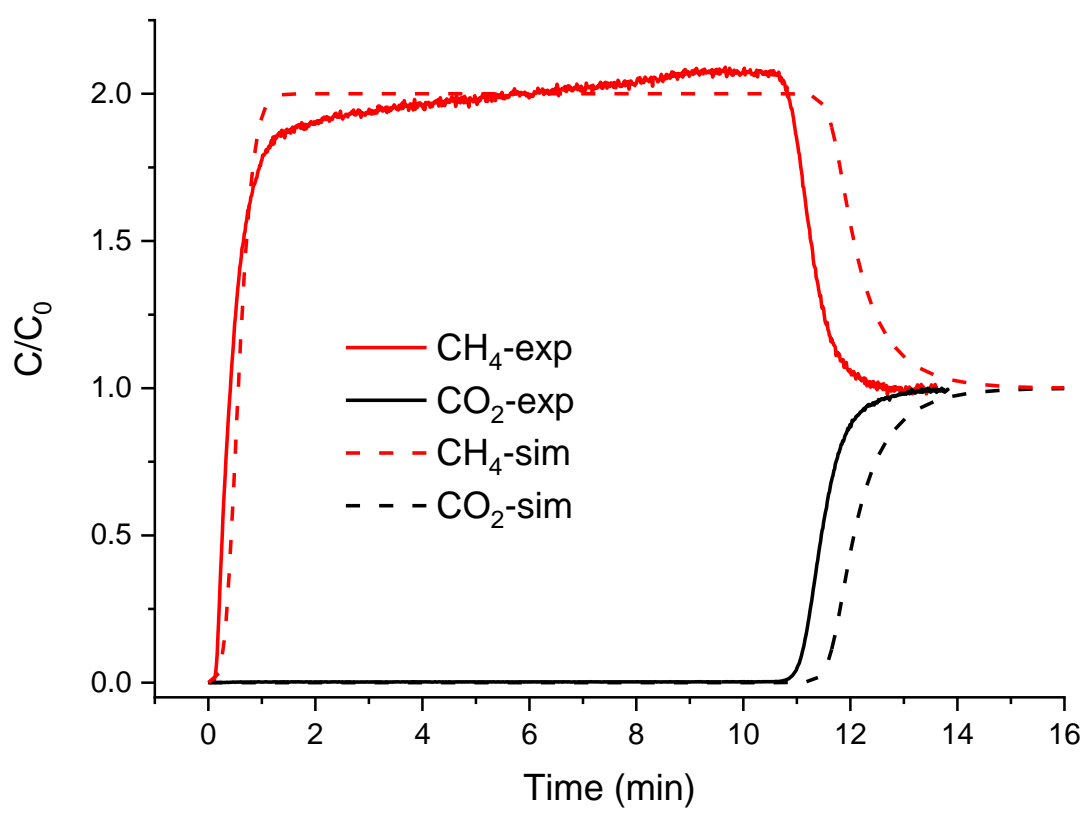

Fig. S47. Experimental breakthrough curves in comparison to simulated one for a mixture of 50/50 $\mathrm{CO}_{2} / \mathrm{CH}_{4}$ at 1.1 bar and $293 \mathrm{~K}$ in an adsorption column packed with MUF-16. 


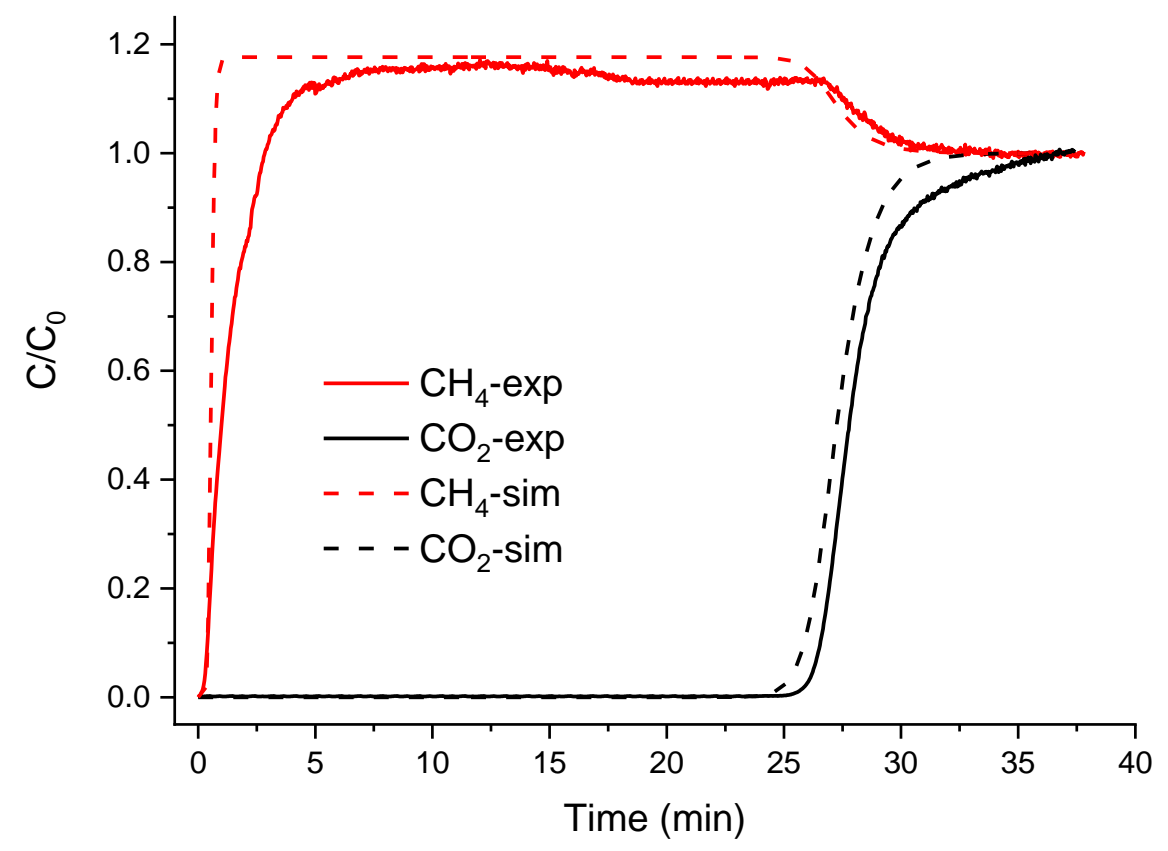

Fig. S48. Experimental breakthrough curves in comparison to simulated one for a mixture of 15/85 $\mathrm{CO}_{2} / \mathrm{CH}_{4}$ at 1.1 bar and $293 \mathrm{~K}$ in an adsorption column packed with MUF-16.

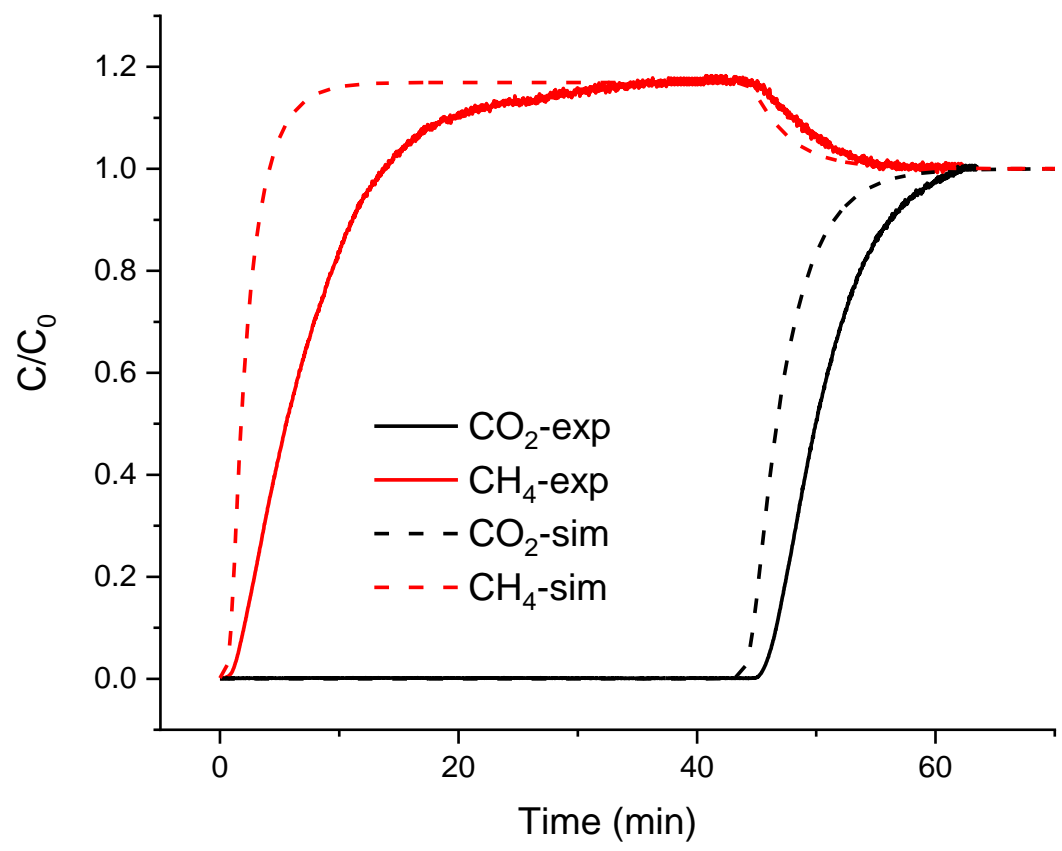

Fig. S49. Experimental breakthrough curves in comparison to simulated one for a mixture of $15 / 85$ $\mathrm{CO}_{2} / \mathrm{CH}_{4}$ at 9 bar and $293 \mathrm{~K}$ in an adsorption column packed with MUF-16. 


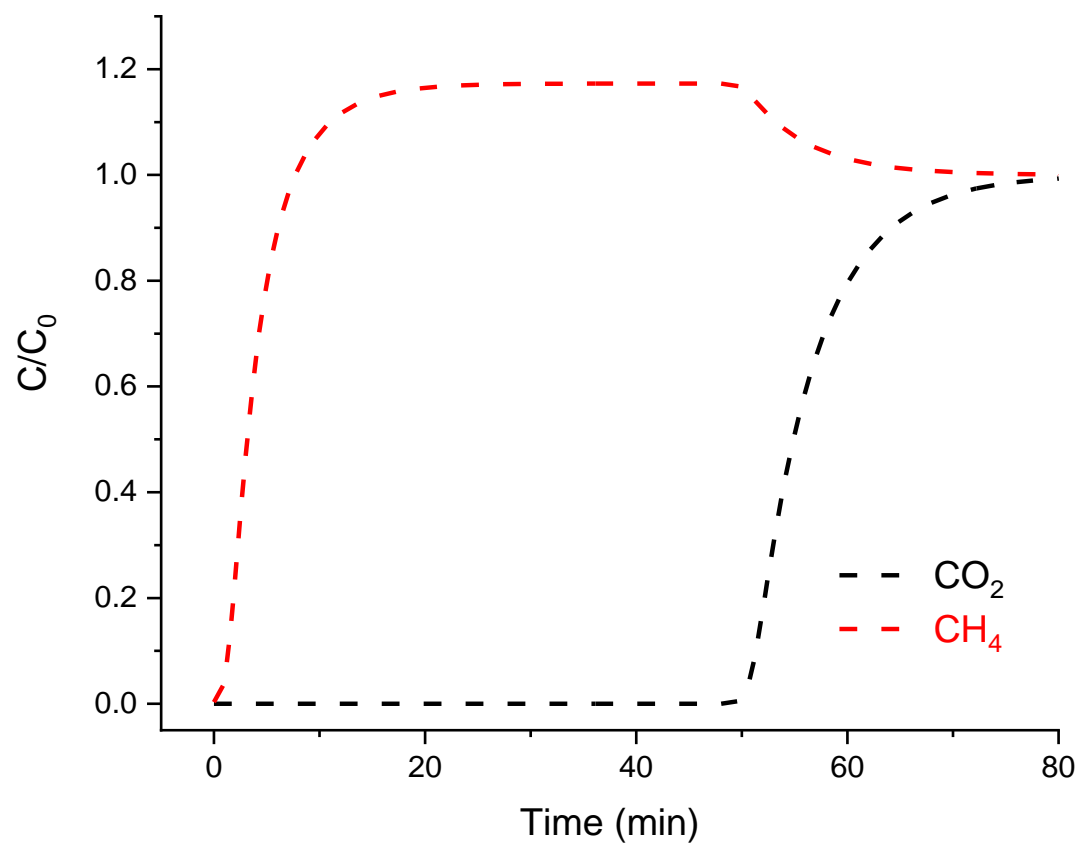

Fig. S50. Simulated breakthrough curves for a mixture of $15 / 85 \mathrm{CO}_{2} / \mathrm{CH}_{4}$ at 50 bar and $293 \mathrm{~K}$ in an adsorption column packed with MUF-16.

\section{2 $\mathrm{CO}_{2} / \mathrm{C} 2$ hydrocarbon separations}

In a typical breakthrough experiment, $0.9 \mathrm{~g}$ of activated MUF-16 was placed in an adsorption column (6.4 $\mathrm{mm}$ in diameter $\times 11 \mathrm{~cm}$ in length) to form a fixed bed. The adsorbent was activated at $130{ }^{\circ} \mathrm{C}$ under high vacuum for 7 hours and then the column was left under vacuum for another 3 hours while being cooled to $20{ }^{\circ} \mathrm{C}$. The column was then purged under a $20 \mathrm{~mL} / \mathrm{min}$ flow of He gas for $1 \mathrm{hr}$ at 1.1 bar prior to the breakthrough experiment. A gas mixture containing different gas pairs of $\mathrm{CO}_{2}$ and $\mathrm{C}_{2} \mathrm{H}_{2}$, $\mathrm{C}_{2} \mathrm{H}_{6}$ or $\mathrm{C}_{2} \mathrm{H}_{4}$ along with $\mathrm{He}$ as a carrier gas was introduced to the column at $1.1 \mathrm{bar}$ and $20^{\circ} \mathrm{C}$. A feed flowrate of 6.0 or $6.85 \mathrm{~mL}_{\mathrm{N}} / \mathrm{min}$ (including helium) was set for the experiments with 50/50 and 5/95 mixture of gases, respectively, and the flowrate of He in the feed was kept constant at $2 \mathrm{~mL} / \mathrm{min}$ for all the experiments. The operating pressure was controlled at 1.1 bar with a back-pressure regulator. The outlet composition was continuously monitored by a SRS UGA200 mass spectrometer. The $\mathrm{CO}_{2}$ was deemed to have broken through from the column when its concentration reached $600 \mathrm{ppmv}$. 


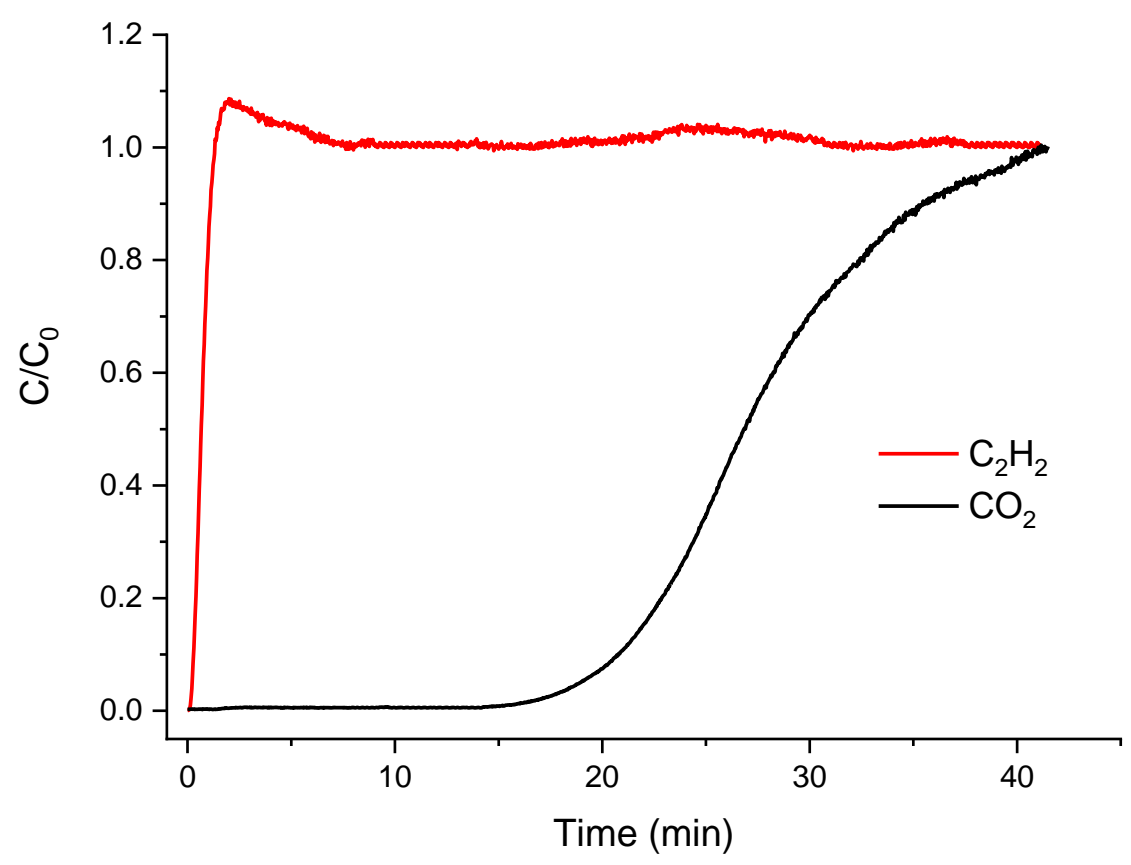

Fig. S51. Experimental breakthrough curves for a mixture of $5 / 95 \mathrm{CO}_{2} / \mathrm{C}_{2} \mathrm{H}_{2}$ at 1.1 bar and $293 \mathrm{~K}$ in an adsorption column packed with MUF-16.

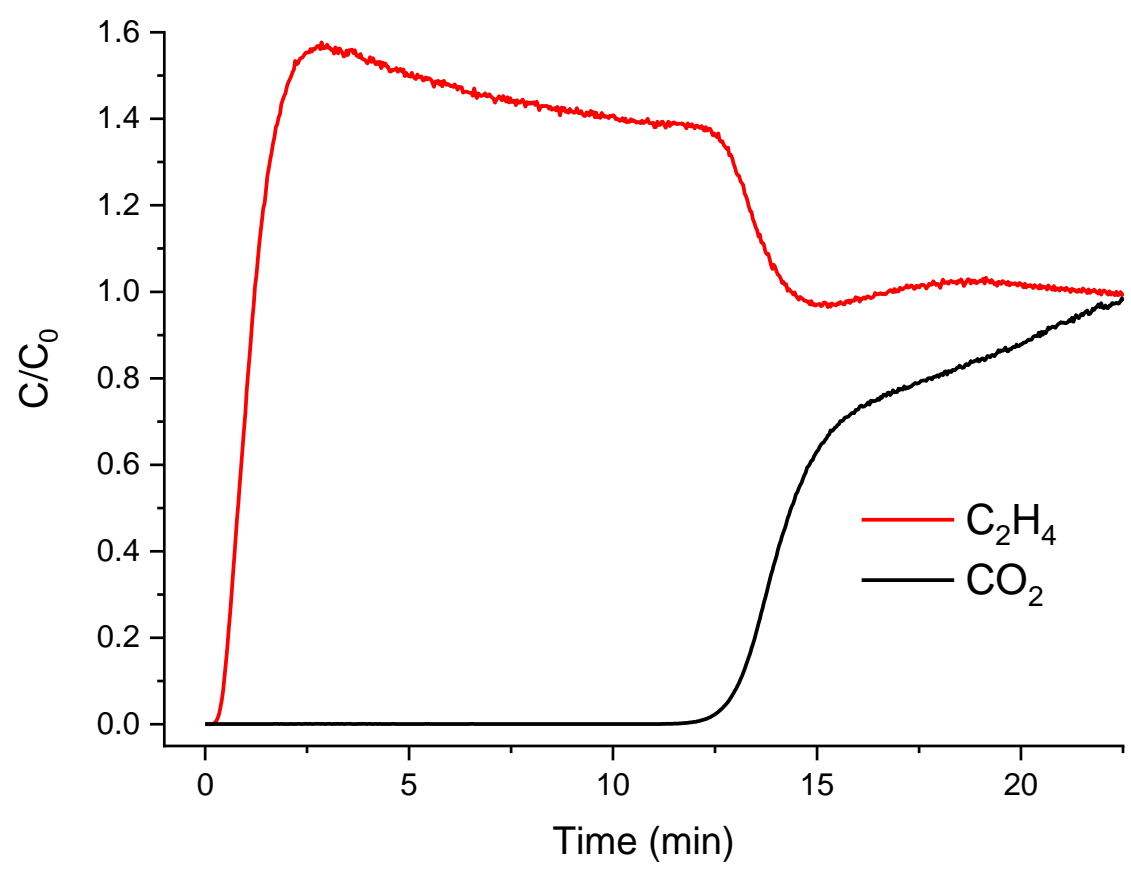

Fig. S52. Experimental breakthrough curves for a mixture of $50 / 50 \mathrm{CO}_{2} / \mathrm{C}_{2} \mathrm{H}_{4}$ at 1.1 bar and $293 \mathrm{~K}$ in an adsorption column packed with MUF-16. 


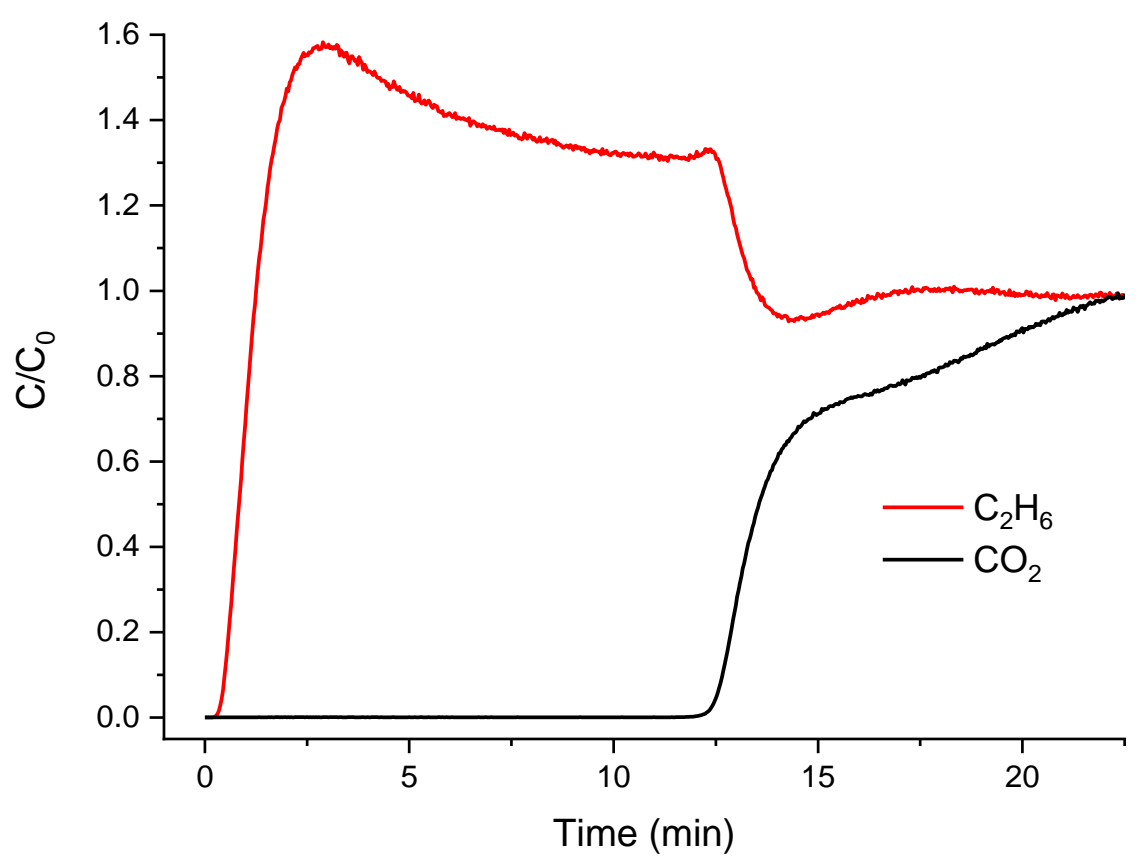

Fig. S53. Experimental breakthrough curves for a mixture of $50 / 50 \mathrm{CO}_{2} / \mathrm{C}_{2} \mathrm{H}_{6}$ at $1.1 \mathrm{bar}$ and $293 \mathrm{~K}$ in an adsorption column packed with MUF-16.

\section{Adsorbent regeneration}

The desorption behaviour of $\mathrm{CO}_{2}$ and $\mathrm{C}_{2} \mathrm{H}_{2}$ from the adsorption column was also investigated. Once the adsorbent was saturated with an equimolar mixture of $\mathrm{CO}_{2}$ and $\mathrm{C}_{2} \mathrm{H}_{2}$, the column was purged with a helium flow of $5 \mathrm{mLN} / \mathrm{min}$ for $18 \mathrm{mins}$ at $20{ }^{\circ} \mathrm{C}$ at 1 bar while monitoring the effluent gas. Then the column was then heated to $80{ }^{\circ} \mathrm{C}$ with a ramp of $10{ }^{\circ} \mathrm{C} / \mathrm{min}$ for $20 \mathrm{mins}$. Finally, the column was heated to $130{ }^{\circ} \mathrm{C}$ with the same ramping for $15 \mathrm{~min}$ before cooling to $20{ }^{\circ} \mathrm{C}$. A breakthrough measurement was then performed, which showed that the absorbent had been fully regenerated. 


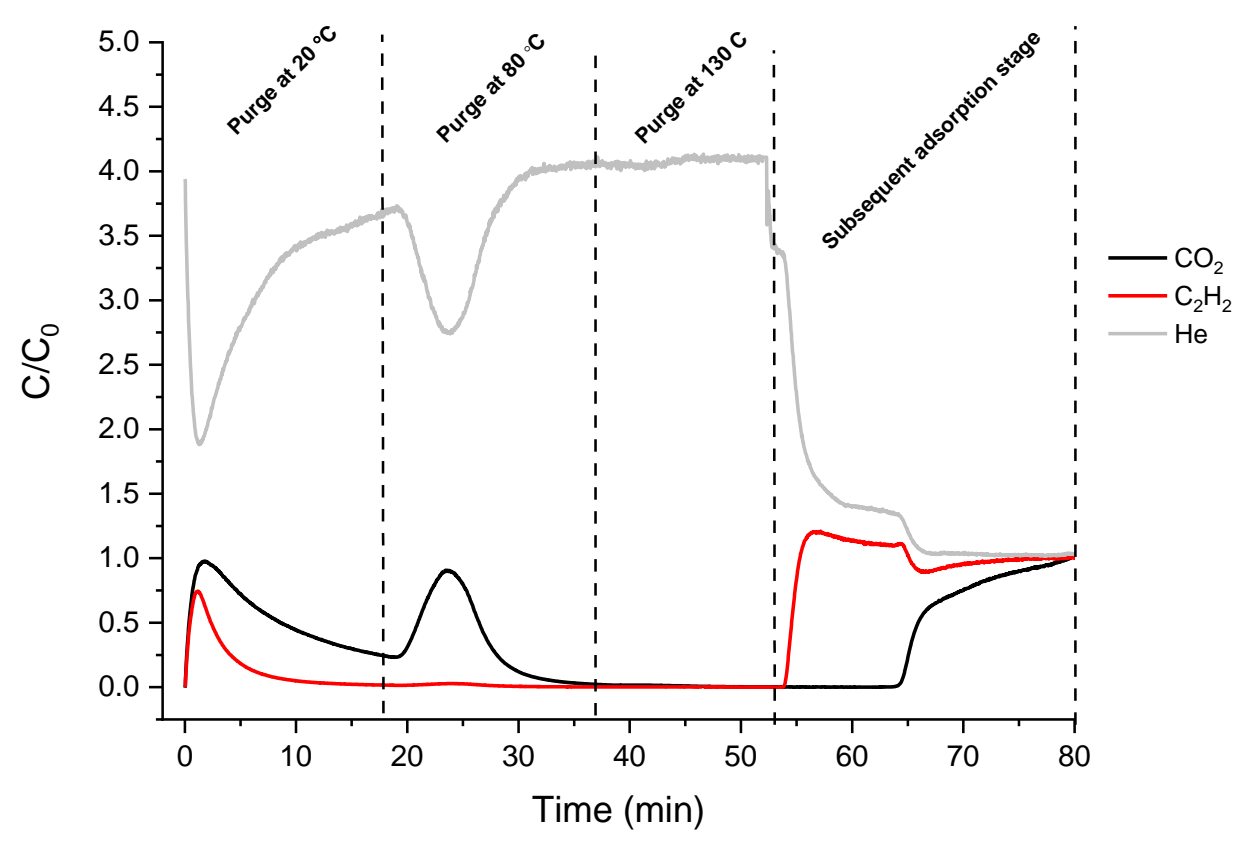

Figure S54. Desorption behaviour of the adsorbates through heating the column at 1 bar under a helium flow of $5 \mathrm{mLN} / \mathrm{min} . \mathrm{C}_{2} \mathrm{H}_{2}$ is fully removed from the bed by purging with helium at room temperature. $\mathrm{CO}_{2}$ is completely desorbed from the column upon heating to $80{ }^{\circ} \mathrm{C}$ with a flow of helium. No adsorbates remained to be removed upon further heating to $130{ }^{\circ} \mathrm{C}$.

\subsubsection{Simulations of $\mathrm{CO}_{2} / \mathrm{C}_{2} \mathrm{H}_{2}$ breakthrough curves}

The simulation of breakthrough curves for $\mathrm{CO}_{2} / \mathrm{C} 2$ hydrocarbons was carried out using the method reported above. A summary of adsorption column parameters and feed characterizations are presented in Table S9.

Table S9. Adsorption column parameters and feed characterizations used for the simulations for MUF16.

\begin{tabular}{ll}
\hline Adsorption bed & Feed \\
Length: $110 \mathrm{~mm}$ & Flow rates: \\
Diameter: $6.4 \mathrm{~mm}$ & $6 \mathrm{~mL} / \mathrm{min}$ for equimolar and $0.1 / 99.9$ mixtures, and 6.85 \\
Amount of adsorbent in the bed: $0.9 \mathrm{~g}$ & $\mathrm{~mL}_{\mathrm{N}} / \mathrm{min}$ for the $5 / 95$ mixture. \\
Bed voidage: 0.84 & Temperature: $293 \mathrm{~K}$ \\
Adsorbent average radius: $0.2 \mathrm{~mm}$ & Pressure: $1.1 \mathrm{bar}$ \\
$\mathrm{k}_{\mathrm{CO} 2}: 0.021 \mathrm{~s}^{-1}$ & Carrier gas $(\mathrm{He})$ flow rate: $2 \mathrm{~mL} / \mathrm{min}$. \\
$\mathrm{k}_{\mathrm{C} 2 \mathrm{H} 2: 0.024 \mathrm{~s}^{-1}}$ & \\
\hline
\end{tabular}




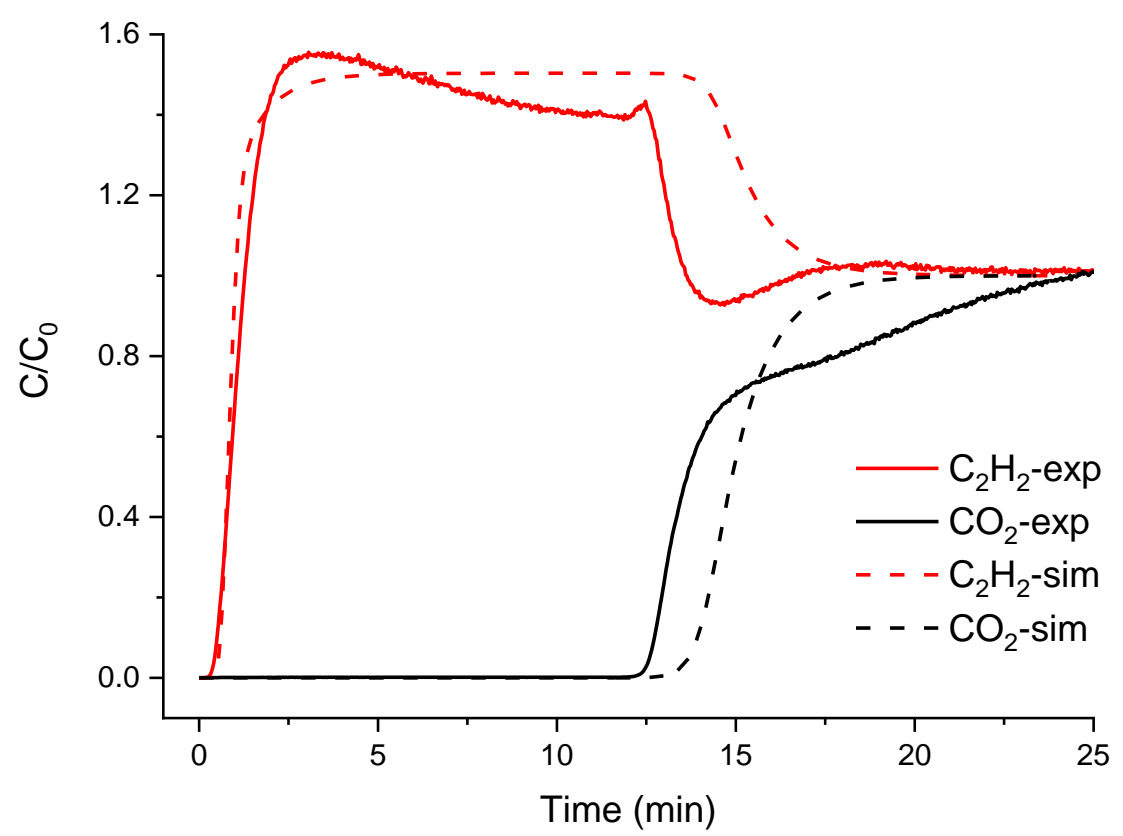

Fig. S55. Experimental breakthrough curves in comparison to simulated one for a mixture of 50/50 $\mathrm{CO}_{2} / \mathrm{C}_{2} \mathrm{H}_{2}$ at 1.1 bar and $293 \mathrm{~K}$ in an adsorption column packed with MUF-16.

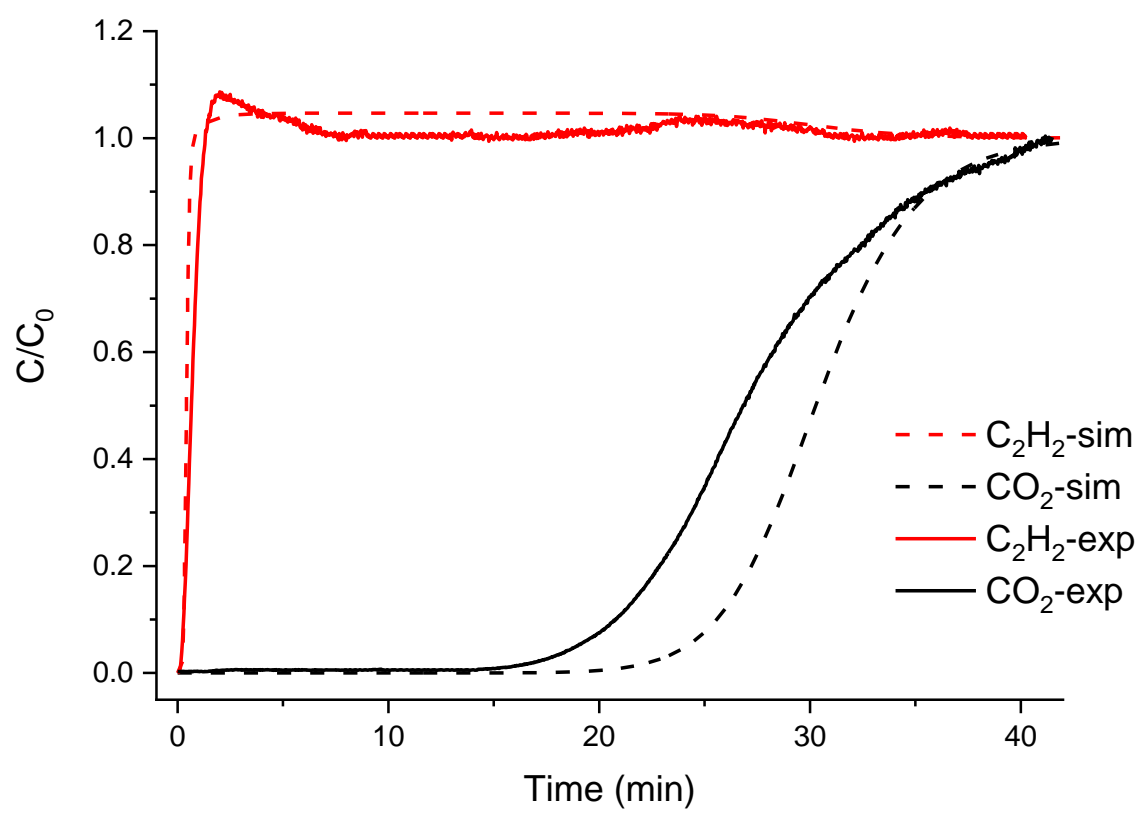

Fig. S56. Experimental breakthrough curves in comparison to simulated one for a mixture of 5/95 $\mathrm{CO}_{2} / \mathrm{C}_{2} \mathrm{H}_{2}$ at 1.1 bar and $293 \mathrm{~K}$ in an adsorption column packed with MUF-16. 


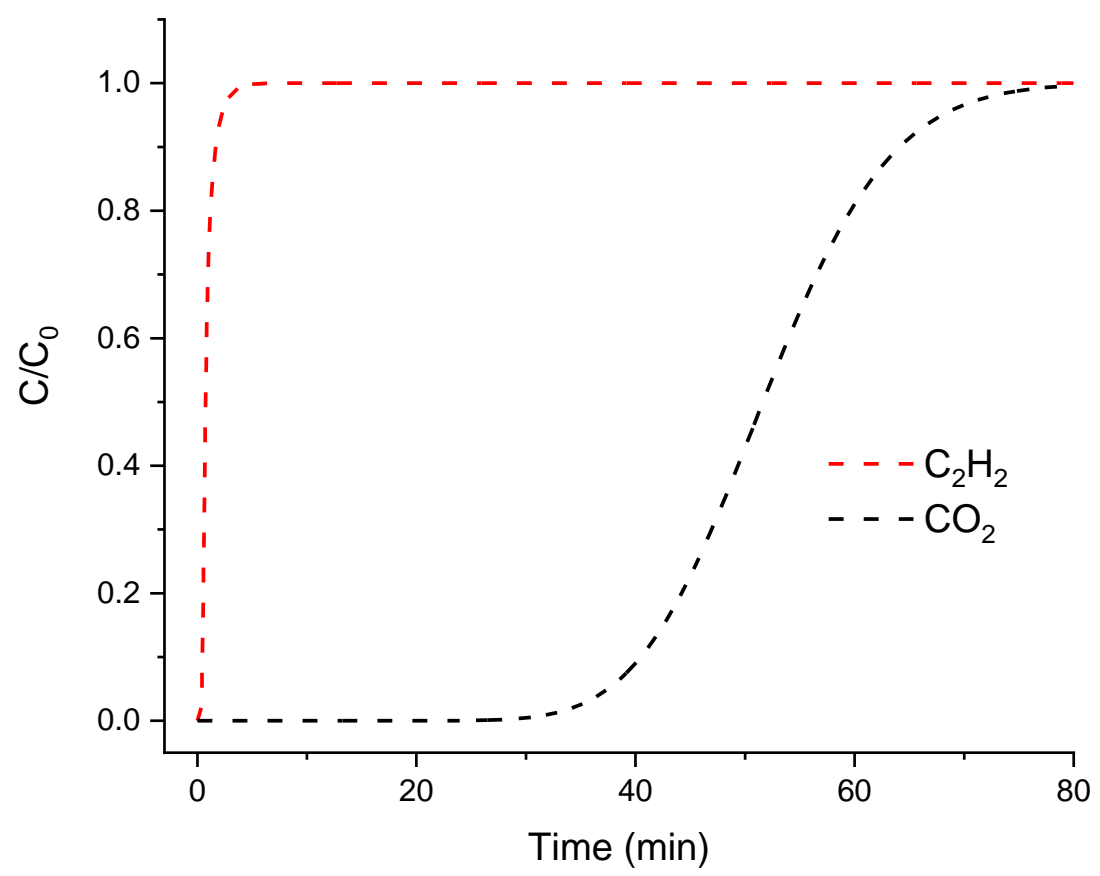

Fig. S57. Simulated breakthrough curves for a mixture of $0.1 / 99.9 \mathrm{CO}_{2} / \mathrm{C}_{2} \mathrm{H}_{2}$ at 1.1 bar and $293 \mathrm{~K}$ in an adsorption column packed with MUF-16.

\section{Tabulated separation metrics}

The $\mathrm{CO}_{2} / \mathrm{CH}_{4}$ and $\mathrm{CO}_{2} / \mathrm{C}_{2} \mathrm{H}_{2}$ separation parameters of MUF-16 in comparison to top-performing MOFs and related materials are presented in Tables S9 and S10. Materials with molecular sieving mechanisms are excluded from this analysis. IAST selectivities are presented for a $50 / 50 \mathrm{CO}_{2} / \mathrm{CH}_{4}$ and $\mathrm{CO}_{2} / \mathrm{C}_{2} \mathrm{H}_{2}$ at 1 bar, unless otherwise stated. $Q_{s t}$ values are reported at low loading, unless otherwise stated. Uptake ratios are calculated by dividing the uptake of $\mathrm{CO}_{2}$ by that of $\mathrm{CH}_{4} \mathrm{Or}_{2} \mathrm{H}_{2}$ (all at 1 bar and the specified temperature in the Table S9 and S10). These were taken from either a direct statement of relevant details in the manuscript or were extracted from Figs. by a digitizer software. 
Table S10. Metrics relevant to $\mathrm{CO}_{2} / \mathrm{N}_{2} / \mathrm{CH}_{4}$ separations for MUF-16 in comparison to a selection of materials reported in the literature.

\begin{tabular}{|c|c|c|c|c|c|c|c|}
\hline \multicolumn{2}{|c|}{ Material } & \multirow{2}{*}{$\frac{\mathbf{T}\left({ }^{\circ} \mathbf{C}\right)}{20}$} & \multirow{2}{*}{$\begin{array}{c}\begin{array}{c}\mathbf{P} \\
(\mathbf{b a r})\end{array} \\
1\end{array}$} & \multirow{2}{*}{$\begin{array}{c}\begin{array}{c}\mathrm{CO}_{2} \mid \mathrm{CH}_{4} \\
\text { uptakes }(\mathrm{cc} / \mathrm{g})\end{array} \\
47.8 \mid \mathbf{1 . 2}\end{array}$} & \multirow{2}{*}{$\begin{array}{c}\mathbf{Q}_{\mathrm{st}}\left(\mathrm{CO}_{2}\right) \\
(\mathrm{kJ} / \mathrm{mol})\end{array}$} & \multirow{2}{*}{$\begin{array}{c}\begin{array}{c}\text { Uptake } \\
\text { ratio }\end{array} \\
\mathbf{3 9 . 8}\end{array}$} & \multirow{2}{*}{$\begin{array}{c}\begin{array}{c}\text { IAST } \\
\text { selectivity } \\
(50 / 50)\end{array} \\
6686\end{array}$} \\
\hline & MUF-16 & & & & & & \\
\hline 象 & MUF-16(Mn) & 20 & 1 & \begin{tabular}{l|l|l|}
50.5 & 3.1
\end{tabular} & 37 & 16.3 & 470 \\
\hline & MUF-16(Ni) & 20 & 1 & \begin{tabular}{l|l|l|}
48.0 & 2.8 \\
\end{tabular} & 37 & $\mathbf{1 7 . 3}$ & 1215 \\
\hline \multirow{18}{*}{ 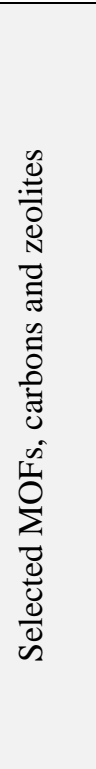 } & Zeolite $13 \mathrm{X}^{14,15}$ & 25 & 1 & \begin{tabular}{l|l}
112 & 13
\end{tabular} & $44-54$ & 8.6 & 103 \\
\hline & Zeolite $5 \mathrm{~A}^{16,17}$ & 30 & 1 & $75.5 \mid 11.8$ & $23^{c}$ & 6.4 & $\mathrm{n} / \mathrm{a}$ \\
\hline & Zeolite $4 \mathrm{~A}^{18,19}$ & $30-32$ & 1 & $105.3 \mid 15$ & 39 & 7 & $\mathrm{n} / \mathrm{a}$ \\
\hline & ${ }_{21}^{\text {BPL Activated }}$ carbon ${ }^{20}$ & 25 & 1 & $46.2 \mid 20.2$ & $21^{\mathrm{c}}$ & 2.3 & 4 \\
\hline & SIFSIX-3-Zn ${ }^{15}$ & 25 & 1 & $57 \mid 17.6$ & 45 & 3.2 & 230 \\
\hline & {$\left[\mathrm{Cd}_{2} \mathrm{~L}\left(\mathrm{H}_{2} \mathrm{O}\right)\right]_{2} .5 \mathrm{H}_{2} \mathrm{O}^{22}$} & 20 & 1 & $47.2 \mid 1.1$ & 37 & 42.9 & $\mathrm{n} / \mathrm{a}$ \\
\hline & UTSA- $120^{23}$ & 23 & 1 & $112 \mid 20.8$ & 27 & 5.4 & 96 \\
\hline & UTSA- $16^{24,25}$ & 23 & 1 & $96 \mid 13.2$ & 33 & 7.3 & 38 \\
\hline & HKUST- $1^{25-27}$ & 25 & 1 & $103 \mid 18.7$ & $35^{\mathrm{c}}$ & 7.4 & 5.5 \\
\hline & Mg-dobdc $15,25,28,29$ & 23 & 1 & $190 \mid 25$ & $47-52$ & 7.6 & 130 \\
\hline & IITKGP-5a $\mathrm{a}^{30}$ & 22 & 1 & $49 \mid 13.6$ & 23 & 3.6 & 24 \\
\hline & WOFOUR-1-Ni ${ }^{31}$ & 25 & 1 & $52 \mid 11.5$ & 66 & 4.5 & $26^{\mathrm{a}}$ \\
\hline & SIFSIX-2-Cu-i ${ }^{15}$ & 25 & 1 & $121.2 \mid 10.5$ & 32 & 11.5 & 33 \\
\hline & CAU $-1^{32}$ & 0 & 1 & $165 \mid 27$ & 48 & 6.1 & $28^{\mathrm{b}}$ \\
\hline & NbOFFIVE-Ni ${ }^{33,34}$ & 25 & 1 & $51.7 \mid 2.2$ & 54 & 23.1 & 366 \\
\hline & TIFSIX-3-Ni ${ }^{33,34}$ & 25 & 1 & $48.6 \mid 4.8$ & 50 & 10.2 & 158 \\
\hline & SIFSIX-14-Cu-i ${ }^{35}$ & 20 & 1 & $110.5|1.3|$ & 38 & 85 & $\mathrm{n} / \mathrm{a}$ \\
\hline & SIFSIX-3-Ni ${ }^{33,34}$ & 25 & 1 & 64.5 | 6.6 & 51 & 8.9 & 130 \\
\hline
\end{tabular}

Values were generally taken from either a direct statement in the manuscript or were extracted from relevant Figs. by a digitizer software. Materials with molecular sieving mechanisms are excluded from this analysis. ${ }^{\mathrm{a}}$ IAST is calculated for a $10 / 90$ mixture. ${ }^{\mathrm{b}}$ Selectivity was calculated from the slope of isotherms at low pressures (Henry constants). ${ }^{\mathrm{c}} \mathrm{Heat}$ of adsorption averaged over $\mathrm{CO}_{2}$ uptakes. 
Table S11. Separation metrics relevant to $\mathrm{C}_{2} \mathrm{H}_{2} / \mathrm{CO}_{2}$ separations for MUF-16 in comparison to other top-performing materials reported in the literature.

\begin{tabular}{|c|c|c|c|c|c|c|c|c|}
\hline MOF & $\mathbf{T}\left({ }^{\circ} \mathbf{C}\right)$ & $\mathbf{P}(\mathbf{b a r})$ & $\begin{array}{c}\mathrm{CO}_{2} \text { uptake } \\
(\mathrm{mmol} / \mathrm{g})\end{array}$ & $\begin{array}{c}\mathrm{C}_{2} \mathrm{H}_{2} \text { uptake } \\
(\mathrm{mmol} / \mathrm{g})\end{array}$ & 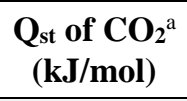 & $\begin{array}{c}Q_{\text {st }} \text { of } \mathrm{C}_{2} \mathrm{H}_{2}{ }^{\mathrm{a}} \\
(\mathrm{kJ} / \mathrm{mol})\end{array}$ & Uptake ratio* & $\begin{array}{c}\text { IAST selectivity } \\
(\mathbf{5 0 / 5 0}) *\end{array}$ \\
\hline \multicolumn{9}{|c|}{$\mathrm{CO}_{2}$-selective MOFs } \\
\hline MUF-16 & 20 & 1 & 2.14 & 0.18 & 32 & 25.8 & 12.0 & 510 \\
\hline$[\mathrm{Mn}(\mathrm{bdc})(\mathrm{dpe})]^{36}$ & 0 & 1 & 2.08 & 0.32 & 29.5 & 27.8 & 6.4 & 9.0 \\
\hline SIFSIX-3-Ni ${ }^{37}$ & 25 & 1 & 2.80 & 3.30 & 51 & 36.5 & 0.8 & $7.5^{\&}$ \\
\hline $\mathrm{K}_{2}\left[\mathrm{Cr}_{3} \mathrm{O}(\mathrm{OOCH})_{6}{ }^{6}\right.$ & 5 & 1 & 0.50 & 0.10 & 38 & 30 & 4.5 & $5.6^{\# \#}$ \\
\hline CD-MOF- $1^{38}$ & 25 & 1 & 2.87 & 2.23 & 41 & 17 & 1.3 & $3.4^{\&}$ \\
\hline CD-MOF-2 $2^{38}$ & 25 & 1 & 2.67 & 2.03 & 67.5 & 25 & 1.3 & $6.1^{\&}$ \\
\hline \multicolumn{9}{|c|}{$\mathrm{C}_{2} \mathrm{H}_{2}$-selective MOFs } \\
\hline UTSA-300a ${ }^{39}$ & 25 & 1 & 0.15 & 3.10 & - & 57 & 20.6 & 700 \\
\hline NKMOF-1-Ni ${ }^{40}$ & 25 & 1 & 2.27 & 2.67 & 41 & 60 & 1.2 & 22 \\
\hline HOF- $3 \mathrm{a}^{41}$ & 23 & 1 & 0.93 & 2.14 & 42 & 19.5 & 2.3 & 21 \\
\hline$\left[\mathrm{Ni}_{3}(\mathrm{HCOO})_{6}\right]^{42}$ & 25 & 1 & 3.00 & 4.20 & 24.5 & 41 & 1.4 & 21 \\
\hline SNNU-45 $5^{43}$ & 25 & 1 & 4.34 & 5.98 & 27.1 & 40 & 1.37 & 4.5 \\
\hline ZJU-196a $a^{44}$ & 25 & 1 & 0.35 & 3.70 & - & 39 & 10.6 & 18 \\
\hline JCM-1 $1^{45}$ & 25 & 1 & 1.69 & 3.34 & 33 & 36.5 & 2.0 & 14 \\
\hline DICRO-4-Ni-i ${ }^{46}$ & 25 & 1 & 1.02 & 1.91 & 34 & 38 & 1.9 & 13.5 \\
\hline UTSA- $74 a^{47}$ & 25 & 1 & 3.00 & 4.80 & 25.5 & 31.5 & 1.6 & 8 \\
\hline TIFSIX-2-Cu-i ${ }^{37}$ & 25 & 1 & 4.20 & 4.10 & 36 & 46 & 0.97 & 6 \\
\hline $\mathrm{Cu}-\mathrm{BTC}^{25,41,48}$ & 25 & 1 & 5.10 & 8.90 & 26.9 & 30 & 1.7 & 5.5 \\
\hline MAF- $2^{49}$ & 25 & 1 & 0.82 & 3.90 & 27 & 33 & 4.7 & 5 \\
\hline UTSA-50a $a^{41}$ & 23 & 1 & 3.10 & 4.10 & 27.8 & 32 & 1.3 & 5 \\
\hline FJU-90a ${ }^{50}$ & 25 & 1 & 4.92 & 8.03 & 21 & 25 & 1.6 & 4.3 \\
\hline ZJU-60a $a^{51}$ & 23 & 1 & 3.12 & 6.69 & 15.5 & 17.5 & 2.1 & 4 \\
\hline ZJU-10a ${ }^{52}$ & 25 & 1 & 3.66 & 7.58 & 26 & 39 & 2.1 & 4 \\
\hline MFM-188 53 & 25 & 1 & 5.35 & 10.20 & 20.8 & 32.5 & 1.9 & 3.7 \\
\hline FeNi-M'MOF ${ }^{54}$ & 25 & 1 & 2.72 & 4.29 & 24.5 & 32.8 & 1.6 & 22.5 \\
\hline
\end{tabular}

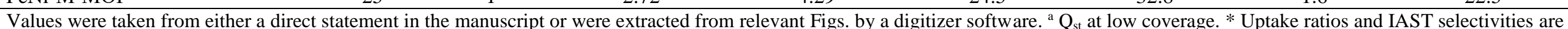

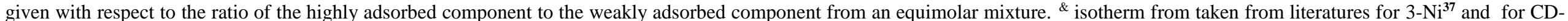

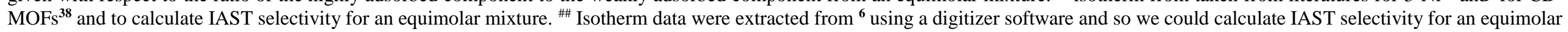
mixture. 


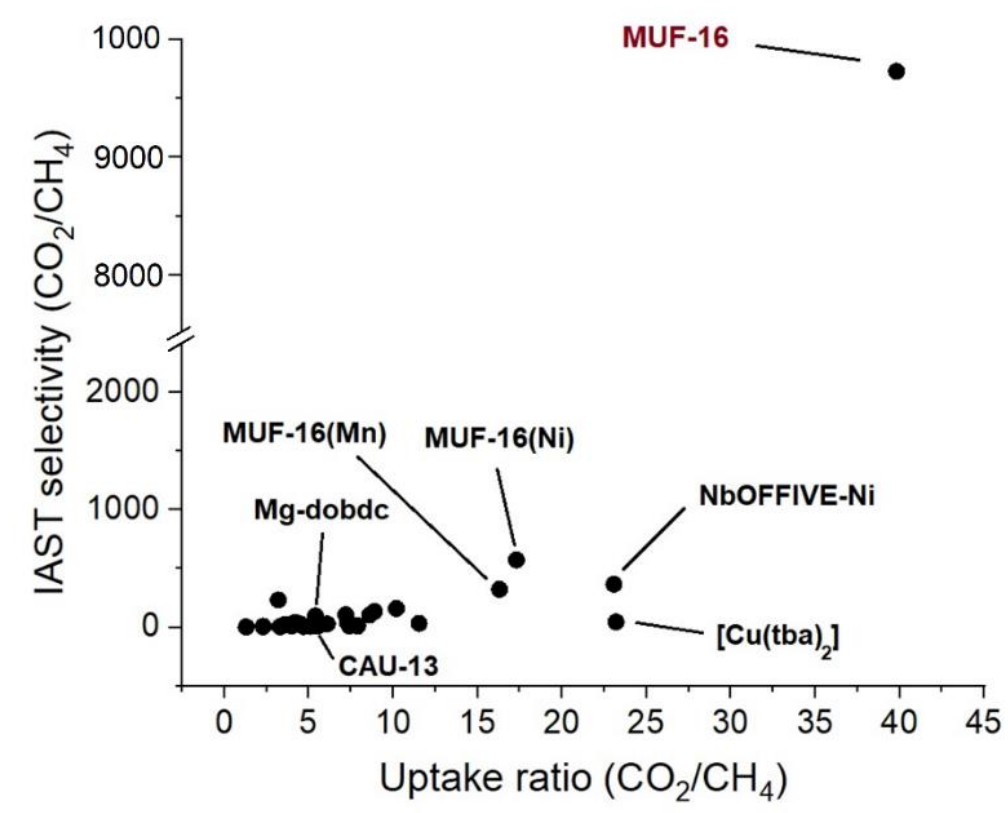

Fig. S58. IAST selectivity of MUF-16 family for an equimolar mixture of $\mathrm{CO}_{2} / \mathrm{CH}_{4}$ in comparison to top top-performing MOFs at 1 bar and ambient temperature versus their uptake ratio at 1 bar.

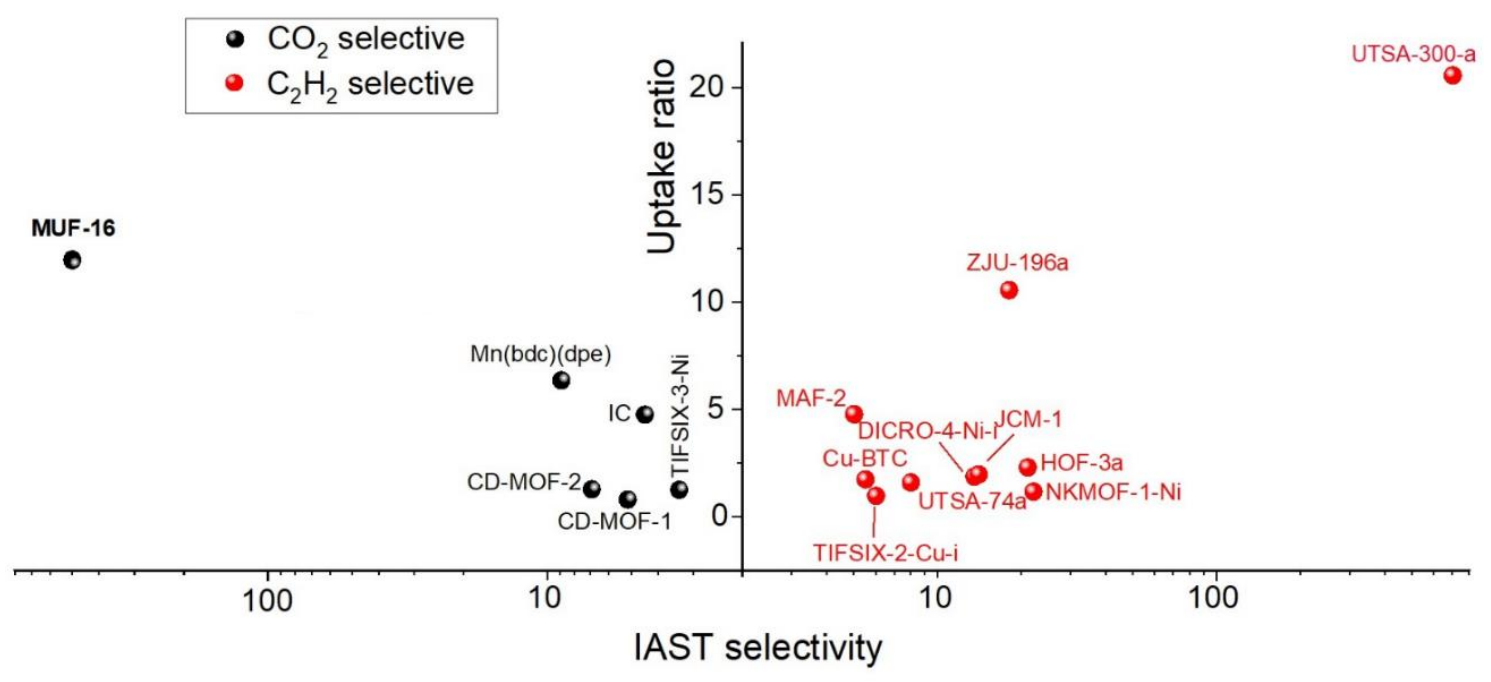

Fig. S59. Predicted IAST selectivity (log scale) from an equimolar mixture of $\mathrm{CO}_{2} / \mathrm{C}_{2} \mathrm{H}_{2}$ plotted against uptake ratio at 1 bar and 293-298 K (except for IC (278 K) and

[Mn(bdc)(dpe)] (273 K)) for MUF-16 in comparison to the best materials reported to date. Selectivity and uptake ratios are defined as $\mathrm{CO}_{2} / \mathrm{C}_{2} \mathrm{H}_{2}$ and $\mathrm{C}_{2} \mathrm{H}_{2} / \mathrm{CO}_{2}$ for $\mathrm{CO}_{2}$-selective and $\mathrm{C}_{2} \mathrm{H}_{2}$-selective materials, respectively. 


\section{References}

1. Tang, E.; Dai, Y.-M.; Zhang, J.; Li, Z.-J.; Yao, Y.-G.; Zhang, J.; Huang, X.-D., Two Cobalt(II) 5-Aminoisophthalate Complexes and Their Stable Supramolecular Microporous Frameworks. Inorg. Chem. 2006, 45, 6276-6281.

2. Tian, C.-B.; He, C.; Han, Y.-H.; Wei, Q.; Li, Q.-P.; Lin, P.; Du, S.-W., Four New MnII Inorganic-Organic Hybrid Frameworks with Diverse Inorganic Magnetic Chain's Sequences: Syntheses, Structures, Magnetic, NLO, and Dielectric Properties. Inorg. Chem. 2015, 54, 2560-2571.

3. Willems, T. F.; Rycroft, C. H.; Kazi, M.; Meza, J. C.; Haranczyk, M., Algorithms and tools for high-throughput geometry-based analysis of crystalline porous materials. Microporous Mesoporous Mater. 2012, 149, 134-141.

4. Dubbeldam, D.; Calero, S.; Ellis, D. E.; Snurr, R. Q., RASPA: molecular simulation software for adsorption and diffusion in flexible nanoporous materials. Mol. Simul. 2016, 42, 81-101.

5. Li, J.-R.; Kuppler, R. J.; Zhou, H.-C., Selective gas adsorption and separation in metalorganic frameworks. Chem. Soc. Rev. 2009, 38, 1477-1504.

6. Eguchi, R.; Uchida, S.; Mizuno, N., Inverse and High $\mathrm{CO}_{2} / \mathrm{C}_{2} \mathrm{H}_{2}$ Sorption Selectivity in Flexible Organic-Inorganic Ionic Crystals. Angew. Chem., Int. Ed. 2012, 51, 1635-1639.

7. Reid, C. R.; Thomas, K. M., Adsorption Kinetics and Size Exclusion Properties of Probe Molecules for the Selective Porosity in a Carbon Molecular Sieve Used for Air Separation. J. Phys. Chem. B 2001, 105, 10619-10629.

8. Li, L.; Lin, R.-B.; Wang, X.; Zhou, W.; Jia, L.; Li, J.; Chen, B., Kinetic separation of propylene over propane in a microporous metal-organic framework. Chem. Eng. J. 2018, 354, 977-982.

9. Walton, K. S.; Snurr, R. Q., Applicability of the BET Method for Determining Surface Areas of Microporous Metal-Organic Frameworks. J. Am. Chem. Soc. 2007, 129, 8552-8558.

10. Dincă, M.; Dailly, A.; Liu, Y.; Brown, C. M.; Neumann, D. A.; Long, J. R., Hydrogen Storage in a Microporous Metal-Organic Framework with Exposed Mn2+ Coordination Sites. J. Am. Chem. Soc. 2006, 128, 16876-16883.

11. Myers, A.; Prausnitz, J. M., Thermodynamics of mixed-gas adsorption. AIChE J. 1965, $11,121-127$.

12. Qazvini, O. T.; Babarao, R.; Shi, Z.-L.; Zhang, Y.-B.; Telfer, S. G., A Robust EthaneTrapping Metal-Organic Framework with a High Capacity for Ethylene Purification. J. Am. Chem. Soc. 2019.

13. Qazvini, O. T.; Babarao, R.; Telfer, S. G., Multipurpose Metal-Organic Framework for the Adsorption of Acetylene: Ethylene Purification and Carbon Dioxide Removal. Chem. Mater. 2019, 31, 4919-4926.

14. Cavenati, S.; Grande, C. A.; Rodrigues, A. E., Adsorption Equilibrium of Methane, Carbon Dioxide, and Nitrogen on Zeolite 13X at High Pressures. J. Chem. Eng. Data 2004, 49, 1095-1101.

15. Nugent, P.; Belmabkhout, Y.; Burd, S. D.; Cairns, A. J.; Luebke, R.; Forrest, K.; Pham, T.; Ma, S.; Space, B.; Wojtas, L.; Eddaoudi, M.; Zaworotko, M. J., Porous materials with optimal adsorption thermodynamics and kinetics for CO2 separation. Nature 2013, 495, 80 .

16. Saha, D.; Bao, Z.; Jia, F.; Deng, S., Adsorption of $\mathrm{CO}_{2}, \mathrm{CH}_{4}, \mathrm{~N}_{2} \mathrm{O}$, and $\mathrm{N}_{2}$ on MOF5, MOF-177, and Zeolite 5A. Environ. Sci. Technol. 2010, 44, 1820-1826.

17. Nam, G.-M.; Jeong, B.-M.; Kang, S.-H.; Lee, B.-K.; Choi, D.-K., Equilibrium Isotherms of $\mathrm{CH}_{4}, \mathrm{C}_{2} \mathrm{H}_{6}, \mathrm{C}_{2} \mathrm{H}_{4}, \mathrm{~N}_{2}$, and $\mathrm{H}_{2}$ on Zeolite $5 \mathrm{~A}$ Using a Static Volumetric Method. J. Chem. Eng. Data 2005, 50, 72-76. 
18. Shao, W.; Zhang, L.; Li, L.; Lee, R. L., Adsorption of $\mathrm{CO}_{2}$ and $\mathrm{N}_{2}$ on synthesized NaY zeolite at high temperatures. Adsorption 2009, 15, 497.

19. Ahmed, M. J.; Theydan, S. K., Equilibrium isotherms studies for light hydrocarbons adsorption on 4A molecular sieve zeolite. Journal of Petroleum Science and Engineering 2013, 108, 316-320.

20. McEwen, J.; Hayman, J.-D.; Ozgur Yazaydin, A., A comparative study of $\mathrm{CO}_{2}, \mathrm{CH}_{4}$ and $\mathrm{N}_{2}$ adsorption in ZIF-8, Zeolite-13X and BPL activated carbon. Chem. Phys. 2013, 412, 72-76.

21. Delgado, J. A.; Águeda, V. I.; Uguina, M. A.; Sotelo, J. L.; Brea, P.; Grande, C. A., Adsorption and Diffusion of $\mathrm{H}_{2}, \mathrm{CO}, \mathrm{CH}_{4}$, and $\mathrm{CO}_{2}$ in BPL Activated Carbon and $13 \mathrm{X}$ Zeolite: Evaluation of Performance in Pressure Swing Adsorption Hydrogen Purification by Simulation. Ind. Eng. Chem. Res. 2014, 53, 15414-15426.

22. Hou, L.; Shi, W.-J.; Wang, Y.-Y.; Guo, Y.; Jin, C.; Shi, Q.-Z., A rod packing microporous metal-organic framework: unprecedented ukv topology, high sorption selectivity and affinity for $\mathrm{CO}_{2}$. Chem. Commun. 2011, 47, 5464-5466.

23. Wen, H.-M.; Liao, C.; Li, L.; Alsalme, A.; Alothman, Z.; Krishna, R.; Wu, H.; Zhou, W.; Hu, J.; Chen, B., A metal-organic framework with suitable pore size and dual functionalities for highly efficient post-combustion $\mathrm{CO}_{2}$ capture. J. Mat. Chem. A 2019, 7, 3128-3134.

24. Masala, A.; Vitillo, J. G.; Mondino, G.; Grande, C. A.; Blom, R.; Manzoli, M.; Marshall, M.; Bordiga, S., $\mathrm{CO}_{2}$ Capture in Dry and Wet Conditions in UTSA-16 MetalOrganic Framework. ACS Appl. Mater. Interfaces 2017, 9, 455-463.

25. Xiang, S.; He, Y.; Zhang, Z.; Wu, H.; Zhou, W.; Krishna, R.; Chen, B., Microporous metal-organic framework with potential for carbon dioxide capture at ambient conditions. Nat. Commun. 2012, 3, 954.

26. Liang, Z.; Marshall, M.; Chaffee, A. L., CO2 Adsorption-Based Separation by Metal Organic Framework (Cu-BTC) versus Zeolite (13X). Energy Fuels 2009, 23, 2785-2789.

27. Liu, B.; Smit, B., Comparative Molecular Simulation Study of CO2/N2 and CH4/N2 Separation in Zeolites and Metal-Organic Frameworks. Langmuir 2009, 25, 5918-5926.

28. Mason, J. A.; Sumida, K.; Herm, Z. R.; Krishna, R.; Long, J. R., Evaluating metalorganic frameworks for post-combustion carbon dioxide capture via temperature swing adsorption. Energy Environ. Sci. 2011, 4, 3030-3040.

29. Herm, Z. R.; Swisher, J. A.; Smit, B.; Krishna, R.; Long, J. R., Metal- organic frameworks as adsorbents for hydrogen purification and precombustion carbon dioxide capture. J. Am. Chem. Soc. 2011, 133, 5664-5667.

30. Pal, A.; Chand, S.; Elahi, S. M.; Das, M. C., A microporous MOF with a polar pore surface exhibiting excellent selective adsorption of $\mathrm{CO}_{2}$ from $\mathrm{CO}_{2}-\mathrm{N}_{2}$ and $\mathrm{CO}_{2}-\mathrm{CH}_{4}$ gas mixtures with high $\mathrm{CO}_{2}$ loading. Dalton Trans. 2017, 46, 15280-15286.

31. Mohamed, M. H.; Elsaidi, S. K.; Pham, T.; Forrest, K. A.; Tudor, B.; Wojtas, L.; Space, B.; Zaworotko, M. J., Pillar substitution modulates CO2 affinity in "mmo" topology networks. Chem. Commun. 2013, 49, 9809-9811.

32. Si, X.; Jiao, C.; Li, F.; Zhang, J.; Wang, S.; Liu, S.; Li, Z.; Sun, L.; Xu, F.; Gabelica, Z.; Schick, C., High and selective $\mathrm{CO} 2$ uptake, H2storage and methanol sensing on the aminedecorated 12-connected MOF CAU-1. Energy Environ. Sci. 2011, 4, 4522-4527.

33. Madden, D. G.; O’Nolan, D.; Chen, K.-J.; Hua, C.; Kumar, A.; Pham, T.; Forrest, K. A.; Space, B.; Perry, J. J.; Khraisheh, M., Highly selective $\mathrm{CO}_{2}$ removal for one-step liquefied natural gas processing by physisorbents. Chem. Commun. 2019, 55, 3219-3222.

34. Mukherjee, S.; Sikdar, N.; O’Nolan, D.; Franz, D. M.; Gascón, V.; Kumar, A.; Kumar, N.; Scott, H. S.; Madden, D. G.; Kruger, P. E., Trace CO2 capture by an ultramicroporous physisorbent with low water affinity. Science Advances 2019, 5, eaax9171. 
35. Jiang, M.; Li, B.; Cui, X.; Yang, Q.; Bao, Z.; Yang, Y.; Wu, H.; Zhou, W.; Chen, B.; Xing, H., Controlling Pore Shape and Size of Interpenetrated Anion-Pillared Ultramicroporous Materials Enables Molecular Sieving of $\mathrm{CO}_{2}$ Combined with Ultrahigh Uptake Capacity. ACS Appl. Mater. Interfaces 2018, 10, 16628-16635.

36. Foo, M. L.; Matsuda, R.; Hijikata, Y.; Krishna, R.; Sato, H.; Horike, S.; Hori, A.; Duan, J.; Sato, Y.; Kubota, Y.; Takata, M.; Kitagawa, S., An Adsorbate Discriminatory Gate Effect in a Flexible Porous Coordination Polymer for Selective Adsorption of $\mathrm{CO}_{2}$ over $\mathrm{C}_{2} \mathrm{H}_{2}$. J. Am. Chem. Soc. 2016, 138, 3022-3030.

37. Chen, K.-J.; Scott, H. S.; Madden, D. G.; Pham, T.; Kumar, A.; Bajpai, A.; Lusi, M.; Forrest, K. A.; Space, B.; Perry, J. J.; Zaworotko, M. J., Benchmark $\mathrm{C}_{2} \mathrm{H}_{2} / \mathrm{CO}_{2}$ and $\mathrm{CO}_{2} / \mathrm{C}_{2} \mathrm{H}_{2}$ Separation by Two Closely Related Hybrid Ultramicroporous Materials. Chem 2016, $1,753-765$.

38. Li, L.; Wang, J.; Zhang, Z.; Yang, Q.; Yang, Y.; Su, B.; Bao, Z.; Ren, Q., Inverse Adsorption Separation of $\mathrm{CO}_{2} / \mathrm{C}_{2} \mathrm{H}_{2}$ Mixture in Cyclodextrin-Based Metal-Organic Frameworks. ACS Appl. Mater. Interfaces 2019, 11, 2543-2550.

39. Lin, R.-B.; Li, L.; Wu, H.; Arman, H.; Li, B.; Lin, R.-G.; Zhou, W.; Chen, B., Optimized separation of acetylene from carbon dioxide and ethylene in a microporous material. J. Am. Chem. Soc. 2017, 139, 8022-8028.

40. Peng, Y.-L.; Pham, T.; Li, P.; Wang, T.; Chen, Y.; Chen, K.-J.; Forrest, K. A.; Space, B.; Cheng, P.; Zaworotko, M. J.; Zhang, Z., Robust Ultramicroporous Metal-Organic Frameworks with Benchmark Affinity for Acetylene. Angew. Chem., Int. Ed. 2018, 57, 1097110975.

41. Li, P.; He, Y.; Zhao, Y.; Weng, L.; Wang, H.; Krishna, R.; Wu, H.; Zhou, W.; O'Keeffe, M.; Han, Y.; Chen, B., A Rod-Packing Microporous Hydrogen-Bonded Organic Framework for Highly Selective Separation of $\mathrm{C}_{2} \mathrm{H}_{2} / \mathrm{CO}_{2}$ at Room Temperature. Angew. Chem., Int. Ed. 2015, 54, 574-577.

42. Zhang, L.; Jiang, K.; Zhang, J.; Pei, J.; Shao, K.; Cui, Y.; Yang, Y.; Li, B.; Chen, B.; Qian, G., Low-cost and high-performance microporous metal-organic framework for separation of acetylene from Carbon dioxide. ACS Sustain Chem Eng 2018, 7, 1667-1672.

43. Tu, B.; Pang, Q.; Wu, D.; Song, Y.; Weng, L.; Li, Q., Ordered vacancies and their chemistry in metal-organic frameworks. J. Am. Chem. Soc. 2014, 136, 14465-71.

44. Zhang, L.; Jiang, K.; Li, L.; Xia, Y.-P.; Hu, T.-L.; Yang, Y.; Cui, Y.; Li, B.; Chen, B.; Qian, G., Efficient separation of $\mathrm{C}_{2} \mathrm{H}_{2}$ from $\mathrm{C}_{2} \mathrm{H}_{2} / \mathrm{CO}_{2}$ mixtures in an acid-base resistant metal-organic framework. Chem. Commun. 2018, 54, 4846-4849.

45. Lee, J.; Chuah, C. Y.; Kim, J.; Kim, Y.; Ko, N.; Seo, Y.; Kim, K.; Bae, T. H.; Lee, E., Separation of Acetylene from Carbon Dioxide and Ethylene by a Water-Stable Microporous Metal-Organic Framework with Aligned Imidazolium Groups inside the Channels. Angewandte Chemie International Editions 2018, 57, 7869-7873.

46. Scott, H. S.; Shivanna, M.; Bajpai, A.; Madden, D. G.; Chen, K.-J.; Pham, T.; Forrest, K. A.; Hogan, A.; Space, B.; Perry Iv, J. J.; Zaworotko, M. J., Highly Selective Separation of $\mathrm{C}_{2} \mathrm{H}_{2}$ from $\mathrm{CO}_{2}$ by a New Dichromate-Based Hybrid Ultramicroporous Material. ACS Appl. Mater. Interfaces 2017, 9, 33395-33400.

47. Luo, F.; Yan, C.; Dang, L.; Krishna, R.; Zhou, W.; Wu, H.; Dong, X.; Han, Y.; Hu, T.-L.; O’Keeffe, M.; Wang, L.; Luo, M.; Lin, R.-B.; Chen, B., UTSA-74: A MOF-74 Isomer with Two Accessible Binding Sites per Metal Center for Highly Selective Gas Separation. J. Am. Chem. Soc. 2016, 138, 5678-5684.

48. Xiang, S.; Zhou, W.; Gallegos, J. M.; Liu, Y.; Chen, B., Exceptionally High Acetylene Uptake in a Microporous Metal-Organic Framework with Open Metal Sites. J. Am. Chem. Soc. 2009, 131, 12415-12419. 
49. Zhang, J.-P.; Chen, X.-M., Optimized Acetylene/Carbon Dioxide Sorption in a Dynamic Porous Crystal. J. Am. Chem. Soc. 2009, 131, 5516-5521.

50. Ye, Y.; Ma, Z.; Lin, R.-B.; Krishna, R.; Zhou, W.; Lin, Q.; Zhang, Z.; Xiang, S.; Chen, B., Pore Space Partition within a Metal-Organic Framework for Highly Efficient $\mathrm{C}_{2} \mathrm{H}_{2} / \mathrm{CO}_{2}$ Separation. J. Am. Chem. Soc. 2019, 141, 4130-4136.

51. Duan, X.; Zhang, Q.; Cai, J.; Yang, Y.; Cui, Y.; He, Y.; Wu, C.; Krishna, R.; Chen, B.; Qian, G., A new metal-organic framework with potential for adsorptive separation of methane from carbon dioxide, acetylene, ethylene, and ethane established by simulated breakthrough experiments. J. Mat. Chem. A 2014, 2, 2628-2633.

52. Duan, X.; Wang, H.; Ji, Z.; Cui, Y.; Yang, Y.; Qian, G., A novel metal-organic framework for high storage and separation of acetylene at room temperature. J. Solid State Chem. 2016, 241, 152-156.

53. Moreau, F.; da Silva, I.; Al Smail, N. H.; Easun, T. L.; Savage, M.; Godfrey, H. G. W.; Parker, S. F.; Manuel, P.; Yang, S.; Schröder, M., Unravelling exceptional acetylene and carbon dioxide adsorption within a tetra-amide functionalized metal-organic framework. Nat. Commun. 2017, 8, 14085.

54. Gao, J.; Qian, X.; Lin, R.-B.; Krishna, R.; Wu, H.; Zhou, W.; Chen, B., Mixed Metal-Organic Framework with Multiple Binding Sites for Efficient C2H2/CO2 Separation. Angew. Chem., Int. Ed. 2020, 59, 4396-4400. 